Louisiana State University

LSU Digital Commons

\title{
Effects of Pitch and Rhythm Priming Tasks on Accuracy and Fluency during Sight-reading
}

Christine Renee Russell

Louisiana State University and Agricultural and Mechanical College

Follow this and additional works at: https://digitalcommons.Isu.edu/gradschool_dissertations

Part of the Music Commons

\section{Recommended Citation}

Russell, Christine Renee, "Effects of Pitch and Rhythm Priming Tasks on Accuracy and Fluency during Sight-reading" (2016). LSU Doctoral Dissertations. 2759.

https://digitalcommons.Isu.edu/gradschool_dissertations/2759

This Dissertation is brought to you for free and open access by the Graduate School at LSU Digital Commons. It has been accepted for inclusion in LSU Doctoral Dissertations by an authorized graduate school editor of LSU Digital Commons. For more information, please contactgradetd@lsu.edu. 


\title{
EFFECTS OF PITCH AND RHYTHM PRIMING TASKS ON ACCURACY AND FLUENCY DURING SIGHT-READING
}

\author{
A Dissertation \\ Submitted to the Graduate Faculty of the \\ Louisiana State University and \\ Agricultural and Mechanical College \\ in partial fulfillment of the \\ requirements for the degree of \\ Doctor of Philosophy \\ in \\ The School of Music
}

by

Christine Renee Russell

B.M., DePauw University, 1997

M.M., Bowling Green State University, 2002

August 2016 


\section{ACKNOWLEDGEMENTS}

The completion of a project such as this is not possible without the help and support of a great many people. Words fail to adequately express the depth of my gratitude for these people and their impact on me personally and professionally.

My sincerest gratitude goes to my advisor Dr. James Byo. I could not have predicted the path that this process would take, but I am profoundly grateful for your patience and wisdom, your faith and trust, your high expectations and encouragement, and your willingness to be a part of the journey.

Thank you to Dr. Jane Cassidy. Your willingness to give so freely of your time, encouragement, and expertise has made me a far better scholar and this a far better project than it otherwise could have been.

Thank you to Professor Carlos Riazuelo, Dr. Melissa Brunkan, and Dr. Kenneth Fasching-Varner, members of my committee, for your time and willingness to engage with me through this process. Your thoughts and ideas continue to challenge me to become better than I am today and to value the process of continually becoming.

Thank you to Sheily Bell, Sean Bramley, Chad Campbell, Eddie Hirst, Carlye Latas, Evan McAleer, Mark Messina, Craig Millet, Daniel Modenbach, Nicole Mlynczek, Joseph Nassar, Patti Roussel, and Jeff Seighman. It was an honor and privilege to work with you and your students and to spend time in your classrooms. Without your support this project would not have been possible.

Thank you to Dr. Evelyn Orman whose time and leadership through the initial development of this project was critical to its ultimate success. 
A special thank you also goes to Emily Mercado for the many hours spent listening to and scoring recordings as well as providing important insights that helped clarify my own thinking. Thank you also to Louie Eckhardt. Your time and insights about the project through the pilot phase were invaluable.

Finally, the task of completing a dissertation would not be possible without the love and support of friends and family. I am deeply thankful to be able to call Abby Lyons South, Loneka Wilkinson Battiste, Kelvin Jones, and Sarah Bartolome friends and colleagues. They challenge my thinking, provide insightful points of view, and make me a better music educator and person because of their place in my life.

I am also deeply grateful for the unconditional love and support of my parents and family. Without your lifelong encouragement and belief in me, this and so many other things would never have been possible. 


\section{TABLE OF CONTENTS}

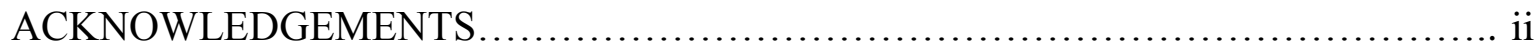

LIST OF TABLES................................................................... vi

LIST OF FIGURES .................................................................. vii

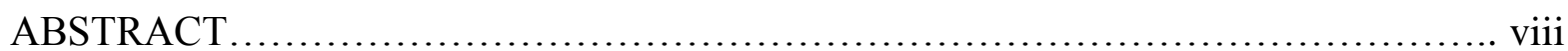

\section{CHAPTER}

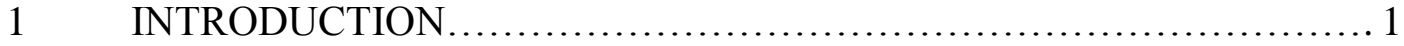

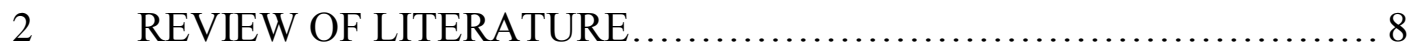

Eye Movement in Sight-reading............................. 8

Rhythm in Sight-reading.................................... 10

Pitch in Sight-reading.......................................... 16

Cognitive Processing........................................ 20

Need for Study ................................................ 26

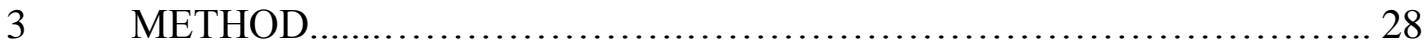

Participants.................................................. 28

Materials.......................................................... 29

Independent Variables......................................... 31

Dependent Variables ................................................ 37

Procedure.......................................................... 40

Scoring ...................................................... 46

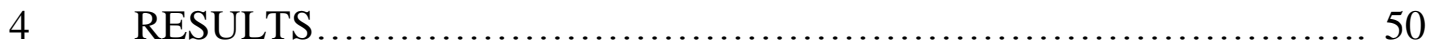

Main Effects.................................................. 51

Secondary Analyses........................................... 53

Post-test Survey............................................. 59

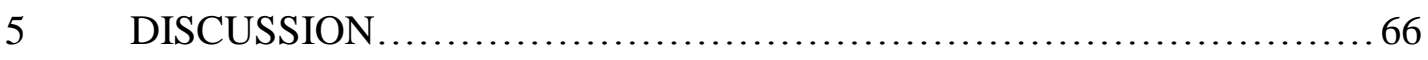

Rhythm and Pitch.............................................. 68

Practice Effects............................................... 73

Further Influences............................................. 74

Toward Refined Understandings................................ 77

Implications and Directions for Future Research................. 82

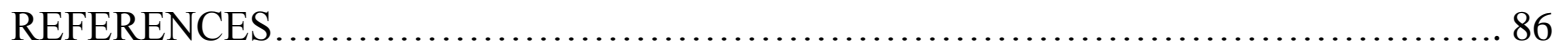

\section{APPENDICIES}

A IRB EXEMPTION FORM........................................... 96

B EXERCISE 10 FORM C ............................................... 97 
C STUDY TREATMENTS ........................................... 98

D LETTER OF EXPLANATION...................................... 102

E PARENTAL PERMISSION FORM................................... 103

F $\quad$ STUDENT ASSENT FORM....................................... 105

G STUDENT DEMOGRAPHIC FORM............................... 106

$\mathrm{H} \quad$ COMPLETE TESTING SCRIPTS ...................................... 107

I SCORING INSTRUCTIONS .......................................... 123

J SAMPLE SCORING FORM ....................................... 124

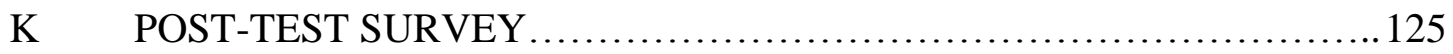

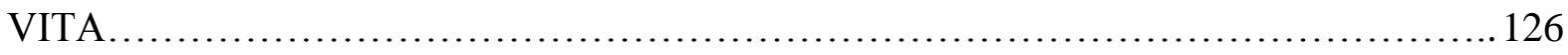




\section{LIST OF TABLES}

3.1 Participants by Instrument....................................... 28

Experimental Design.............................................. 36

Experimental Rotations.............................................. 38

Experimental Group Membership........................................ 41

4.1 Repeated Measures MANOVA Multivariate Effects Table..................... 53

$4.2 \quad$ Post-test Survey Results.................................................. 61

4.3 "Other" Sight-reading Hardest Element Responses........................... 62

$4.4 \quad$ "Other" Sight-reading Focus Responses.................................. 62

4.5 Pearson Product Moment Correlation of Task Difficulty and Score............. 64 


\section{LIST OF FIGURES}

3.1 Rhythm Treatment Excerpt from Stimulus Exercise ........................ 34

3.2 Pitch Treatment Excerpt from Stimulus Exercise .......................... 34

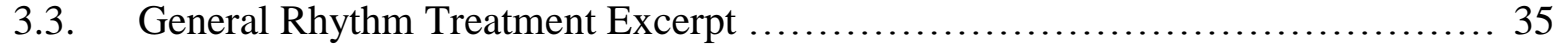

3.4 General Pitch Treatment Excerpt....................................... 36

4.1 Music Element Means by Priming Condition...............................52

4.2 Pre-test to Post-test Time and Element Interaction ............................ 55

4.3 Task Order Scores by Element.......................................... 55

4.4 Accuracy Scores across Six Treatment Orders............................... 57

4.5 Accuracy Scores by School......................................... 58

4.6 Accuracy Scores by Ensemble...........................................59

4.7 Instrument Family and Element Interaction............................. 60 


\begin{abstract}
Given the prevalent use of sight-reading in the classroom, at music festivals, and in audition procedures, it is important to know the most effective practices in preparing students to sight-read musical excerpts. Previous studies suggest that rhythm accuracy is a significant indicator of sight-reading ability. However, others have observed a possible influence of pitch on the performance of rhythm. In an effort to better understand that relationship, the purpose of this study was to investigate the effects of pitch and rhythm priming tasks on sight-reading accuracy and fluency. High school wind instrumentalists $(N=182)$ sight-read selected stimulus exercises from the Watkins-Farnum Performance Scale under one of four conditions: pre/post rhythm, pre/post pitch, post only rhythm, or post only pitch. As part of a repeated measures design, two priming treatments and a control condition were administered. Participants played through either the rhythms on one pitch or through the sequence of pitches on quarter notes during perceptual priming tasks and through either a general rhythm exercise or scale exercise during conceptual priming tasks. Those in pre-test/post-test groups first sight-read the exercise as written while those in the post-test only groups began with treatments.
\end{abstract}

Using a three-way repeated measures MANOVA, no significant differences were found in rhythm, pitch or fluency accuracy based on treatment condition (pitch or rhythm) or exposure condition (pre/post or post only). Significant differences were found based on priming condition $(p<.02)$. Rhythms scores were significantly lower after both perceptual and conceptual priming than after control conditions. No significant differences in pitch accuracy or fluency were detected based on priming condition but each significantly improved over time. These results suggest that rhythm processing was influenced in different ways than pitch. The independent consideration of fluency revealed important relationships between pitch and sight- 
reading accuracy. In addition, significant differences in pitch were found between brass and woodwind players suggesting the importance of aural representation skills in accurate sightreading. Based on these outcomes, future research should continue to investigate the complex roles of rhythm and pitch processing during music reading performance tasks. 


\section{CHAPTER 1: INTRODUCTION}

Since the beginning of music education in America, teachers have been concerned with their students' ability to read music at sight. In 1994 the National Standards for Arts Education clearly outlined the importance of reading music by sight. Under standard number 5 , Reading and Notating Music, all students starting in grade 5 were expected to "read at sight simple melodies in both the treble and bass clefs" (Consortium of National Arts Education Associations, 1994, p. 44), and those in an ensemble were expected to "sightread, accurately and expressively" (p. 44) music of various degrees of difficulty. The newest standards set forth by the National Coalition for Core Arts Standards through the National Association for Music Education (NAfME), which focus on performances that are rehearsed and improvised (NAfME, 2014), specify that music reading skills, which can be assumed to include sight-reading as defined in the Core Arts Standards Glossary, are important for the analyses of musical works to be performed.

Students in higher education are also expected to be able to sight-read. According to the standards put forth by the National Association of Schools of Music (NASM), all students pursuing a baccalaureate degree in music should be able to "read at sight with fluency demonstrating both general musicianship and, in the major performance area, a level of skill relevant to professional standards appropriate for the particular music concentration" (NASM, 2015). Sight-reading is embedded into many of our musical activities such as auditions, studio work, or even filling in for another musician at the last minute, and it remains a complex skill that is not completely understood.

Sight-reading, as defined by the Oxford Dictionary of Music, is "the reading or singing of music at first sight in order to perform it." It is valued by educators for its ability to give access to a broader range of musical literature (Lillya, 1953), to allow greater enjoyment of music 
(Bachman, 1955), to facilitate the communication and interpretation of notated music (Snyder, 1963), and to "help students reduce the time it takes to prepare" the music on which they are working (Crider, 1989, p. 29). Many local and national festivals, as well as most auditions, require students to sight-read as individuals or as part of a large ensemble. With this in mind, music teachers need to have effective methods of helping their students to become more accomplished sight-readers.

Many music educators suggest similar approaches when it comes to large ensemble sightreading. They believe that sight-reading activities should be consistently incorporated into rehearsal (Solomon, 1984; Wright, 1976) and that each activity should begin with a period of time in which the students scan the music (Reid, 1995; Soloman, 1984; Stauffer, 2005; Wright, 1976). Research has found that higher ability sight-readers use scanning time more effectively than low ability sight-readers (Killian \& Henry, 2005); therefore, it seems to be important that students are instructed in what to look for during the scanning period (Earlenbaugh \& Klein, 2011; Johnson, 2001). Once students have had the opportunity to review the music, ensemble directors are encouraged to lead their students through a group study time (Reely, 1994; Shaw, 2006; Solomon, 1984) saving a time for student questions until the end. At that point students should play through the piece from beginning to end without stopping (Stauffer, 2005; Wright, 1976).

Sight-reading is a skill which many practitioners approach as a unique way of creating music and thus needs specific techniques to cultivate. In a text dedicated to the development of sight-singing skills, Demorest (2001) provides a comprehensive approach to sight-singing in a choral rehearsal. Although there are books which address sight-reading for solo instruments, no equivalent instrumental method was found to Demorest's choral method. However, approaches 
and techniques for instrumental ensemble sight-reading are included as chapters or sections in more broadly based texts. For example in his 1997 text, Schleuter suggests that "sight reading skills should be developed through careful building of tonal and rhythm pattern vocabularies, audiation skills, playing by ear, technical skills, and regular practice with unfamiliar notation" (p.138). Jagow (2007) encourages band directors to include different sight-reading exercises into every rehearsal. There are several method books devoted specifically to these types of exercises. Fourteen Weeks to a Better Band (Maxwell, 1974) provides monotone rhythm exercises, melodic passages using only the specified rhythm, and melodic passages using combinations of previously learned rhythms. 101 Rhythmic Rest Patterns (Yaus, 1953) is set up in a similar manner with specific rhythm patterns used in each exercise increasing in difficulty throughout the book. All exercises are unison and limited in technical challenges using only the keys of F, B flat, and E flat. Fussell (1967) takes a different approach by providing distinct sections in his method: chorale style warm-ups; technical exercises based on scales, intervals, and arpeggios; and rhythm drills using both monotone and melodic exercises.

In spite of the many approaches to sight-reading developed by practitioners, our understanding of how to best help students successfully complete sight-reading tasks remains incomplete and continues to be a topic of importance. Fundamentally, the reading and performance of music requires one to know and understand two primary musical elements: pitch and duration. Conventional wisdom suggests that rhythm, as the organizing feature, is most important and should be of primary focus when developing music reading skills (Fiske, 1969). Experienced practitioners suggest using consistent counting systems (Cantwell, 1951; Crider, 1989; Forssmark, 1941; Reely, 1994; Soloman, 1984) and physical movement such as clapping or tapping feet (Pearson, 1996; Shaw 2006; Whaley, 2004) to improve rhythm accuracy in sight- 
reading. Generally research findings support these suggestions. Salzberg and Wang (1989) found that counting out loud using a traditional number system made a significant difference for students with low sight-reading abilities. Systems that use words or syllables also seem to be as effective, and with young students more effective, as traditional number counting (Bebeau, 1982; Colley, 1987; Palmer, 1976). Clapping rhythms and tapping the beat with the foot led to significantly higher scores on sight-reading tasks (Boyle, 1970).

Although rhythm instruction has been and continues to be a focus in both practitioner and research literature, the element of pitch, particularly for wind instrumentalists, has not. The concept of pitch is most often approached from a sight-singing standpoint. Researchers have investigated various methods of promoting pitch accuracy in singing and found that students seem to sing more accurately when using a pitch identification system such as solfege than singing on neutral syllables (Cassidy, 1993). They also sang with greater accuracy after instruction in pitch sets (Henry, 2004) and when they sang with harmonic accompaniment (Boyle \& Lucas, 1990). These results point to a common belief that students need to have an understanding of the function of the pitches they are singing within the context of the harmonic structure (Heydenburg, 1960; Miller, 1930; Nye, 1948). Studies that investigated pitch accuracy in instrumentalists have focused on how beginners learn pitches best. In each case, students who learned new notes as part of musical contexts scored significantly higher on sight-reading tasks than those who did not (Grutzmacher, 1987; Hahn, 1987; MacKnight, 1975).

Much has been written on the subject of how to best teach rhythms and we have some literature about developing pitch accuracy; however, very little exists regarding the connection between the two or how those ideas transfer to different contexts. Does knowing how to count a rhythmic unit in isolation mean that a student will count it correctly in the context of a musical 
excerpt? Does knowing how to physically produce a note correctly in isolation mean that they will accurately produce that note during the performance of a musical work? Boyle (1969) found that "Many subjects could play a given rhythm pattern correctly when it was notated on a single pitch, but they were unable to play the same pattern correctly when it was part of a melody" ( $p$. 42-43). This suggests that varying musical contexts change the way that these notated symbols are perceived and therefore the accuracy with which they are performed. We do not have a clear understanding of how pitch and rhythm influence the performance accuracy of each other. Although much focus in both practitioner and research literature has been on how to improve rhythm accuracy, Boyle seems to indicate that knowing how the rhythm goes is not enough.

Observations made in studies focused on pianists and vocalists support the idea that pitch may play a more important role than has been generally recognized. Henry (2011) found that rhythm achievement was a significant predictor of success in pitch based tasks and suggests that singers may focus on singing the correct notes before they focus on singing at the right time. In pianists it seems that pitch and rhythm errors happen simultaneously (Drake \& Palmer, 2000; Lowder, 1973) and those who play more correct notes make the least number of timing errors (Lehmann \& Ericsson, 1993). Less skilled pianists also seem to focus on pitch while the more skilled focus on the element of time (Drake \& Palmer, 2000). Pike and Carter (2010) observed that class piano students in their control group may have been focused on playing the right notes to the detriment of rhythm accuracy and continuity. Similarly, Cassidy, Betts, and Hanberry (2001) found a connection in the performance of pitch and rhythm of undergraduate class piano students. In their study, which looked at the effects of left-hand practice on harmonization and sight-reading accuracy, they found that pitch was more accurate than rhythm. Participants would disrupt the flow of rhythmic continuity in order to achieve pitch accuracy. The many rhythm 
errors were then not actually mistakes in duration but instead seemed to be a need to focus on one element of the music, in this case pitch or rhythm, before another.

With so little understood about the relationship between pitch and duration, this study is a step toward a better understanding of the function of pitch and rhythm in the initial performance of a piece of music. Published research indicates that rhythm errors are more frequent than pitch errors during sight-reading. However, going beyond the simple descriptive nature of more and less, it has been observed in some vocal and piano literature that rhythm errors are created because participants are focused on producing the correct pitch. Therefore, in an effort to gain a better understanding of the relationship between pitch and rhythm, the primary purpose of this study is to investigate effects of pitch and rhythm priming tasks on sight-reading accuracy and fluency. What is the accuracy of pitch and rhythm in the context of sight-reading and how does prior knowledge of one or the other impact the accuracy and fluency with which sight-reading excerpts are performed?

A secondary goal of the study will be to look at the impact of excerpt repetition. Sightreading has been defined as "the ability to play music from a printed score or part for the first time without benefit of practice" (Wolf, 1976). This definition might imply that sight-reading could only occur with the immediate performance of a musical work upon visual perception. It is possible that even a brief scan through the notation could be construed as "practice." A longer scan with the possibility to mentally rehearse or physically manipulate an instrument might then certainly be deemed practicing. Yet, many musicians and teachers would still consider both of these examples to be sight-reading. Where then do we draw the line? Although much of the published sight-reading literature indicates sight-reading accuracy improves between pre-test and post-test, few studies have analyzed the effect of familiarity on sight-reading. Fine, Berry and 
Rosner (2006) did find that significantly fewer errors were made during the second reading of a musical excerpt; however, few other studies provide clear evidence of the impact of familiarity. In an effort to garner more evidence about that effect, this study will compare the musical accuracy and fluency of students who read excerpts once with those who have an opportunity to read the same excerpt a second time. 


\section{CHAPTER 2: REVIEW OF LITERATURE}

In spite of the oft professed importance of sight-reading skills, our understanding of the complex skill of reading and performing music at first sight or how to teach for proficient sightreading is relatively limited. Although some published literature has focused on extra-musical factors related to sight-reading, the physical process of reading, the role of rhythm in sightreading, and the role of pitch in sight-reading make up the bulk of what has been written regarding sight-reading achievement. In nearly all cases researchers and practitioners alike have focused on participants' ability to play the right notes at the right time highlighting the fundamental nature of pitch and rhythm in the creation of music.

\section{Eye Movement in Sight-reading}

It is possible that at one point or other, every musician has been told to "look ahead" while reading music in order to prepare for what is coming next. When it comes to the physical process of looking at music, this idea that it is essential to look ahead for successful sight-reading has been perpetuated by instrumental music teachers across time (Feldman, 1963; Hickman, 1980; Soloman, 1984). However, much of the research literature indicates that just "looking ahead" is not the physiological process most conducive to successful sight-reading.

Some of the oldest research in the area of sight-reading focuses on the physiological behavior of the eyes while reading music notation. Eye movement during reading, much like all eye movement, is both a voluntary and an involuntary process. Involuntary motion, which is of specific interest to those who study visual perception, involves a combination of rapid back and forth motions (saccades) and pauses (fixations) (Goolsby, 1994). Jacobson (1931) used photography to capture this reading process. He found that eye movements varied based on the music being read and the challenge it presented to the reader. The eye-performance span, the 
number of notes to which the eyes looked ahead while performing, and the range of recognition, the number of recognizable notes during any pause, were influenced by the tempo and physical notation of the music as well as the performance ability of the reader. Qualities of the music such as rhythm, key, interval, or accidental usage seemed to affect the number of pauses. More pauses, as well as backward eye movements, were also present when there seemed to be difficulty in reading the music. Proficient readers seemed to have regular eye movements during reading while those less proficient did not. In other words, music readers use both backward and forward eye-movements in successful reading.

In general it seems less skilled readers use fewer and longer fixations than more skilled readers (Goolsby, 1989; Waters \& Underwood, 1998). When there is more score complexity, readers use longer fixations and more regressive fixations. It seems with more complexity there is a higher cognitive processing demand and therefore fewer notes are focused on for longer periods of time to allow for that processing to occur (Wurtz, Mueri, \& Wiesendanger, 2009). Unlike less skilled readers, expert's overall eye-movement behaviors and fixation durations were constant in spite of variations in the tonal complexity of the music (Waters \& Underwood, 1998). Although the timing and distance of saccades are influenced by notational complexities, they may also be a part of a mechanism that controls the flow of information within the brain (Kinsler \& Carpenter, 1995). Goolsby (1994) found expert readers tended to look further ahead during fixations but only needed short regressive saccades to return to the current performance note. In a study of novice and amateur pianists, Penttinen and Huovinen (2011) found skill in sight-reading was related to the speed of identification of music symbols and a shortening of time on first pass fixations. They suggest this skill development might be seen in the ways that sight-readers respond to the unexpected in their perceptual span. Although the conventional wisdom of just 
"looking ahead" may not be physiologically what happens, "looking ahead" may help one to cognitively process the foundational knowledge that is needed to successfully read music.

\section{Rhythm in Sight-reading}

It is believed that rhythmic-reading ability is a primary predictor of sight-reading achievement (Boyle, 1970; Elliot, 1982a, 1982b). Isaac (1966) even goes so far as to suggest that "rhythm is one of the most essential elements of instrumental music, possibly being even more basic than melody or harmony" (p. 47). Practitioners and researchers alike have spent decades suggesting ways in which music teachers might improve the rhythmic ability of their students.

One way to improve students' rhythm often discussed in the literature is using a physical response to the music. It is believed that the development of large muscle movements in response to music is the first step toward a readiness to read rhythms (Hicks, 1980). Based on the work of Dalcroze, teachers are encouraged to have children walk to the music to develop this readiness (Forssmark, 1941; Sorlien, 1951). In an effort to teach the concept of pulse, on which rhythm is based, many educators use some version of foot tapping. Hoover (1968) suggests using a foot tap to represent both the beat and the subdivision of the beat. The foot always comes down on the beat and goes up on the "and" between beats. Conversely Mixon $(2002,2008)$ encourages students to tap their heels in order to help them feel the beat. It is not enough, he claims, for young students to simply tap their toes; they need the large muscle movement created by a heel tap. Pearson (1996) holds another viewpoint altogether. While he supports the idea that large muscle movements are beneficial to developing students' sense of pulse, he rejects the notion that foot tapping systems are large muscle movements and instead advocates for using hand clapping to represent pulse. Once the concept of steady beat has been established, teachers suggest students should clap and count rhythmic patterns before playing them on their instrument 
(Shaw, 2006; Whaley, 2004). Bennett (1984) also encourages clapping and counting as a strategy that may help to solve rhythmic problems, but cautions that in groups some students may simply be imitating others and not actually understanding what they are reading.

In his 1970 study, Boyle investigated the relationship between body movement and reading and performing rhythms. Students in the experimental group tapped their foot, clapped the rhythm, and then played the rhythm on a single pitch while tapping their foot as they learned various rhythms during the 14-week treatment period. He found students who used kinesthetic activities, such as marking time, hand clapping, and foot tapping, scored significantly higher on rhythm-reading and sight-reading tasks than students who did not. Contrary to Boyle's findings, Salzberg and Wang (1989) found no significant difference based on foot tapping in rhythmreading achievement. They did find, however, that counting the beat out loud significantly improved the achievement of students in the lowest ability levels thereby suggesting that various methods of approaching sight-reading may be warranted for students of various ability levels. In a similar study which compared clapping the rhythm, counting the rhythm, sizzling, and a combination of clapping the rhythm and counting the beat as learning procedures, Pierce (1992) found no difference based on learning procedure. He did find a significant difference in learning time based on both procedure and ability group, which again seems to support the idea that various methods may be appropriate for different contexts.

Although Salzberg and Wang, as well as Pierce, had students verbally count the beat, most teachers choose to use verbal counting methods to represent patterns of rhythms in the music. The traditional counting system is based on the pattern " $1-\mathrm{e}-\&-\mathrm{a}$ ", but it is not the only counting system that teachers have championed through the years. The Eastman System uses syllables such as "1-te, 2-ta-te-ta" and "1-lah-lee, 2 lah-lee" (McHose \& Tibbs, 1945). Those 
trained in Kodály instructional methods promote the use of syllables such as "ta" and "ti-ti" to represent specific duration values and patterns (Campbell \& Scott-Kessner, 2014). The Takadimi syllables promote a beat oriented system in which every syllable represents a specific metric function. For example quarter notes are represented by "Ta" while two eighth notes are represented by "Ta-di." Every beat will start with "Ta" while the duple subdivision of every beat will be represented by “di” (Ester, Scheib, \& Inks, 2006). Still others promote using word associations such a "Mississippi" for four sixteenth notes, "Hop-a-long Cassidy" for two triplets (Cantwell, 1951) or similar word-chant systems (Campbell \& Scott-Kessner, 2014) much like the Orff-Schulwerk approach to rhythm.

With all the different counting systems used by teachers, the question becomes, is one more effective than another? Palmer (1976) compared the effectiveness of rhythm-reading instruction methods based on the Richards and Gordon approaches to rhythm. Richards's system, based primarily on the work of Kodály, uses "ta" and "ti-ti" to chant rhythms (Richards, 1964). Gordon's system combines the numeric value of the beat with syllables such as "ta" and "ne" to get sixteenth note groupings of "1-ta-ne-ta" (Gordon, 1971). Palmer found there was a significant difference between the experimental groups' performances and the control group's performance indicating that rhythmic-reading achievement does indeed improve with systematic instruction. She also found no significant differences in written or performance task between those instructed with the Richards/Kodály approach and those instructed with the Gordon approach indicating that each method is equally suitable for increasing rhythm-reading skills (Palmer, 1976).

In a 1982 study, Bebeau compared traditional rhythm instruction with a simplified "speech cue" method. This method uses words such as "tahn" (quarter note) and "tick-a-tick-a" 
(four sixteenth notes) as well as visual cues for held notes, such as moving the hands in a large circle while saying "watermelon" for whole notes. She found that third grade students who were instructed with the "speech cue" method performed significantly more accurately on rhythmreading tasks than did those who received traditional instruction. Because all students made significant gains in their rhythm-reading abilities after instruction, she proposes that it is not necessary to delay rhythm-reading instruction for students who do not yet possess the math skills required in the traditional counting system.

Based on findings in both Palmer and Bebeau, syllabic verbalizations seem to play a key role in effective rhythmic-reading instruction for young students. Colley (1987) compared the effectiveness of three syllabic based methods in her research with second and third grade students. She chose to compare Kodály syllables, Gordon syllables, and a set of researcher assigned "Word" syllables. While the Kodály syllables are standard, Colley chose to use Gordon's syllables from 1980 which include "Du" and "Du-de" rather than a combination of numbers and syllables. The "Word" method she designed assigned full words to represent various rhythmic patterns. For example she uses "Maine" to represent a quarter note and "Kansas" to represent two eight notes. A unique aspect of this method is that she chose to use complete words, such as "Nobody" for an eighth note and two sixteenths, rather than combining various syllables to represent the different note values. As with previous rhythmic syllable studies, all methods produced a significant gain in scores between the pre-test and post-test. However, the group using researcher designed "Word" syllables made significantly bigger gains in performance and had significantly higher scores in the dictation task than all other experimental groups. Colley concluded that of the three methods tested ("Word", Gordon, and Kodály) the "Word" method was the most suitable for reading complete rhythmic patterns. 
It appears then that counting systems, which provide a systematic organization of note values, improve students' accuracy in reproducing rhythms. In order for these systems to work, however, rhythms must be notated in such a way as to represent beat groupings. As Ward (1966) points out, a series of eighth or sixteenth notes may become more difficult to decipher when they are standing alone rather than beamed together. Sheldon (1996) investigated the effect of beamed and beamless notation on the sight-reading accuracy of high school band musicians. After an unlimited amount of silent study time, students played through two sight-reading excerpts: one with beamed notation and one without. Students performed excerpts with beamed notation significantly better than those without. Thus beaming notes may be important to the way that high school band students recognize groups of notes. But how far does this organization need to extend for students to continue to benefit from groupings? While beamed notes seem to have relevance in the visual perception of music symbols, other notational symbols may not have the same effect. In one study on rhythm reading, the inclusion or removal of barlines had no significant effect on accuracy (Byo, 1988). A follow up study (Byo, 1992) looked at the effect of barlines in both rhythm and melody reading. Based on significant interaction effects between barline condition and meter, when barlines are present during unchanging meters they appear to neither help nor hinder readers. However, their presence in excerpts with changing meters leads to significantly less accurate scores. This seems to suggest that while it is essential for musicians to have rhythmic organization at the level of the beat, larger organizational methods may not be necessary and in some cases may be harmful to reading accuracy.

Although researchers have spent time investigating best practices for teaching rhythm reading, and practitioners claim that "rhythm may be the most critical aspect of sightreading" (Lambrecht, 2008), what is the actual impact of rhythm reading ability on students' sight-reading 
ability as a whole? Elliott (1982b) investigated the relationship of several student based factors in sight-reading achievement of undergraduate wind instrumentalists. He looked at the variables of technical proficiency, rhythm reading ability, sight singing ability, and grade point averages for music theory classes, performance juries, applied lessons, as well as cumulative averages. Rhythm reading ability and performance jury grade point average accounted for $88 \%$ of the variance in sight-reading scores.

In his seminal sight-reading study, Elliott (1982a) identified, categorized, and compared the types of errors students made. Errors were classified into five categories: pitch, rhythm, expression, articulation, and other. He found that $61 \%$ of errors were rhythmic in nature. He also found that $51 \%$ of pitch errors were due to key signature mistakes and $46 \%$ of rhythm errors were due to meter signature mistakes and suggested that these were most likely careless errors on the part of the student. The best readers made mistakes across all evaluated categories with the greatest, though not significant, proportion made in the area of pitch. By contrast, $70 \%$ of mistakes made by the least skilled readers were rhythmic mistakes.

Even though Elliott found a large percentage of errors were rhythmic in nature, a closer look at the results seems to suggest that additional factors may need to be considered. Of the total rhythmic errors ( $61 \%$ of all errors), only $23 \%$ were actual errors in durational value (Elliot, 1982a). We also need to consider the fact that while the least skilled readers made significantly more rhythmic errors than anything else, the most skilled readers made mistakes across all categories. One explanation for this discrepancy might be that less skilled readers have fewer rhythmic skills. Another explanation might be that these less skilled readers are focused on accurately performing other musical aspects such as pitch and are less able to handle the simultaneous responsibilities of pitch and time. Although this alternative explanation is only 
conjecture, careful consideration of Elliott's results might suggest that pitch plays a larger role in the process of sight-reading.

\section{Pitch in Sight-reading}

The concept of pitch in sight-reading is often addressed from the standpoint of interval training for sight-singing. With no buttons to push or keys to strike, vocalists must internalize the sounds of various intervals to recreate them in song. According to Miller (1930) teachers had been discussing the issue of music reading and the use of various pitch syllable systems to increase skill in accurate pitch performance since the beginning of public school music education. At the time of his publication, various forms of sol-fa systems were used, but Miller contended these systems were inadequate to address several musical challenges and they created an artificial barrier between students and music. Another early writer suggested that because sight-singers read by interval, Lowell Mason's procedure of using numerals to represent pitch was the best way to teach intervals (Nye, 1948). In an early study of the impact of solmization, Silvey (1937) concluded that although solmization may have been helpful for the musically talented, it was not warranted for the general population. In spite of proponents of alternative ways to represent pitch, solfège systems did not disappear from the classroom. In fact more recent authors have suggested that because the syllables are more conducive to singing they should be used over other systems (Giles, 1991).

As a long standing topic of discussion among school music practitioners, pitch verbalization has also become an area of focus for music education researchers. Henry and Demorest (1994) found no difference in sight-reading achievement between students who used moveable "do" and those who used fixed "do" solfège systems. Reifinger (2012) investigated the effect of syllable systems and the familiarity of patterns on second grade students' sight-singing 
ability. He found that in familiar patterns the use of a syllable system led to greater contour accuracy in the post-test. However, with unfamiliar patterns the use of a neutral syllable was more beneficial. He suggests that although solfège may serve as an efficient prompt during sightsinging it can add to the cognitive load of a student. Therefore, if patterns are sufficiently familiar, then the specific prompt is useful, otherwise a student must decode the prompt as well as the pattern. Cassidy (1993) also investigated the use of syllable systems in sight-singing achievement. At the undergraduate level, those who used solfège, with and without hand signs, scored significantly higher than those who used a neutral syllable, letter names, or had no training. Although groups were intact classes, leading to possible selection issues, she suggests that the labeling function of a solfège system, much like syllabic verbalization in rhythmreading, may contribute to greater success in pitch reading and performance.

The idea that it may be the function of intervals in sight-singing, and not the syllables in and of themselves, has been investigated through a series of studies focused on pitch sets. Henry (2001) created an inventory of pitch sets (interval patterns) of varying difficulties in an effort to create a sight-reading test to be used in secondary classrooms. Through the testing and validation process of different test versions, she found the context of those sets matters. The difficulty of each pitch set did not function in isolation but was dependent upon what preceded it (Henry, 2003). Students with lower sight-reading abilities significantly improved their sight-singing skills after receiving instruction focused on the pitch sets (Henry, 2004). It is interesting to note that although the order of notes and more specifically intervals was a significant factor in sightsinging achievement, key signature was not. Within the limited range of key signatures used, vocalists in the study were able to produce the same intervals in a variety of keys without any significant difference in achievement levels (Henry, 2013). This is not necessarily the case with 
instrumentalists. In a similar effort to create pitch sets across different keys for string players, Alexander and Henry (2012) found significant achievement differences based on key signature indicating that context matters in instrumental sight-reading because different physical techniques are often required to produce various combinations of pitches.

While pitch has been approached from an interval and solfège standpoint in vocal literature, it is mainly considered in terms of technical proficiency for instrumentalists. Practitioners suggest that instrumentalists must be well versed in scale and chord patterns in order to be successful in sight-reading (Bachman, 1955; Elliot, 1983). In order to become more familiar with key signatures and the notes used within each key, George (2013) suggests a method of playing a simple melody in all the major and minor keys. Ward (1966) proposes that students learn the tetrachord patterns of scales to assist in faster recognition of fingering needs. Others suggest that students should write out their scales (Crider, 1989) to improve understanding of basic music theory concepts. In a contrasting view, Savler (1945) opposes the spelling out of notes as an unnecessary and time consuming step. Instead, he encourages teachers to point out the patterns of motion in the notes. He suggests that by making a direct association between what is seen in the notation and the physical key that creates that note, students will read music faster and more easily.

Research seems to support the idea that pattern recognition plays an important role in sight-reading ability. Just as singers improved in sight-singing achievement after pitch-set instruction, wind players also saw significant improvement when they learned notes in the context of tonal patterns rather than in isolation (MacKnight, 1975). Students scored significantly better on both sight-reading tasks and aural skills tasks when instruction emphasized tonal patterns (Grutzmacher, 1987). Learning notes in the context of musical excerpts, rather than as 
isolated notes, may help students to better perceive musical contour and pattern (Hahn, 1987) and contributes to a significant difference in the performance quality of rehearsed music (Price, Blanton, \& Parrish, 1998). Pike and Carter (2010) also emphasized tonal patterns, or chunks, during instruction of university class piano students. While there was no significant overall difference in sight-reading skills, they propose that isolating pitch chunks allowed participants to recognize patterns faster and pay attention to other details based on the significant findings in subcategories. Waters, Townsend, and Underwood (1998) found more skilled sight-readers were able to group larger amounts of information together. They also suggest that sight-reading achievement depends on an ability to form auditory representations of the visual notation above and beyond the ability to simply recognize patterns. It is possible, McPherson (1995) suggests, this connection may have to do with students' abilities to "think in sound" (p. 157). He found high correlations for playing by ear and improvising, and that sight-reading is more closely related to improvising than to performing rehearsed music. Results from a recent meta-analysis also seem to indicate that "a deeper musical understanding" (Mishra, 2014, p. 147) promotes improvement in sight-reading skills. Research suggests this ability to form auditory representations may develop as skill level develops (Fine, Berry, \& Rosner, 2006).

The challenge then of instrumentalists relying on technique (scale playing) or pattern recognition is that there seems to be no clear connection between the physical action of creating the sound and the sound being created. In other words, does learning one's scales and arpeggios automatically transfer to the auditory representation that seems to be important to successful sight-reading? Given the challenges that many university music students face in aural skills classes, it would seem that the transfer is not automatic (Davidson \& Scripp, 1988). Pearson (1996) encourages instrumental teachers to have students sing to develop their pitch sense rather 
than relying on just the instrument to produce the correct note. Conlee (1966) suggests that teaching instrumentalists to read numbers, which represent scale degree, may be an effective method of creating this connection. He contends that this system of first singing and then playing using numbers, rather than traditional pitch notation, encourages a connection between the symbol and the sound. Students eventually transcribe the exercises they have completed by number into standard musical notation, thereby strengthening the understanding that written notes are not simply symbols but are a specific sound.

\section{Cognitive Processing}

Reading and decoding symbol systems of any kind is controlled by cognitive processes, which are influenced by a vast array of variables including the complexity of the material. In defining the construct of task complexity, Wood (1986) suggested all tasks have three components: products, acts, and information cues. Products are measurable results of acts, which are patterns of behavior with some identifiable purpose. Information cues are pieces of information which enable individuals to make decisions during the performance of the task. Task complexity then describes the relationships between task inputs (acts and information) and products. Wood proposed three types of task complexity: component complexity, which is a function of the number of acts and information cues that must be processed; coordinative complexity, which is the nature of the relationship between task inputs and products; and dynamic complexity, which are changes in the state of the environment that impact the relationship between task inputs and products. Successful performance of tasks then depends upon changes in knowledge, skill, and effort based on task complexity.

Sight-reading is a complex task that requires a musician to simultaneously decode a visual symbol system and to perform specific pitches at a designated time in addition to 
executing those tasks at a specified loudness and in a stylistically appropriate manner. The multiple responsibilities required in musical performances lead to differing degrees of intrinsic cognitive load based on the expertise of the performer. Wickens, Larish, and Contorer (1989) described three assumptions of cognitive impact when attending to multiple tasks. First there is a fixed cognitive cost to all tasks being performed concurrently. Second costs increase as the demand level increases. Finally, costs are affected by the extent that tasks uses similar cognitive resources. Although much of the research into multitask performance has occurred in fields outside music, a few studies do specifically address musicians need to attend to multiple tasks.

Gudmundsdottir (2010) asked second and third year piano students to play three different 8-measure long pieces. These pieces were composed to represent three different levels of complexity. At the lowest level of complexity was a single melody that was passed back and forth between the left and right hands. The second level of complexity involved the right hand playing a single line melody while the left hand played half notes. The most complex piece involved a single line melody in the right hand and blocked chords played in the left hand. Unlike many studies that consider only one category of errors, pitch errors in this study were categorized as erroneous pitches, redundant pitches, or omitted pitches. By using this scoring system, Gudmundsdottir more specifically identified types of errors leading to the possibility of more focused solutions for those errors. She found that for younger students, the complexity of the information being decoded seemed to present a challenge that lead to a tendency during sight-reading to repeat notes. For example when younger students were asked to play with two hands simultaneously, repetitions occurred more often than when they used one hand after the other to the play the melody. She also found that nearly $30 \%$ of erroneous notes were corrected 
by the students themselves indicating that the students knew what the correct notes were but had difficulty producing them in context of a musical performance.

Various complexities exist not only in the physical creation of music, such as the role of two hands in playing the piano, but also in the music itself. Henry (2011) used nine pitch skills and nine rhythm skills, identified in previous research, to investigate the interaction effects between pitch and rhythm. High school singers participating in a choir camp were assigned randomly to sing one of three melodies, each of which contained three of the possible nine combinations of pitch and rhythm skills. Using a logistic regression model, she found that rhythm achievement was a significant predictor of success in pitch based tasks. She observed that while pitch tasks were unaffected by rhythm tasks, rhythm was indeed influenced by pitch. She suggests that singers may focus on singing the correct notes before they focus on singing at the right time.

On the basis of research results outside the field of music, Keller (2001) proposed a theory of attentional resource allocation needed during music ensemble performances. Ensemble participation requires musicians to attend to both their own performance and how their performance fits within the context of the group. Keller suggested a performer's intrinsic cognitive-motivational state, intrinsic executive state, and extrinsic state are linked to cognitive resource availability which in turn determines the attention that individuals give to specific elements of their performance. Similarly Chaffin (2011) reviewed literature related to the cognitive workload of instrumental music conductors. He also suggested that the divided attention necessary for monitoring multiple concurrent performances is impacted by the complexity of the task and the expertise of the conductor. 
Because of task complexity and attentional demands in musical performance, working memory can become overloaded to the detriment of performance quality. Working memory is defined as "a system for holding and manipulating information over brief periods of time, in the course of ongoing cognitive activities" (Engel de Abreau, Conway, \& Gathercole, 2010, p. 552). In one of the few published research articles concerned with music in this area, Kopiez and Lee (2006) established a relationship between working memory capacity and sight-reading achievement. Among the general cognitive abilities measured, working memory was significantly related to sight-reading achievement across various ability levels. Meinz and Hambrick (2010) extended that research by investigating the relationship between working memory capacity, musical practice, and sight-reading achievement. They found that high levels of working memory capacity were significantly related to sight-reading achievement regardless of the amount of time spent in deliberate sight-reading practice. It seems possible that in spite of deliberate practice and experience in sight-reading, which is often suggested as the best way to improve sight-reading ability, there is more involved in the process.

Given that the human brain processes a limited amount of material at any given time, limitations exist in the complexity of music able to be accurately performed during sight-reading. While investigating errors made by college freshmen during a piano sight-reading test, Lowder (1973) noted that pitch errors usually happened with rhythmic errors. In other words if a pitch was missed, it was highly likely that the rhythm would be missed as well. This phenomenon was also seen in a study by Lehmann and Ericsson (1993). In that study, which compared college piano performance majors and accompanying majors, participants played through excerpts of the accompaniment for two flute pieces. Through an analysis of the transcribed performances, Lehman and Ericsson found "performers who play more correct notes also made the least 
amount of timing errors" (p. 192). In their 2000 study, Drake and Palmer studied the process of gaining performance skills on an unfamiliar piece of music in novice and expert pianists. The pianists each played a musical excerpt many times in a row, and errors in pitch and duration as well as repetitions and pauses were recorded. They found pitch and duration errors happened more frequently together than either one alone and observed less skilled pianists focused on pitch while the more skilled focused on the element of time.

Cassidy, Betts, and Hanberry (2001) also found a connection in the performance of pitch and rhythm of undergraduate class piano students. In their study, which focused on the effects of left-hand practice on harmonization and sight-reading accuracy, they found that pitch was more accurate than rhythm. They observed that participants would disrupt the flow of rhythmic continuity in order to achieve pitch accuracy. The many rhythmic errors were then not actually mistakes in duration but instead seemed to be a need to focus on one element of the music before another.

Looking at the role of pitch and rhythm from a different perspective, Pike and Carter (2010) studied the effect of cognitive chunking techniques in freshman group piano students. Students assigned to the control group simply participated in sight-reading activities with no prior rehearsal of specific skills. Those in the experimental groups either rehearsed pitch drills or rhythm drills prior to playing the related sight-reading examples during class. The pitch drills were composed by isolating sequence of pitches from both the right and left hand lines of the original sight-reading exercise. Likewise, the rhythm drills were created based on the original rhythms of each exercise. Drills were progressive in nature by starting with each hand isolated and then adding them back together in closer approximations of the actual sight-reading example. Pre- and post-tests were given and scored based on pitch and rhythm accuracy as well 
as continuity. They found no significant difference among groups but did find significant differences between the pre- and post-tests. There was a significant correlation between rhythm and pitch accuracy for both experimental groups and significant improvement in rhythm accuracy for both experimental groups. It is interesting to note that there was also significant improvement in pitch accuracy for the experimental group that received pitch treatments and for the control group. While it seems logical that students in the pitch treatment group would improve in pitch skills, the improvement of the control group in pitch accuracy is unexpected. Pike and Carter observed that students in the control group seemed to focus on playing the right notes to the detriment of rhythmic accuracy and continuity.

Based on current understandings of cognitive processes, it is reasonable to believe that as cognitive load decreases performance quality improves. One method of decreasing cognitive load may be through tasks that prime the brain for upcoming experiences. Priming is defined as a form of implicit memory (Tulving \& Schacter, 1990). It is "a change in the ability to identify or produce an item as a result of a specific prior encounter with the item" (Schacter \& Buckner, 1998, p. 185). Priming allows individuals to respond more quickly and more accurately to previously experienced materials (Dell, Ratcliff, \& McKoon, 1981). Perceptual priming can be achieved through simple repeated exposure to an item, but it is sensitive to context during repetitions (Wiggs \& Martin, 1998). Alternatively, conceptual priming seems to involve a level of encoding that allows individuals to respond more quickly based on categorical information rather than direct repetition (Schacter \& Buckner, 1998). Cognitive load is therefore decreased when information processing becomes more automatic as a result of repetition or connection to a previously established set of schema (Paas \& van Merriënboer, 1994). Consequently it stands to reason that skills such as rhythm reading or playing scales contribute to a musician's ability to 
more efficiently solve musical problems as presented in sight-reading examples. Presumably by building more automaticity, through playing scales, recognizing various pitch patterns, and even isolated rhythmic patterns, students will be able to use that knowledge while sight-reading unfamiliar music.

\section{Need for Study}

Sight-reading accurately has been recognized as an important part of musicians' abilities. The literature extends back over 80 years with researchers and practitioners alike seeking ways to help musicians better those abilities with few clear outcomes. As Hodges (1992) points out "it is apparent that the bulk of these studies are technique or strategy driven rather than based on any underlying theory of music reading" (p. 468). Given this lack of a coherent theory, practitioners seem to continue teaching reading skills, and thereby sight-reading skills, in ways that seem logical and have produced what they perceive as positive outcomes. At best research in the field has produced mixed results with a few studies indicating that rhythm abilities are related to overall sight-reading abilities. However, going beyond the simple descriptive nature of more and less accuracy, it has been observed in some vocal and piano literature that rhythm errors are created because participants are focused on producing the correct pitch. The cognitively complex task of simultaneously dealing with rhythm and pitch during musical performance has received little attention in the research literature. Therefore, the purpose of this study is to investigate the effect of rhythm and pitch priming tasks on sight-reading accuracy and fluency. In order to solve the novel problems presented by sight-reading, musicians must at a minimum be able to decode and perform both pitch and rhythm. Given our limited understanding of how these two elements are cognitively processed and evidence that there seems to be a relationship between pitch and rhythm errors, this study seeks to determine whether various types of rhythm or pitch priming 
tasks significantly change the accuracy and fluency of sight-reading musical excerpts and to provide further evidence regarding the roles of pitch and rhythm during sight-reading. In total this study aims to address the following questions:

1. What is the effect of perceptual (specific) and conceptual (general) cognitive priming tasks on pitch, rhythm, and fluency accuracy during sight-reading?

2. Is there a significant difference in pitch, rhythm, or fluency accuracy between students who are primed through pitch exercises and those who are primed through rhythm exercises prior to playing the musical selection as originally composed?

3. Does playing through a musical selection a second time significantly change the accuracy of pitch, rhythm, or fluency? 


\section{CHAPTER 3: METHOD}

\section{Participants}

Participants $(N=182)$ in this study were southern Louisiana high school wind instrumentalists. Sample size was determined by the statistical needs of the experimental design. A minimum of 5 participants were required in each cell for analysis with a total of 36 cells. In addition, a priori power analyses gave an $N$ range of 144 to 224 as necessary to achieve acceptable power levels. Initially, a total of 193 participants completed study tasks. Following testing, data from eleven participants were excluded from analysis due to incomplete data sets caused by recording problems $(n=5)$, incorrect stimulus rotations $(n=3)$, and inability to complete study tasks $(n=3)$.

Students enrolled in band were recruited from public high schools. All participants played either a woodwind $(n=105)$ or brass instrument $(n=77)$ and represented every standard concert band instrument family. Percussionists were not included in this study. Table 3.1 lists a full breakdown of participants by instrument.

Table 3.1

Participants by Instrument

\begin{tabular}{lc}
\hline Instrument & $n$ \\
\hline Woodwind & 34 \\
Flute & 34 \\
Clarinet & 10 \\
Bass Clarinet & 20 \\
Saxophone (Alto, Tenor) & 7 \\
Double Reeds (Oboe, Bassoon) & \\
Brass & 29 \\
Trumpet & 12 \\
Horn & 20 \\
Trombone & 6 \\
Euphonium & 10 \\
Tuba &
\end{tabular}


In order to minimize the confounding influence that level of performance skill might have on test results, participants had at least 3 years of prior playing experience on a wind instrument. Stratified sampling of brass and woodwind instrumentalists accounted for the possibility that different methods of sound production could also be a confounding factor in test scores. Because students were recruited from multiple schools and ensembles, random assignment of participants to experimental groups was by school and ensemble level to ensure balanced representation in each experimental group. A detailed description of the sampling method is outlined in the procedures section below. Prior to school and participant recruitment, a request for exemption from institutional oversight was granted by the LSU Institutional Review Board (see Appendix A). Signed consent forms from participating schools' administration and band directors, as well as parental consent and student assent forms, were collected before treatment began.

\section{Materials}

Due to its long history of reliability, the Watkins-Farnum Performance Scale (Watkins \& Farnum, 1954, 1962) has been a standard in research literature for measuring sight-reading ability. In order to present appropriate challenges in rhythm and pitch, exercise \#10 from Forms $\mathrm{A}$ and $\mathrm{B}$ (henceforth referred to as exercises 10A and 10B) were chosen as two of the three stimulus exercises for this study. The exercises fall at the upper end of the range in which high school students would be expected to achieve based on the average score chart of data compiled by Farnum during the development of the performance scale (Watkins \& Farnum, 1954). Results of pilot testing showed it was unlikely that a student would achieve either a perfect score or not score any points for these exercises (Russell, 2015). Mean scores from pilot testing fell in a range of 57\% to $77 \%$ accuracy. Analyses of skewness and kurtosis for each variable revealed a normal distribution in all cases indicating no floor or ceiling effect in the performance of the exercise. 
Watkins (1942) developed the original exercises (10A \& 10B) of his performance test to serve as equivalent tasks. In order to provide enough material for the repeated measures design of the present study, a third version of Watkins-Farnum \#10 was newly composed by the investigator using the same harmonic structure, rhythm units, range, and style as 10A and 10B. It was labeled Form C, and henceforth will be referred to as exercise 10C. The newly composed 10C is included in Appendix B; permission to reprint the original exercises was not received. This third exercise was constructed in such a way as to maintain musical qualities found in the original material. For example, the third measure in both $10 \mathrm{~A}$ and $10 \mathrm{~B}$ contain a dotted rhythm and syncopation, so a dotted rhythm and syncopation were used in the third measure of $10 \mathrm{C}$ as well. The harmonic analysis of 10A and 10B revealed a shift in chords every two measures with melodic notes selected from the key of those chords. Likewise, the same pitch sets were used for 10C. Notes in the new exercises were arranged to mimic, but not duplicate, the patterns of conjunct and disjunct motion of the original melodies. Similar numbers of small and large leaps were used as well as similar accidental patterns and similar articulation patterns. Pilot testing confirmed equivalency among all three exercises.

Exercises 10A, 10B, and 10C served as stimulus exercises for the present study. Each is sixteen measures in length and notated in common time. Structurally they contain two pairs of four-bar phrases. Each pair of phrases begins in the major tonic, moves to a related minor by the end of four measures, and returns to the major tonic at the end of eight measures. Because the Watkins-Farnum Performance Scale (WFPS) is used in individual settings, exercises are presented in written key signatures that allow for comparable use of instrument ranges rather than simple transpositions. Watkins-Farnum \#10 is presented in Concert A-flat for all instruments except for oboe, which read in the key of Concert F, and horn, which read in the key 
of Concert E-flat. The melodies are diatonically based with frequent chromatic accidentals included and cover the range of a minor tenth. The lack of rests as well as the use of several slurred passages contributes to the legato, chorale style of the music. Each melody uses both conjunct and disjunct motion, with large melodic leaps often used in combination with syncopated rhythms. Note values up to the sixteenth note subdivision, including dotted and syncopated rhythms, make up the entirety of each melody. Although a performance tempo is provided (quarter note $=63$ ) no other musical expression markings, such as character descriptions, dynamics, or tempo changes, are given.

Additional study materials were developed to serve as treatment exercises. Aspects of the stimulus exercises were manipulated to create materials for each experimental condition. These are described as part of the independent variables below.

\section{Independent Variables}

The design of this study allowed for the comparison of three independent variables: treatment condition, priming type, and exposure condition.

Treatment Condition. Participants were randomly assigned to one of two treatment conditions: rhythm $(n=91)$ or pitch $(n=91)$. Madsen and Madsen (1970) define music as "organized sound and silence in time" (p. 20). Consequently, rhythm and pitch, as the two fundamental properties of musical sound, have long been a focus of sight-reading research. Researchers have investigated the effect of learning pitch with different solfege systems (Cassidy, 1993; Henry \& Demorest, 1994; Reifinger, 2012) and as part of patterns (Grutzmacher, 1987; Hahn, 1987; Henry, 2004; MacKnight, 1975). Rhythm has also been investigated in terms of learning styles (Bebeau, 1982; Boyle, 1970; Colley, 1987; Palmer, 1976; Pursell, 2007). In addition the visual presentation of rhythm as a function of rhythm reading has been a focus of 
study (Byo, 1988, 1992; Gregory, 1972; Sheldon, 1996). Authors of several studies have made observations about the interaction of pitch and rhythm (Cassidy, Betts, \& Hanberry, 2001; Drake \& Palmer, 2000; Lehmann \& Ericsson, 1993; Pike \& Carter, 2010). The present study sought to isolate pitch and rhythm in hopes of gaining a better understanding of the role they play in the process of sight-reading. In the practice of music education, teachers in rehearsal and knowledgeable students in their own practice employ "treatments" that isolate pitch and rhythm in a process of decontextualization/re-contextualization (Duke, Simmons, \& Cash, 2009). The treatments in the present study were intended to mirror this practical application.

Priming. Within each treatment condition, participants experienced two different forms of priming as well as a contact control experience across three different, but equivalent, stimulus exercises. Treatments were developed with principles of priming in mind, principles that have been culled from a literature that focuses on priming in, for example, visual and word recognition tasks. Priming is a form of implicit memory that is activated primarily through experiences of repeated exposures to a stimulus. It is said to have occurred if identification response time decreases or accuracy of response increases (Tulving \& Schacter, 1990). As the number of repetitions increase, the priming effect increases, though there seem to be limits to this principle (Dell, Ratcliff, \& McKoon, 1981). If during exposure the stimulus is not the focus of attention, then exposure is immaterial and priming effects are not exhibited (Wiggs \& Martin, 1998). For example, reciting a list of words written in different colors will prime for the list of words but not the colors. In order to prime for the colors, the colors would need to be recited. In addition to focus of attention during both study and testing, the context of stimulus presentation during those encounters impacts the degree of priming exhibited (Clayton, Habibi, \& Bendele, 1995; Schacter \& Buckner, 1998). When the stimulus is presented in the same modality and 
same order in testing as it was during study, priming effects are increased. It was hypothesized that by priming either pitch or rhythm, more accurate sight-reading would occur for those elements and might lead to more accurate performance of other elements due to a reduced cognitive load.

Perceptual and conceptual priming are two basic types of priming. Perceptual priming relies only on exposure not semantic encoding. In the present study, specific rhythm and pitch treatments for the stimulus exercises served as perceptual priming tasks. These treatments were literal, near-transfer reproductions of the rhythm and pitch of the stimulus exercises. Specific treatments were direct transcriptions of rhythm or pitch from the stimulus exercises in order to maintain the context of the elements, which is necessary for priming to occur.

Using a single line staff, specific rhythm treatments were created by transcribing all rhythms directly from each stimulus exercise with only a meter signature at the beginning and bar lines to identify measures. Students played the exercise on a comfortable pitch of their choosing. This style of notation is found in both standard method books (Fussell, 1967) and in newer materials such as the on-line resource Sight Reading Factory (Sight Reading Factory, 2015). Through the use of a single line staff, rather than a full staff with only one pitch, participants should not have experienced any mixed signals that might come from reading a different pitch than they chose to play or in a different clef from which they used to playing. No indications of key signature or tempo were given. Figure 3.1 shows an excerpt of the specific rhythm treatment from one of the stimulus exercises. The full treatments are presented in Appendix C.

A specific pitch treatment included all pitches re-notated as quarter notes, regardless of their original value of duration, in the order in which they appeared in each stimulus exercise. 


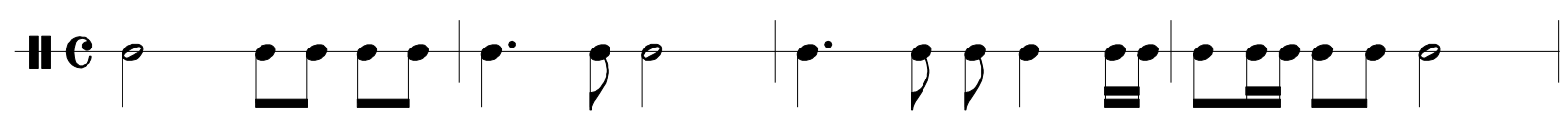

Figure 3.1. Rhythm Treatment Excerpt from Stimulus Exercise

Participants played the series of notes at a steady pace. The original clef and key signature were provided. In order to allow for the use of accidentals as used in the original material, bar lines were provided but meter signatures were not. Figure 3.2 shows an excerpt of a specific pitch treatment from one of the stimulus exercises.

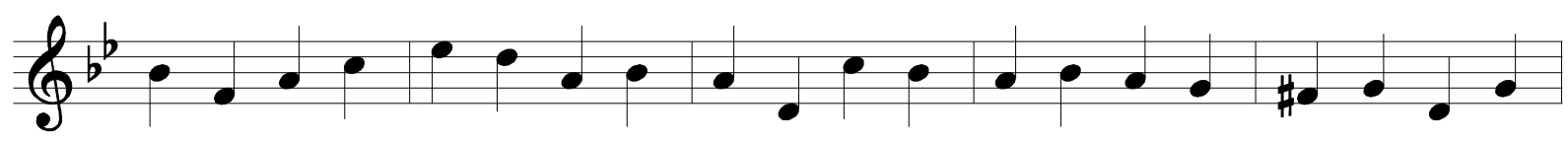

Figure 3.2. Pitch Treatment Excerpt from Stimulus Exercise

Unlike perceptual priming, conceptual priming relies on a level of semantic encoding. Semantic encoding involves perceiving the meaning of a word or object in such a way as to be able to store that information in memory. Usually this type of priming is seen in categorical tasks where subjects "are biased to produce previously studied category exemplars" (Schacter \& Buckner, 1998, p. 187). For example, one might study a list of words including "rose" (an exemplar) and then be asked to list flower types (a category) as part of a test. The greater the connection that is made during study between the exemplar and its contextual meaning (i.e., rose as a flower rather than a color or a past tense verb), the greater the priming effect during testing. General treatments consisting of rhythm and scale patterns served as conceptual priming tasks in the present study. Rhythm units and pitch collections (scales) might be considered category exemplars for the broader categories of rhythm and key center. Participants were exposed to them out of context during treatment, and then asked to replicate them in the context of a musical 
example during testing. Although it is perhaps an imperfect application of conceptual priming, presenting rhythm and scale patterns replicates teaching methods regularly used in instrumental music classrooms presumably to promote transfer of learning between technique building exercises and other musical experiences.

A general rhythm treatment was newly composed by the investigator using rhythm units contained in the stimulus exercises. Figure 3.3 contains the first four measures of that exercise. Musical analysis revealed fifteen unique, one or two beat rhythm units used across the three stimulus exercises. Fourteen of these units were ordered in various patterns throughout the treatment; the fifteenth unit, a whole note, was not used. As with the specific treatment, rhythms were notated on a single line, composed in common time, and sixteen measures in length.

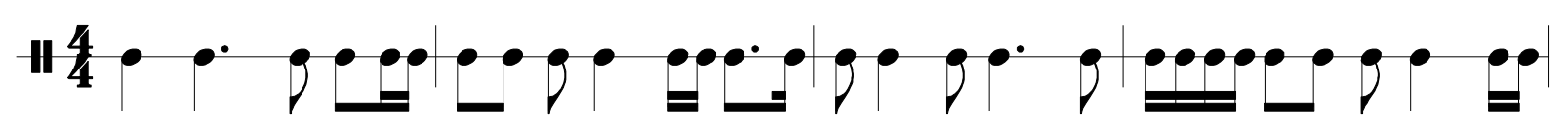

Figure 3.3 General Rhythm Treatment Excerpt

As with the rhythm treatments, a general pitch treatment was also created. As evidenced by instrumental technique books and band method books (Fussell, 1967; Ployhar, 1972;

Williams \& King, 1998), pitch is generally addressed through the practicing of scales, arpeggios, and scale pattern exercises. Therefore, the general pitch treatment was composed of five-note scale patterns along with their corresponding arpeggios. The scales chosen were based on the harmonic structure of the melody and notated in a simple rhythm pattern. Figure 3.4 displays the first four measures of the general pitch treatment. 


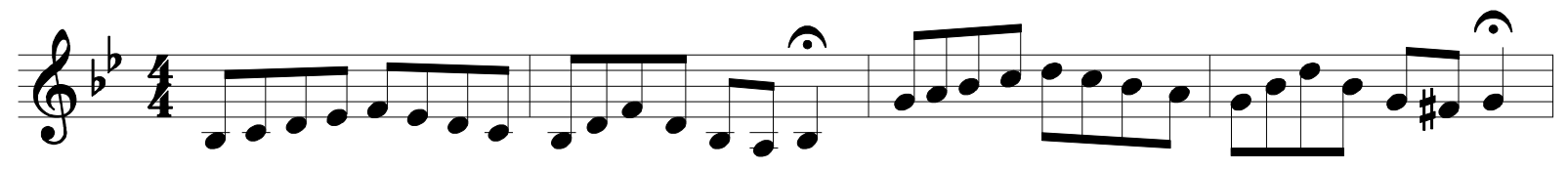

Figure 3.4 General Pitch Treatment Excerpt

Stimulus and Exposure. Participants were part of one of two exposures conditions: pretest/post-test or post-test only. Given the complexity of issues inherent in the research questions of this study, the experimental design must allow for the isolation of a number of variables. For this reason a repeated measures design was chosen, illustrated in Table 3.2, using both pretest/post-test and post-test only groups. One of the challenges to internal validity faced in sight-

Table 3.2

Experimental Design

\begin{tabular}{|c|c|c|c|c|c|c|c|c|c|}
\hline \multirow{2}{*}{$\begin{array}{c}\text { Group } \\
1\end{array}$} & \multirow[b]{2}{*}{$\mathrm{R}$} & \multicolumn{3}{|c|}{ Stimulus Excerpt 1} & \multicolumn{3}{|c|}{ Stimulus Excerpt 2} & \multicolumn{2}{|c|}{ Stimulus Excerpt 3} \\
\hline & & $\mathrm{O}$ & $\mathrm{X}_{1}$ & $\mathrm{O}$ & $\mathrm{O}$ & $\mathrm{X}_{2}$ & $\mathrm{O}$ & $\mathrm{O}$ & $\mathrm{O}$ \\
\hline 2 & $\mathrm{R}$ & $\mathrm{O}$ & $X_{3}$ & $\mathrm{O}$ & $\mathrm{O}$ & $\mathrm{X}_{4}$ & $\mathrm{O}$ & $\mathrm{O}$ & $\mathrm{O}$ \\
\hline 3 & $\mathrm{R}$ & & $\mathrm{X}_{1}$ & $\mathrm{O}$ & & $\mathrm{X}_{2}$ & $\mathrm{O}$ & & $\mathrm{O}$ \\
\hline 4 & $\mathrm{R}$ & & $X_{3}$ & $\mathrm{O}$ & & $\mathrm{X}_{4}$ & $\mathrm{O}$ & & $\mathrm{O}$ \\
\hline $\begin{array}{l}\mathrm{R}=\mathrm{Ran} \\
\mathrm{X}_{1}=\mathrm{Sp} \\
\mathrm{X}_{2}=\mathrm{Ge} \\
\mathrm{X}_{3}=\mathrm{Sp} \\
\mathrm{X}_{4}=\mathrm{Ge}\end{array}$ & om a & $\begin{array}{l}\text { hithn } \\
\text { itch } \\
\text { ittcin }\end{array}$ & $\begin{array}{l}\text { reatm } \\
\text { tmen } \\
\text { tmen }\end{array}$ & & & & & & \\
\hline
\end{tabular}

reading studies comes in the form of testing or instrumentation threats. In order to measure the effectiveness of a treatment, one must have a pre-treatment and post-treatment test. With sightreading, however, if the testing instrument, or musical selection, is the same for both tests then it is possible the test itself will influence the results. On the other hand, if a different test or musical selection is used, it is possible the tests will not be equivalent and therefore may not measure the same thing. This study design uses the same musical selections in a pre-test/post-test format in 
order to control for the instrumentation threat (Groups 1,2). It then replicates all treatments using separate post-test only groups to control for the possible testing threat (Groups 3, 4).

In order to ascertain the effect of rhythm priming and pitch priming on accuracy and fluency of sight-reading, treatments for each element were designed and administered to randomly assigned groups of students. Two groups of students $(1,3)$, one pre-test/post-test ( $n=45)$ and one post-test only $(n=46)$, were assigned to rhythm priming $\left(X_{1}, X_{2}\right)$, and two groups $(2,4)$, one pre-test/post-test $(n=45)$ and one post-test only ( $n=46)$, were assigned to pitch sequence priming $\left(X_{3}, X_{4}\right)$. All groups also completed a no-treatment condition, which served as contact control observations for the study. Random assignment to groups and inclusion of a no-treatment condition in this design addressed the threats of selection bias, history, maturation, mortality, and regression to the mean.

Due to the repeated measures design of the study and the need to measure sight-reading rather than practiced performance, three equivalent musical exercises were used. Stimulus and treatment exercises were rotated in order to control for possible order effects or unintended treatment effects. Within each experimental group there were six different orders of stimulus exercises and treatments. Each of the six treatment orders was paired with three of the six stimulus exercise orders to create eighteen possible combinations for each experimental group (see Table 3.3).

\section{Dependent Variables}

Participants' sight-reading performances were evaluated in three ways: pitch accuracy, rhythm accuracy, and fluency accuracy. For the purposes of this study, pitch accuracy was defined as playing the correct pitch as notated in the exercises. Pitches that were added by participants or not played at all counted as errors. Intonation was not considered as long as each 
Table 3.3

Experimental Rotations

\begin{tabular}{c|c|c}
\hline Experimental Groups 1 and 3 & & \\
\hline Observation 1 & Observation 2 & Observation 3 \\
\hline $\mathrm{A}_{1}$ & $\mathrm{~B}_{2}$ & $\mathrm{C}_{3}$ \\
$\mathrm{~B}_{1}$ & $\mathrm{C}_{2}$ & $\mathrm{~A}_{3}$ \\
$\mathrm{C}_{1}$ & $\mathrm{~A}_{2}$ & $\mathrm{~B}_{3}$ \\
\hline $\mathrm{A}_{1}$ & $\mathrm{C}_{3}$ & $\mathrm{~B}_{2}$ \\
$\mathrm{~B}_{1}$ & $\mathrm{~A}_{3}$ & $\mathrm{C}_{2}$ \\
$\mathrm{C}_{1}$ & $\mathrm{~B}_{3}$ & $\mathrm{~A}_{2}$ \\
\hline $\mathrm{A}_{2}$ & $\mathrm{~B}_{3}$ & $\mathrm{C}_{1}$ \\
$\mathrm{~B}_{2}$ & $\mathrm{C}_{3}$ & $\mathrm{~A}_{1}$ \\
$\mathrm{C}_{2}$ & $\mathrm{~A}_{3}$ & $\mathrm{~B}_{1}$ \\
\hline $\mathrm{A}_{2}$ & $\mathrm{C}_{1}$ & $\mathrm{~B}_{3}$ \\
$\mathrm{~B}_{2}$ & $\mathrm{~A}_{1}$ & $\mathrm{C}_{3}$ \\
$\mathrm{C}_{2}$ & $\mathrm{~B}_{1}$ & $\mathrm{~A}_{3}$ \\
\hline $\mathrm{A}_{3}$ & $\mathrm{~B}_{1}$ & $\mathrm{C}_{2}$ \\
$\mathrm{~B}_{3}$ & $\mathrm{C}_{1}$ & $\mathrm{~A}_{2}$ \\
$\mathrm{C}_{3}$ & $\mathrm{~A}_{1}$ & $\mathrm{~B}_{2}$ \\
\hline $\mathrm{A}_{3}$ & $\mathrm{C}_{2}$ & $\mathrm{~B}_{1}$ \\
$\mathrm{~B}_{3}$ & $\mathrm{~A}_{2}$ & $\mathrm{C}_{1}$ \\
$\mathrm{C}_{3}$ & $\mathrm{~B}_{2}$ & $\mathrm{~A}_{1}$ \\
\hline
\end{tabular}

\begin{tabular}{c|c|c}
\hline Experimental Groups 2 and 4 & \multicolumn{2}{c}{} \\
\hline Observation 1 & Observation 2 & Observation 3 \\
\hline $\mathrm{A}_{4}$ & $\mathrm{~B}_{5}$ & $\mathrm{C}_{6}$ \\
$\mathrm{~B}_{4}$ & $\mathrm{C}_{5}$ & $\mathrm{~A}_{6}$ \\
$\mathrm{C}_{4}$ & $\mathrm{~A}_{5}$ & $\mathrm{~B}_{6}$ \\
\hline $\mathrm{A}_{4}$ & $\mathrm{C}_{6}$ & $\mathrm{~B}_{5}$ \\
$\mathrm{~B}_{4}$ & $\mathrm{~A}_{6}$ & $\mathrm{C}_{5}$ \\
$\mathrm{C}_{4}$ & $\mathrm{~B}_{6}$ & $\mathrm{~A}_{5}$ \\
\hline $\mathrm{A}_{5}$ & $\mathrm{~B}_{6}$ & $\mathrm{C}_{4}$ \\
$\mathrm{~B}_{5}$ & $\mathrm{C}_{6}$ & $\mathrm{~A}_{4}$ \\
$\mathrm{C}_{5}$ & $\mathrm{~A}_{6}$ & $\mathrm{~B}_{4}$ \\
\hline $\mathrm{A}_{5}$ & $\mathrm{C}_{4}$ & $\mathrm{~B}_{6}$ \\
$\mathrm{~B}_{5}$ & $\mathrm{~A}_{4}$ & $\mathrm{C}_{6}$ \\
$\mathrm{C}_{5}$ & $\mathrm{~B}_{4}$ & $\mathrm{~A}_{6}$ \\
\hline $\mathrm{A}_{6}$ & $\mathrm{~B}_{4}$ & $\mathrm{C}_{5}$ \\
$\mathrm{~B}_{6}$ & $\mathrm{C}_{4}$ & $\mathrm{~A}_{5}$ \\
$\mathrm{C}_{6}$ & $\mathrm{~A}_{4}$ & $\mathrm{~B}_{5}$ \\
\hline $\mathrm{A}_{6}$ & $\mathrm{C}_{5}$ & $\mathrm{~B}_{4}$ \\
$\mathrm{~B}_{6}$ & $\mathrm{~A}_{5}$ & $\mathrm{C}_{4}$ \\
$\mathrm{C}_{6}$ & $\mathrm{~B}_{5}$ & $\mathrm{~A}_{4}$ \\
\hline & 1 = Specific Rhythm Treatment & $4=$ Specific Pitch Treatment \\
& $2=$ General Rhythm Treatment & $5=$ General Pitch Treatment \\
& 3 = Contact Control (Rhythm) & $6=$ Contact Control (Pitch) \\
\hline A, B, C $=$ Sight-reading Excerpt & &
\end{tabular}


note was recognizable to scorers as the right pitch. Rhythm accuracy was defined as playing the correct durational value in relation to the notes preceding and/or following the note being played. As dependent variables, pitch and rhythm accuracy are the natural consequents to pitch and rhythm treatments. There was also relative objectivity in measuring pitch and rhythm (Byo, 1993).

Fluency is a term borrowed from the field of reading literacy. Fuchs, Fuchs, Hosp, and Jenkins (2001) suggest that

oral reading fluency represents a complicated, multifaceted performance that entails, for example, a reader's perceptual skill at automatically translating letters into coherent sound representations, utilizing those sound components into recognizable wholes and automatically accessing lexical representations, processing meaningful connections within and between sentences, relating text meaning to prior information, and making inferences to supply missing information. (p. 239-240)

One might substitute the words "notes" for "letters" and "phrases" for "sentences" and begin to understand how fluency might describe a musical performance. In this study, fluency was defined as the degree to which music was performed with a consistent pulse. Others, in the music field, have used terms such as hesitations (Kostka, 2000) or beat continuity (Hanberry, 2004) to describe this concept. The ability to play without stopping, hesitating, repeating material, or abruptly changing tempos is an essential skill for students to develop in order to perform musically. It is also a distinctly different skill than performing notes for their correct durational value. Sight-reading is a complex task and fluency in performance may be an indicator of cognitive load (Fuchs, Fuchs, Hosp, \& Jenkins, 2001). It has been observed that students disrupt the pulse in order to find the correct notes (Cassidy, Betts, \& Hanberry, 2001; Henry, 2011; Pike \& Carter, 2010) suggesting that the intrinsic cognitive load of the task could not be processed in the allotted time. Given the hypothesis that priming may decrease the cognitive load during 
musical performance, it follows that fluency, as a measure of consistent performance in time, should be considered in addition to pitch and rhythm.

\section{Procedures}

Participant recruitment. Public high schools geographically located in a region surrounding the university at which this present study was conducted were considered for participation. Band directors with successful programs, as defined by reasonably balanced instrumentation, consistently high festival ratings, consistent student participation in honor bands and solo and ensemble festivals, and positive assessment by university music education faculty, were contacted with an introductory e-mail which included both a personal introduction and a broad overview of the study. A personal visit was scheduled with each band director to discuss details of the study, including study procedures, space and material needs of the investigator, and a potential timeline. A follow-up visit was scheduled with those directors who indicated an interest and willingness to assist in the study. During this follow-up visit, qualified students at each school were invited to participate in the study by the investigator and band director(s). In order to conform to Institutional Review Board (IRB) requirements, students were provided a letter of explanation (see Appendix D), parental permission form (See Appendix E), and student assent form (see Appendix F) to be taken home to their parents. Students who returned signed permission and assent forms were scheduled for testing.

Sampling Method. Based on the number of forms returned, the investigator worked with each school's band directors to schedule testing days that fit within the school calendar and band rehearsal schedule. It was hypothesized that differences in methods of sound production could be a confounding factor in sight-reading accuracy. Differences brought on by the "right partial" challenge for brass players are a most likely culprit (Elliot, 1982a), although evidence from a 
pilot study indicated otherwise (Russell, 2015). In order to account for this factor, a stratified sampling method was used in the random assignment of participants to experimental groups.

Prior to the start of testing at each school, participants' names were sorted first by ensemble level and then by woodwind or brass and specific instrument. Names were then drawn randomly and assigned sequentially to an experimental group. In other words, the names of all participants who played flute were put into a hat and drawn. The first name drawn was assigned to group 1, the second to group 2, and so on. This process continued through each instrument section with the first name drawn assigned to the next experimental group. Therefore, if the last participant who played flute was assigned to group 3, the first participant in the next woodwind instrument section was assigned to group 4. The process was repeated with participants who played brass instruments in order to maintain a proportional number of brass and woodwind players in each group. Table 3.4 lists the breakdown of each group by school, instrument family, and ensemble level.

Table 3.4

Experimental Group Membership

\begin{tabular}{lcccc}
\hline & $\begin{array}{c}\text { Group 1 } \\
n=45\end{array}$ & $\begin{array}{c}\text { Group } 2 \\
n=45\end{array}$ & $\begin{array}{c}\text { Group 3 } \\
n=46\end{array}$ & $\begin{array}{c}\text { Group 4 } \\
n=46\end{array}$ \\
\hline School & & & & 6 \\
1 & 5 & 5 & 5 & 15 \\
2 & 9 & 11 & 15 & 10 \\
3 & 10 & 9 & 10 & 10 \\
4 & 12 & 11 & 8 & 5 \\
5 & 9 & 9 & & 21 \\
Instrument & 18 & 19 & 27 & 25 \\
Brass & 27 & 26 & & 21 \\
Woodwind & & & 23 & 21 \\
Ensemble Level & 22 & 27 & 18 & 4 \\
$\quad$ Top & 19 & 4 & 5 & \\
Second & 4 & 4 & & \\
Third & & & & \\
\hline
\end{tabular}


Testing procedure. At the time of testing, individual participants were invited into the testing area. In each school this was an individual practice room or office adjacent to the band room. This area was equipped with two chairs, a music stand, research music, metronome, small Zoom H5 digital recorder, and a digital video recorder. Prior to testing, each participant was asked demographic survey questions (see Appendix G) regarding their primary instrument, the number of years they played their primary instrument, current school ensemble(s), secondary instruments and how long they have played each, ensembles in which they participate outside of school, and private lesson participation.

After collecting initial information, the investigator read the instructions for study tasks appropriate to the experimental group in which the participant has been assigned (see Appendix $\mathrm{H}$ for complete testing scripts). Those participants assigned to a pre-test/post-test group (Groups 1 or 2) were provided a copy of the stimulus exercise, appropriate to their instrument, and asked to spend 30 seconds silently preparing to play it. At the end of 30 seconds, a metronome was turned on to give the performance tempo indicated (quarter note $=63$ ), and participants were asked to play through the exercise one time as accurately as possible. After each participant began playing, the metronome was silenced and participants played through the entire stimulus exercise. At the end of their performance, the music was removed from sight.

For those participants assigned to the rhythm treatment group (Group 1), a rhythm treatment exercise was then placed on the stand. The investigator focused participants' attention on the rhythms as either a transcription of the exercise they just played (specific treatment) or as a variation on the exercise they just played (general treatment). Procedurally it is important that participants were focused on the applicability of each treatment in order for priming to be operational. Participants were asked to play through the sequence of rhythms one time as 
accurately as possible. In a similar manner, those assigned to pitch treatment (Group 2) were given a pitch exercise and asked to play through the exercise one time as accurately as possible. Again, participants' attention was directed to the literal transcription of pitches in the specific treatment and the more general connection of scales in the general treatment to the stimulus exercises. As a result of observations made during the pilot study, participants were provided a performance tempo for both treatments, which matched the performance tempo of the original exercise, and asked to keep a steady tempo through the exercise. Just as with each musical example, the metronome was silenced after four quarter notes and students were responsible for the pulse; however, they were not penalized for any variation of pulse.

It was originally thought that students might radically slow down the tempo during treatments. Some literature suggests practicing at tempos other than the performance tempo is detrimental to the final performance quality (Duke \& Pierce, 1991; Pierce, 1992), but in these cases students had an unlimited amount of practice time and were required to use slower or faster tempos during that practice time. Contrasting literature has found that when students choose to slow the tempo down as a deliberate practice technique, their musical performance is not negatively impacted (Duke, Simmons, \& Cash, 2009; Miksza, 2007). In an effort to allow students to use this technique, participants in the pilot were not given a prescribed tempo at which the treatment exercises needed to be played. Similar to Wilkins and Kiff (2015), participants were asked to choose a tempo at which they could play the exercise accurately. The original exercise has a tempo marking of 63 beats per minute (bpm) and the WFPS allows for a variation of up to $12 \mathrm{bpm}$ faster or slower before a tempo error is to be marked. Therefore, students could conceivable play the original exercise at a tempo in the range of $51 \mathrm{bpm}$ up to 75 bpm before an error would be marked. If this same tempo range were applied to the pitch and 
rhythm treatments, it was unlikely students would exceed that range; therefore, providing a prescribed tempo seemed unnecessary. After analyzing pilot test recordings, it was observed that many participants did not slow down the pulse but rather increased the tempo dramatically. Because tempo contributes to the difficulty level of musical exercises, a starting tempo was thought to be appropriate during treatment in order to maintain similar challenge levels between tests and treatments.

It was also possible that participants might stop during the treatment exercise. The original WFPS allows for pauses between measures without penalty but counts a pause within a measure as an error. Because the treatment exercises were not being scored, there was no penalty if a student stopped; however, the student was encouraged to continue from where they stopped if the pause became overly extended.

Once participants finished playing through the treatment exercise, the appropriate stimulus exercise was once again placed on the music stand and participants had 30 seconds to silently prepare to play it. At the end of the preparation time, participants were given an audible pulse from a metronome and asked to play through the exercise one time as accurately as possible. As with the pre-test, the metronome was silenced after the participant began to play. This procedure was repeated with a second form of the exercise and a second treatment as well as a third form of the exercise in which no treatment was administered. During the period in which no treatment was administered, the investigator engaged the participants in conversation unrelated to the music being sight-read for an equivalent amount of time, approximately 1 minute, between each playing of the stimulus exercise. Each participant was asked what they most liked about playing their instrument and if they had any favorite music they had played in band. The order of treatments and stimulus exercises were rotated. 
Participants assigned to a post-test only treatment group (Group 3 or 4) began with either the rhythm or pitch treatment exercise or control condition, based on their group assignment. After they completed the treatment, they had 30 seconds to silently scan the associated stimulus exercise. At the end of that time, the investigator turned on the metronome and asked the participants to play through the stimulus exercise one time as accurately as possible. As with all other groups, the metronome was silenced after the participant began to play. This procedure was repeated with the other stimulus exercises and treatment conditions.

All testing and treatment sessions were digitally audio-recorded onto a 32 giga-byte secure digital (SD) memory card using a Zoom H5 portable recorder. Prior to analysis individual audio files of each pre-test and post-test were isolated from the session recordings using digital audio software. A notation was made on each student's demographic survey to indicate the audio file numbers for each stimulus exercise. These files were then randomized using a random number sequence generator (Random.org, 2015) and compiled for blind analysis by the investigator and a reliability judge. A video recording was also made of all sessions as both a backup for the audio recordings and as an additional source of information to aid in analysis. The video camera was positioned in such a way as to be focused only on the student's instrument and his or her hands so that playing technique could be analyzed. Video analysis allowed the investigator to confirm if errors in playing were caused by inaccurate finger patterns or inaccurate sound production techniques.

Finally, following all study tasks participants were asked to complete a short descriptive survey based on their perception of tasks included in the study. This survey solicited their opinion of the difficulty of tasks, the helpfulness of treatments, and their perception of pitch and rhythm in their own general performance (see Appendix K). 


\section{Scoring}

The WFPS, from which stimulus exercises in this study were developed, is scored using full measures as the scoring unit with an error in any category leading to loss of credit for the entire measure. Results of a pilot study (Russell, 2015) indicated that using a full measure as the scoring unit, as is specified in the WFPS, would not provide precise enough information for the purposes of this study. Therefore, in a modification of that scoring system, the beat was used as the scoring unit and scored as either correct or incorrect for each category of errors. In other words, if two notes were played incorrectly during the course of one beat, only one error was marked in the category of pitch. Each category of errors was considered independently. It was therefore possible to have a pitch, rhythm, and fluency error all assigned to the same beat. All stimulus exercises were 16 measures in length with 4 beats per measure; therefore, the highest possible raw score for rhythm was 64 . Pitch accuracy was determined based on the beat on which the pitch began. Therefore, notes that extended beyond one quarter note in length were only judged on the pitch performed in the first quarter note. Although it is possible that a mistake could be recognized and corrected after the first quarter note, this was not observed during pilot testing. Fluency was also only assessed based on the start of each note. Because half notes and whole notes do not have the possibility for pauses or hesitation between beats, a fluency score was given only for the first beat of those durations. Possible maximum raw scores for pitch and fluency then were 54 (10A), 55 (10B), and 53 (10C).

As originally outlined in the WFPS scoring instructions, pitch and rhythm accuracy were scored by the following criteria:

- Pitch errors - An error in pitch will be assigned to beats on which the following occurs:

- Tones are played on the wrong pitch 
- Imprecise attacks and minor irregularities in tone and intonation will not be considered errors as long as most of the note is recognizable as the correct pitch

- If the wrong pitch is sounded on the attack, but it is fingered correctly and immediately corrected without re-tonguing, it will not be counted as an error. (i.e., wrong partial, wrong octave)

- Tones are added or omitted

- Repeated tones will not count as a pitch error but will instead be categorized as a fluency error.

- Rhythm errors - An error in rhythm will be assigned to beats on which the following occurs:

- Notes are not given correct durational value (see also Fluency errors)

- Sustained notes must be held within one beat of the correct value.

Fluency errors were scored by the following criteria:

- Fluency errors - An error in fluency will be assigned to beats in which there is a disruption to the pulse in one of the following ways:

- Pauses or hesitations between notes within or between beats in a measure - errors assigned to the beat in which the error was made (within) or to the beat that did not occur in time (between)

○ Pauses or hesitations between measures -errors assigned to the first beat of the second measure 
- Repetition of notes in a measure (going back and replaying a note, not adding notes) - errors assigned to the beat immediately following where the break to repeat occurred

- Radical/abrupt change in tempo (more than $12 \mathrm{bpm}$ )-errors assigned to the beat in which it happened

Criteria for scoring fluency were developed from ideas contained within the original WFPS. Unlike the original WFPS scoring method, pauses between measures were counted as fluency errors in the present study. Complete scoring instructions are included in Appendix I.

All pre-test and post-test recordings $(N=816)$ were scored by the investigator. Participants in pre-test/post-test experimental groups $(n=90)$ had two individual recordings for each of the three tasks, while those in the post-test only groups $(n=92)$ had one recording for each of the tasks. An investigator developed scoring form (see Appendix J) was used to mark pitch, rhythm, and fluency errors for each beat of each stimulus exercise. The number of errors in each category was subtracted from the total possible score to determine raw pitch, rhythm, and fluency scores. Raw scores were then divided by the total possible and multiplied by 100 in order to allow for direct comparisons between musical elements and forms. Fifteen percent of the recordings $(n=123)$ were randomly selected to be scored by an independent reliability judge. Randomized files were compiled on an external flash drive and corresponding scoring forms were provided. Reliability between judges' scores for each category (rhythm, pitch, and fluency) and total summed scores for each recording was determined using Cronbach's Alpha as a measure of internal consistency. The minimum acceptable level of reliability in scoring for this study was set at Cronbach's $\alpha=.80$. Reliability for rhythm scores was Cronbach's $\alpha=.880$. Reliability for pitch scores was Cronbach's $\alpha=.972$. Reliability for fluency scores was 
Cronbach's $\alpha=.853$. Reliability for total summed scores was Cronbach's $\alpha=.951$. All measures exceeded minimum standards for reliability in this study and full statistical analyses proceeded. 


\section{CHAPTER 4: RESULTS}

The purpose of this study was to investigate the effect of rhythm and pitch priming tasks on sight-reading accuracy and fluency. Participants were assigned to either a rhythm or pitch treatment condition and received three levels of priming treatment: specific, general, and control. Specific priming consisted of playing either the rhythms, on a single pitch, or the pitches, each for a quarter note duration, of the associated musical example. General priming consisted of rhythm and scale patterns related to, but not transcriptions of, the associated musical example. Each participant was individually recorded under either a pre-test/post-test or post-test only exposure condition. Those in the pre-test/post-test condition sight-read the musical example, completed priming treatment, and then sight-read the same musical example again. Those in the post-test only condition completed the priming treatment and then sight-read the musical example. This process was completed with three different musical examples, one for each priming condition. Audio recordings were evaluated for pitch, rhythm, and fluency accuracy.

Findings were statistically analyzed using multivariate analysis of variance (MANOVA) techniques with an alpha level set at $p=.05$. Data were entered into IBM SPSS and screened for entry errors, coding errors, or missing values. Following this screening, data were examined through an initial analysis using descriptive statistics including data range, means, and standard deviations. Given the complexity of the study design and the number of potential confounding variables, a series of two-way repeated measures ANOVAs were run to confirm balance between experimental groups. There were no significant differences in group means based on participants' gender, grade, or outside music experiences, such as lessons or community-based ensemble participation. School, ensemble level, and instrument family were balanced through stratified sampling methods and two-way repeated measures ANOVAs confirmed no significant 
differences in group means based on those factors. Based on these analyses, it was reasonable to consider each experimental group to have equivalent samples of participants.

Due to the repeated measures design of the study, multiple musical examples were needed as stimulus exercises. A one-way repeated measure ANOVA, with musical exercise as a within subjects factor, showed no significant difference in means. This confirmed pilot study findings of equivalency between versions of the stimulus exercises.

\section{Main Effects}

In order to address the three research questions, a three-way repeated measures MANOVA was computed using post-test scores to determine the main effects of priming condition (specific, general, or control), treatment condition (rhythm or pitch), and exposure condition (pre/post or post-only) on the accuracy of three musical elements (rhythm, pitch, and fluency). Unless otherwise noted all accuracy scores had a total of 100 possible points. Assumptions of multivariate normality were tested with Box's Test of Assumptions of Equality of Covariance Matrices. Although Box's Test results were significant, indicating a lack of normality in the data, results of the MANOVA were considered robust against effects of departures from multivariate normality due to equal cell sizes and the large sample size;

therefore Wilks' $\lambda$ values were used. Mauchley's Tests of Sphericity were not significant for any dependent measure and sphericity was assumed for all univariate comparisons.

There was a significant effect due to priming condition, Wilks' $\lambda=.92, F(6,173)=$ 2.60, $p=.02$ partial $\eta^{2}=.08$. In other words holding all other factors constant, scores under each priming condition were different from scores under other priming conditions. Univariate tests revealed a significant difference in mean rhythm scores based on priming condition, $F(2,356)=5.20, p=.01$, partial $\eta^{2}=.03$. Levene's Test of Equality of Error Variances 
confirmed univariate normality, and pairwise comparisons using Bonferroni adjustments for multiple comparisons showed that rhythm accuracy scores under specific priming $(M=$ $90.28, S D=11.45)$ and general priming $(M=90.58, S D=11.14)$ were significantly lower $(p<.001)$ than under the control condition $(M=92.11, S D=9.34)$.

Although there was no significant difference in pitch based on priming condition, scores were lower under general priming conditions $(M=80.80, S D=18.25)$ than specific $(M=$ $81.86, S D=18.03)$ or control $(M=81.80, S D=16.55)$ conditions. Fluency scores were also not significantly different based on priming condition. They were consistently higher than pitch scores, but virtually unchanged between specific $(M=83.73, S D=12.34)$, general $(M=$ 83.93, $S D=12.58)$, and control $(M=83.43, S D=11.45)$ conditions (see Figure 4.1).

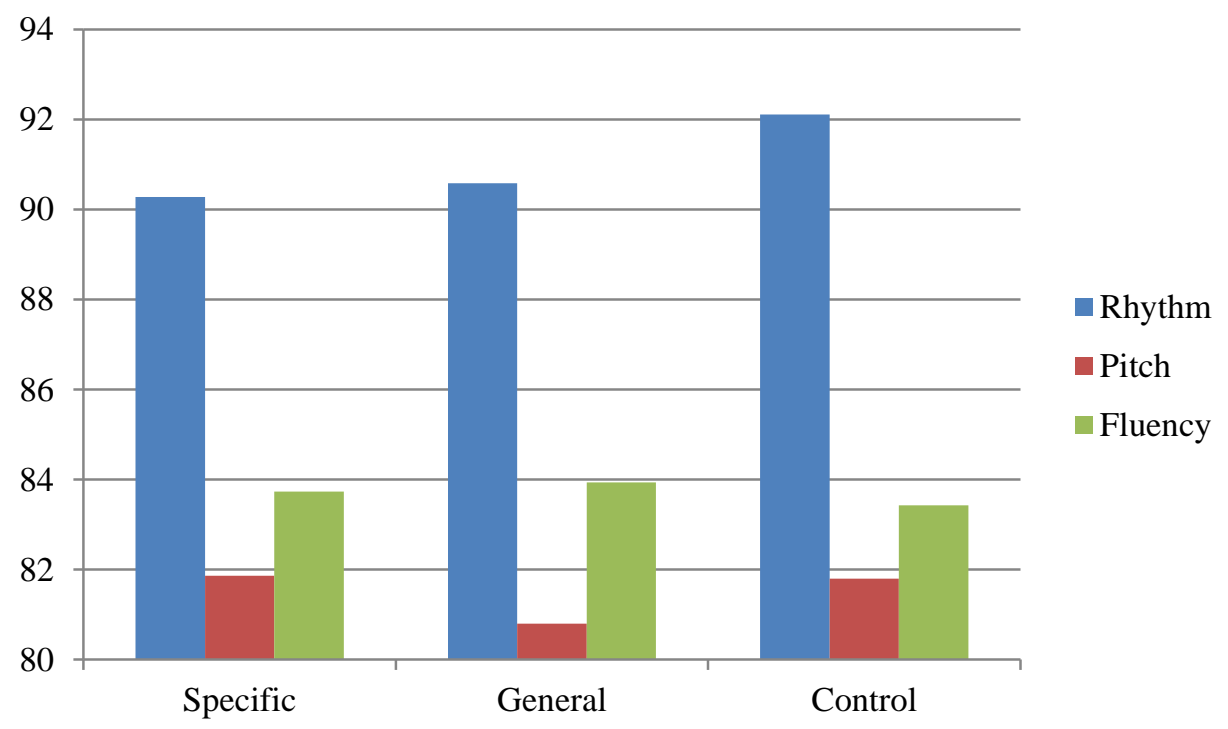

Figure 4.1. Music Element Means by Priming Condition

There was no significant main effect for treatment condition, Wilks' $\lambda=.99, F(3,176)=.81, p=.49$ partial $\eta^{2}=.01$. Accuracy scores under rhythm treatments 
$(M=85.29, S D=14.37)$ were nearly the same as those under pitch treatments $(M=$ $85.49, S D=14.39)$.

There was also no significant main effect for exposure condition, Wilks' $\lambda=$ $.99, F(3,176)=.349, p=.79$ partial $\eta^{2}=.01$. Participants in the pre-test/post-test condition scored slightly higher $(M=86.16, S D=14.12)$ than those in the post-test only condition $(M=85.66, S D=14.58)$. Finally, there was no significant interaction between treatment condition and exposure condition, Wilks' $\lambda=.99, F(3,176)=.30, p=.82$ partial $\eta^{2}=.01$. Multivariate interactions between within-subjects and between-subjects factors were nonsignificant and can be found in Table 4.1.

Table 4.1

Repeated Measures MANOVA Multivariate Effects Table

\begin{tabular}{|c|c|c|c|c|c|c|}
\hline Source & $\begin{array}{l}\text { Wilks' } \lambda \\
\text { Value }\end{array}$ & $\mathrm{F}$ & $\mathrm{df}$ & Frror $\mathrm{df}$ & $\mathrm{Sig}$ & $\begin{array}{c}\text { Partial Eta } \\
\text { Squared }\end{array}$ \\
\hline Treatment & .99 & .81 & 3 & 176 & .49 & .01 \\
\hline Exposure & .99 & .35 & 3 & 176 & .79 & .01 \\
\hline Treatment* Exposure & .99 & .30 & 3 & 176 & .82 & .01 \\
\hline Priming & 92 & 2.60 & 6 & 173 & .02 & .08 \\
\hline Priming * Treatment & 69 & 1.25 & 6 & 173 & .28 & .04 \\
\hline Priming * Exposure & .98 & .47 & 6 & 173 & .83 & .02 \\
\hline Priming $*$ Treatment $*$ & & & & & & \\
\hline Exposure & .97 & 1.00 & 6 & 173 & .43 & .03 \\
\hline
\end{tabular}

\section{Secondary Analyses}

This study was planned using a repeated measures design with participants serving as their own control. Two levels of priming served as treatments along with a control condition. It was hypothesized that priming would improve playing accuracy. Because priming condition was a significant factor in sight-reading accuracy scores, it is important to consider that the repeated nature of the tasks, both from pre-test to post-test and between the three tasks, may have created a carry-over effect due to priming as well. Participants were also recruited from multiple schools 
and ensembles and played a variety of wind instruments. The purposeful inclusion of a broad sampling of high school students was to increase the generalizability of the results to the extent possible. Potential confounding factors were identified and balanced across experimental groups. While there were no significant differences between groups based on those factors, it is appropriate to further consider what, if any, differences in accuracy exist due to those factors.

Effects of Pre-test. Study design created the opportunity to compare scores over time in two distinct ways, from pre-test to post-test and over the course of three different tasks. Half of the participants were assigned to experimental groups under a Pre-test/Post-test exposure condition, giving them the opportunity to repeat the same musical example two times. Using data only from participants in the Pre-test/Post-test condition $(n=90)$, a two-way repeated measures MANOVA with priming condition and time (pre and post) as within subjects factors was computed. Unlike the main analysis, there was no significant difference in accuracy based on priming condition, Wilks' $\lambda=.91, F(6,84)=1.4, p=.22$, partial $\eta^{2}=.09$. There was a significant difference in accuracy scores based on time, Wilks' $\lambda=.85, F(3,87)=5.08, p<$ .01 , partial $\eta^{2}=.15$. Univariate tests revealed a significant difference in both pitch scores, $F(1,89)=8.317, p<.01$, and fluency scores, $F(1,89)=10.795, p=.001$ based on time. Post-test pitch scores $(M=82.39, S D=17.93)$ were higher than pre-test pitch scores $(M=$ $80.78, S D=16.81)$. Post-test fluency scores $(M=84.44, S D=11.52)$ were higher than pretest fluency scores $(M=82.96, S D=11.14)$. There was no significant difference in rhythm scores between pre-test and post-test (see Figure 4.2).

Order effects. Participants completed three different tasks as part of the study. Post-test accuracy scores for all participants were compared based on task order. It is possible that accuracy changed due to a practice effect between tasks or as a result of treatment order. A two- 


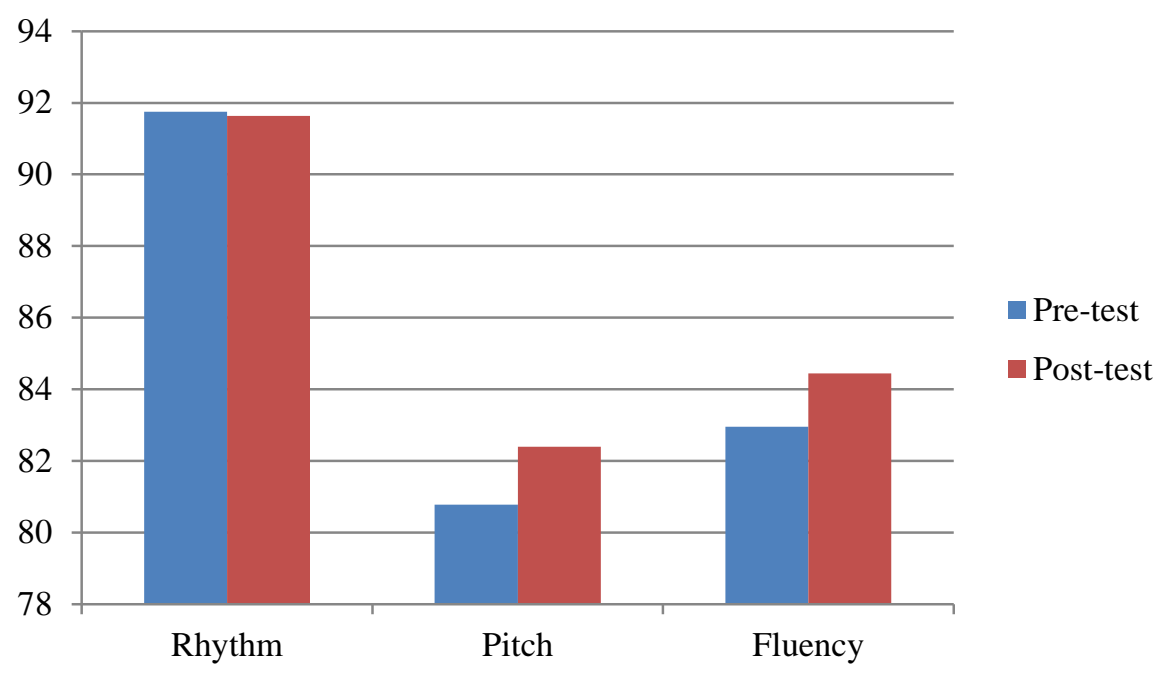

Figure 4.2. Pre-test to Post-test Time and Element Interaction

way repeated measures MANOVA with task order as a within-subject factor and treatment order as a between subjects factor was conducted. A significant main effect for task order was detected, Wilks' $\lambda=.87, F(6,171)=4.16, p=.001$, partial $\eta^{2}=.13$. Univariate tests revealed significant differences in pitch accuracy, $F(2,352)=8.82, p<.001$ and fluency accuracy, $F(2,352)=6.23, p<.01$ based on order of task. As seen in Figure 4.3, and confirmed by

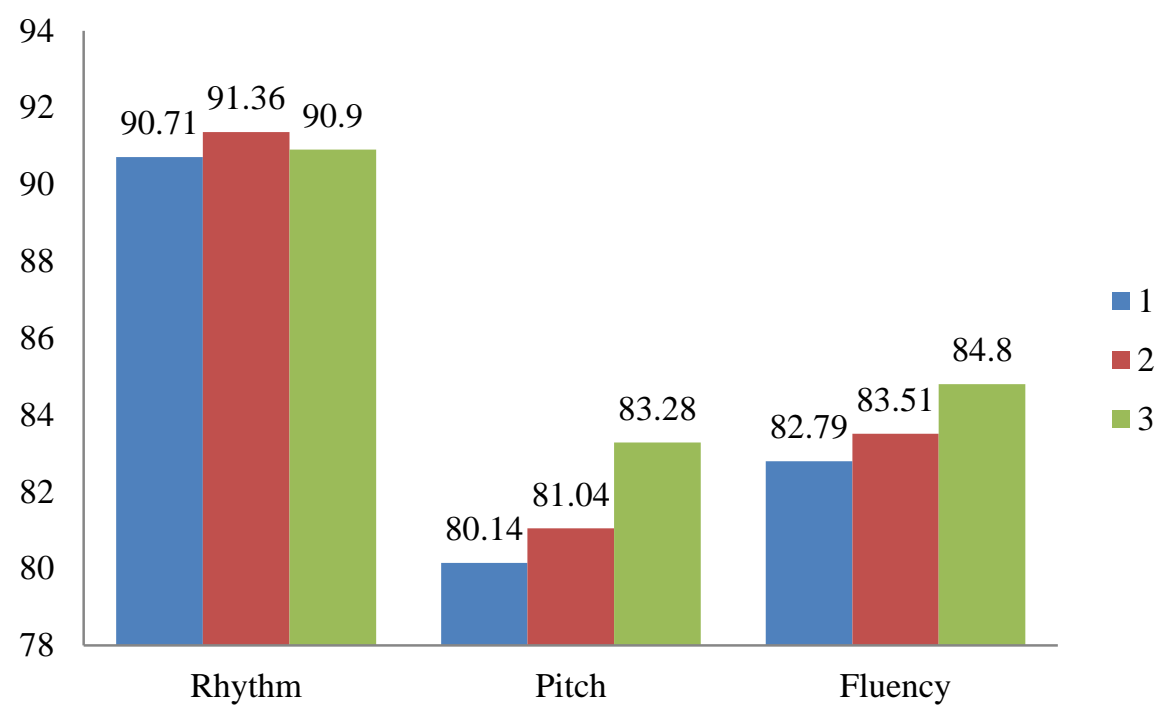

Figure 4.3. Task Order Scores by Element 
pairwise comparisons with Bonferroni adjustments, mean pitch accuracy significantly increased between tasks 1 and 2 and tasks 2 and 3. Fluency was significantly more accurate in the third task than the first task. Task order did not significantly change rhythm accuracy. There was no significant effect in accuracy based on treatment order, $F(5,176)=.44, p=.82$, partial $\eta^{2}=.01$

It is interesting to note that although there were no significant effects for treatment order, both pitch and fluency scores mirror the significant result of task order. In each case, except for pitch scores in treatment order 2, scores were highest for the priming condition presented as the third task. In a confirmation of the significant main effects of priming condition, rhythm accuracy scores were highest under the control condition in four of the six task orders regardless of treatment order. Figure 4.4 displays these trends.

School, instrument family, and ensemble level. Through the process of stratified sampling, experimental groups were balanced for the factors of school, instrument family, and ensemble level. Repeated measures MANOVAs confirmed no significant difference in group means based on these factors; however, there were significant differences within each of these factors. Because there were significant differences within these factors, it is important to investigate in what ways scores differed for each of these groups so that results might be interpreted more appropriately.

Fluency accuracy was significantly different based on school, $F(4,177)=3.53, p<.01$. As seen in Figure 4.5, and confirmed by pairwise comparisons with Bonferroni adjustments, participants from School 1 were more fluent $(M=90.47, S D=9.64)$ than participants from School $3(M=81.46, S D=11.04)$ and School $5(M=80.29, S D=12.85)$. Although it might seem there should be a significant difference in scores based on pitch given the range of scores, 
a. Rhythm

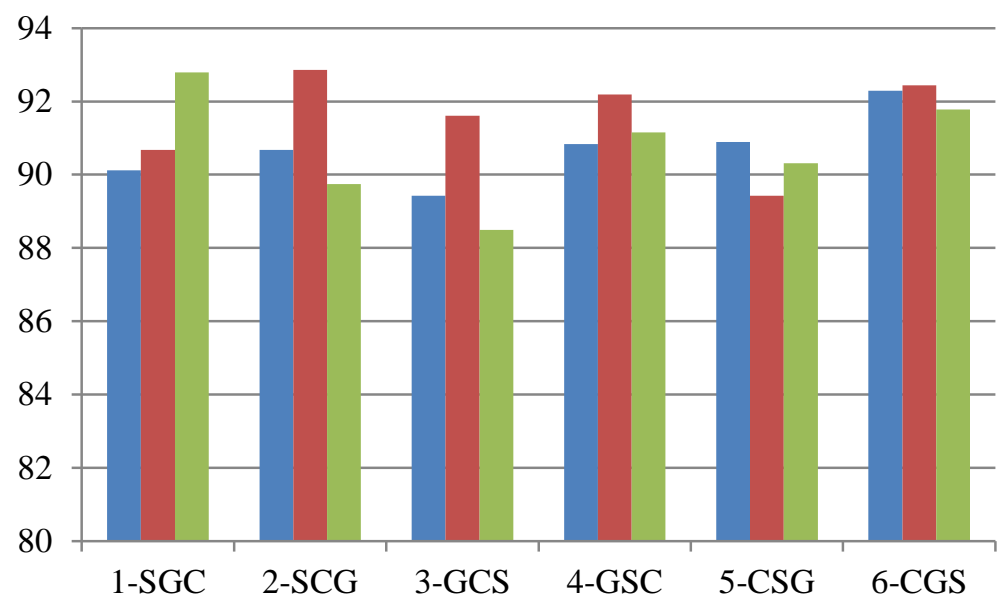

\section{b. Pitch}

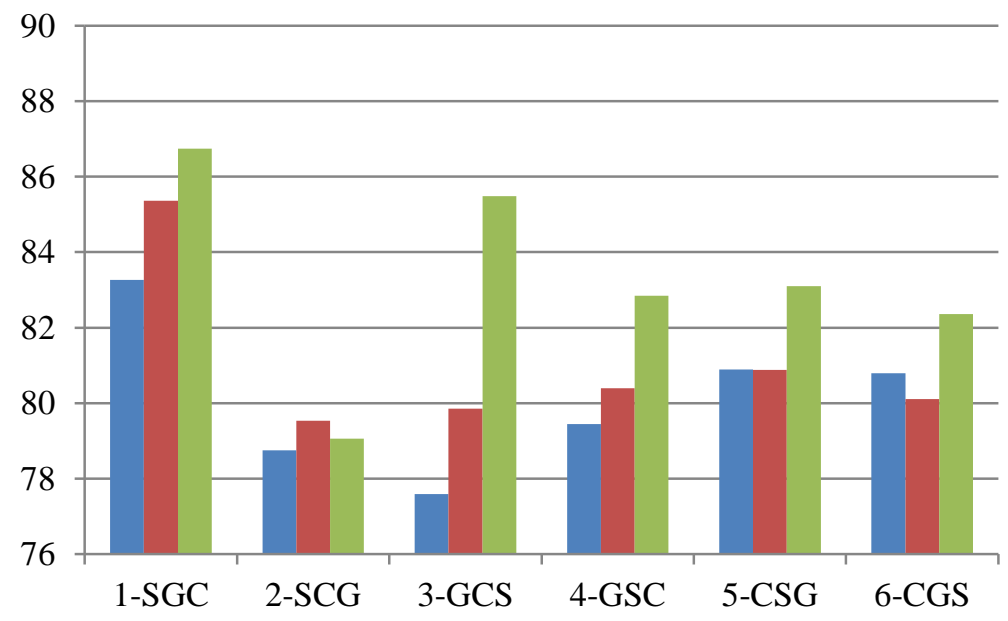

\section{c. Fluency}

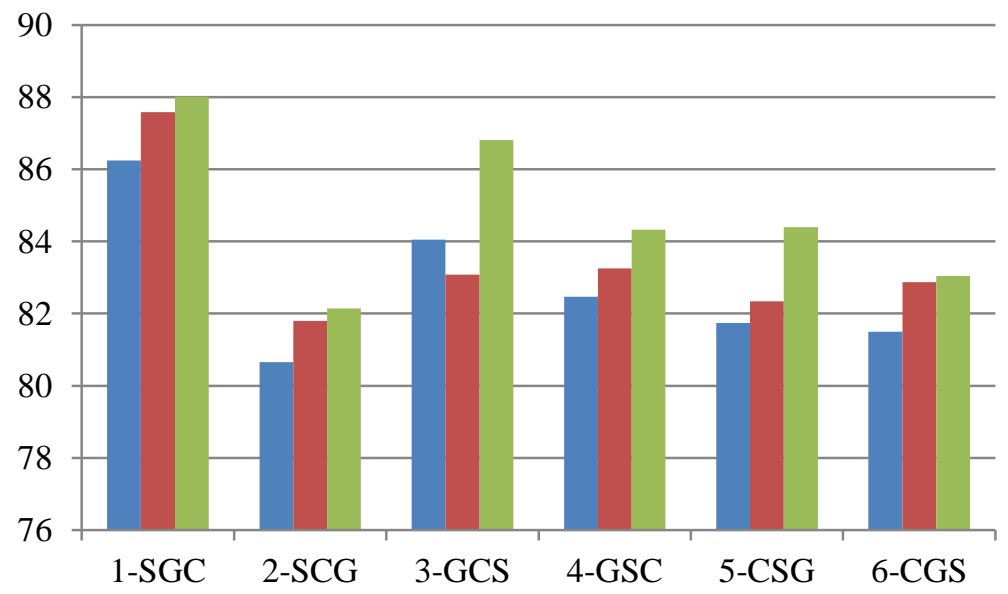

- First Sight-reading Example - Second Sight-reading Example - Third Sight-reading Example
- First Sight-reading Example - Second Sight-reading Example - Third Sight-reading Example
- First Sight-reading Example - Second Sight-reading Example - Third Sight-reading Example

Figure 4.4. Accuracy Scores across Six Treatment Orders $\mathrm{S}=$ specific priming, $\mathrm{G}=$ general priming, $\mathrm{C}=$ control condition 


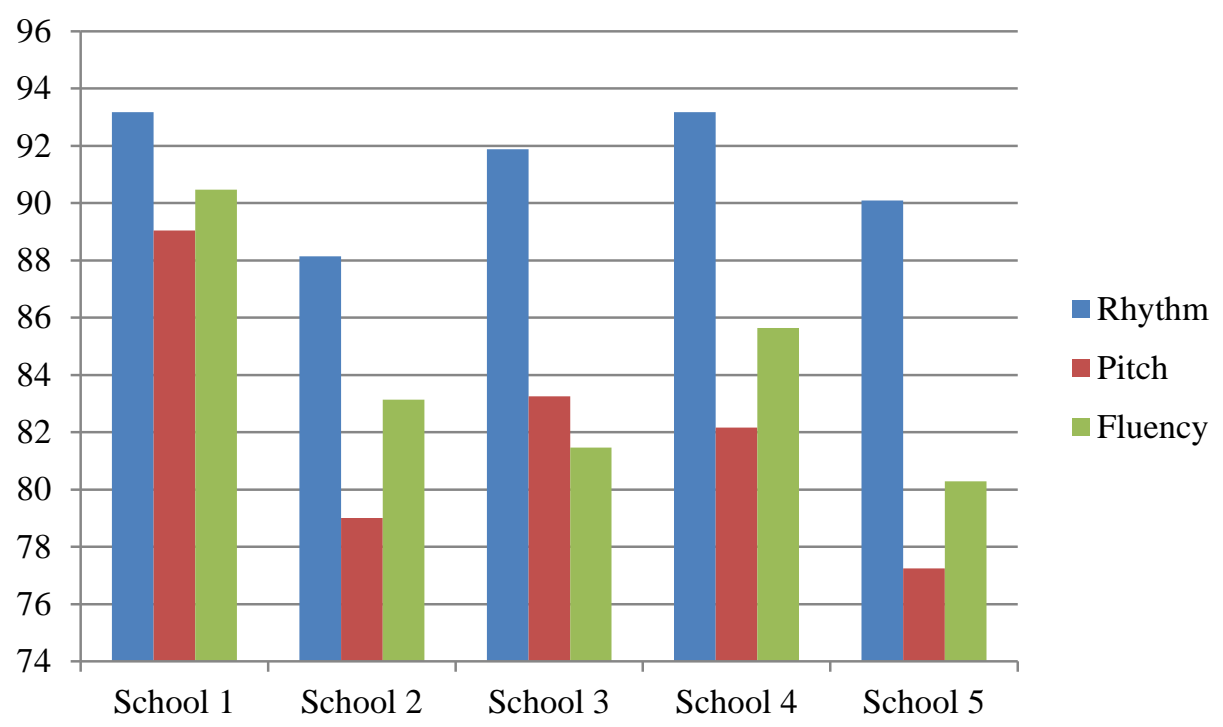

Figure 4.5. Accuracy Scores by School

large variances in pitch scores led to non-significant differences. There were no other significant differences between schools.

Significant differences based on ensemble level existed in rhythm accuracy, $F(2,179)=$ $9.49, p<.001$, pitch accuracy, $F(2,179)=8.60, p<.001$, and fluency, $F(2,179)=$ $30.28, p<.001$. Pairwise comparisons with Bonferroni adjustments revealed participants in top ensembles had more accurate rhythm $(M=93.88, S D=7.80)$ than participants in second ensembles $(M=88.14, S D=12.38)$ or third ensembles $(M=87.29, S D=12.38)$. Top ensemble participants also had better pitch accuracy $(M=86.25, S D=14.75)$ than those in second ensembles $(M=76.31, S D=18.97)$ but not third ensembles. Finally, participants in top ensembles played with better fluency $(M=89.08, S D=8.84)$ than members of second ensembles $(M=77.22, S D=12.71)$ or third ensembles $(M=81.69, S D=11.09)$. There were no significant differences in accuracy scores between participants in the second and third ensembles (see Figure 4.6). 


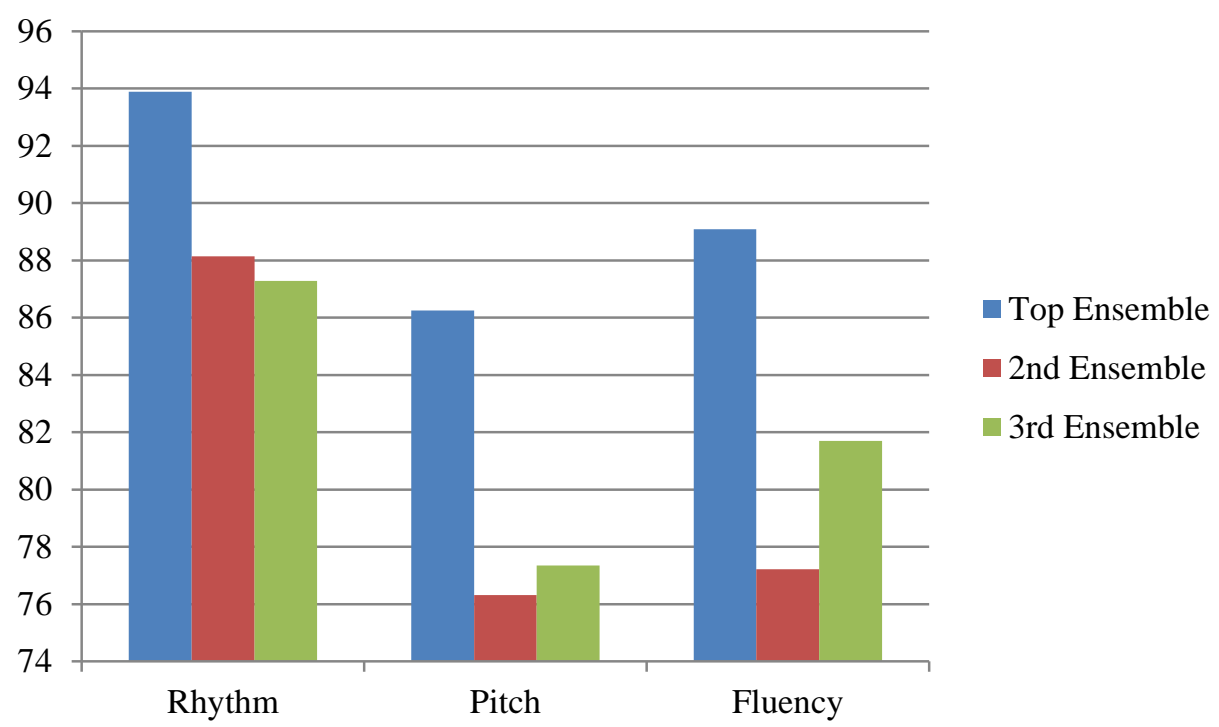

Figure 4.6. Accuracy Scores by Ensemble

Instrument family was another source of differences in sight-reading accuracy scores. There was no significant difference in rhythm accuracy or fluency scores; however, pitch accuracy was significantly different, $F(1,180)=58.27, p<.001$ based on instrument family. As can been seen in Figure 4.7, participants who played woodwind instruments $(M=$ $88.47, S D=10.32$ ) played significantly more accurate pitches than those who played brass instruments $(M=71.97, S D=20.76)$.

\section{Post-test Survey}

Participants completed a brief post-test survey (see Appendix K) following the final sight-reading exercise. The survey asked for participants' overall perception of difficulty for the sight-reading tasks, the element they found most difficult in sight-reading, the element on which they most focused during sight-reading, the element which they believed to be most difficult to master during rehearsed music preparation, and their perception of the helpfulness of the priming exercises. For each item on the survey, students circled the answers they felt best applied to their own playing. 


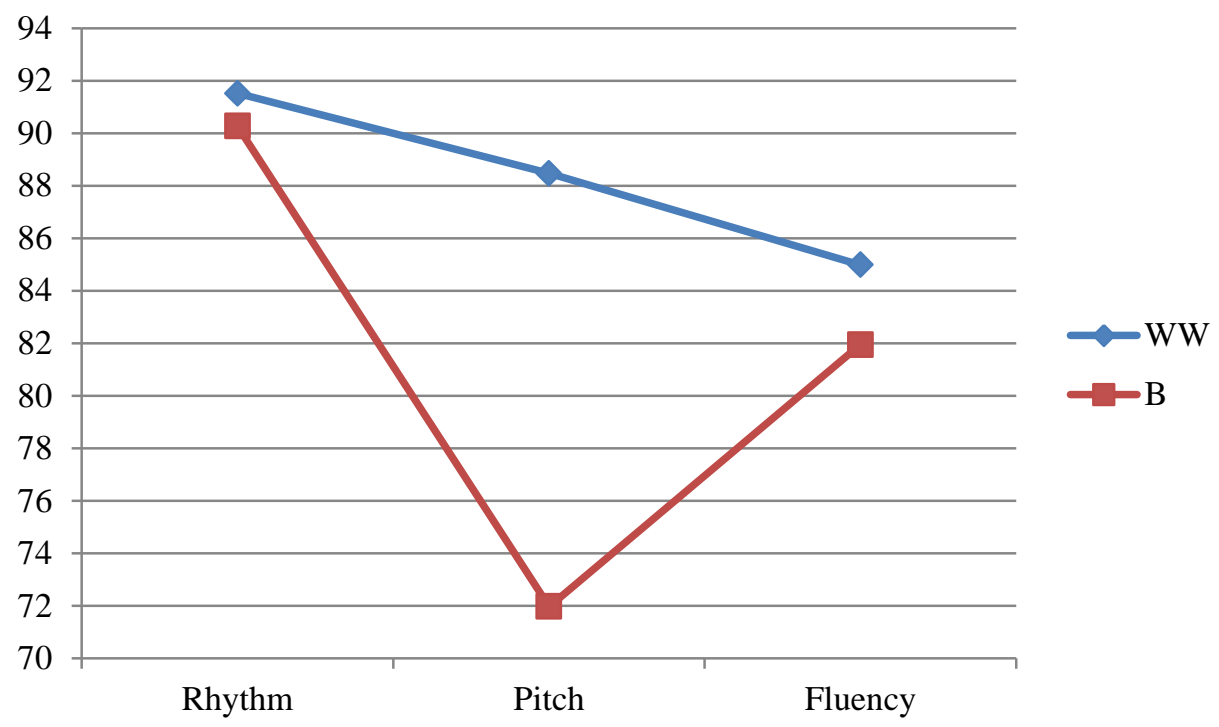

Figure 4.7. Instrument Family and Element Interaction.

Difficulty of the task was measured on an 8-point scale anchored by the phrases " $1=$ Not at all" and " $8=$ One of the hardest things I've done." Overall participants rated the tasks as somewhat difficult $(M=4.98, S D=1.38)$. This rating seems to confirm pilot test data that showed the exercises to be challenging yet appropriate for the skill level of study participants. When asked to identify what they found most difficult in sight-reading, $52.7 \%$ of participants reported "playing the right rhythms" as the hardest part of the task, while $30.2 \%$ reported "playing the right notes" as hardest (see Table 4.2 for full results). Given the significant difference in pitch accuracy between brass and woodwind players, it is interesting to note that a greater percentage of brass players $(38 \%)$ than woodwind players $(25 \%)$ perceived "playing the right notes" as hardest. Participants could also choose to describe an "other" element as most difficult. Of the $17 \%$ of respondents who chose "other" as most difficult, $64.5 \%$ listed "both" rhythm and notes as the most difficult element. It is possible that response may represent participants' perception of challenges posed by simultaneous responsibilities during sight- 
reading. Participants also described challenges with key signature, pulse, partials, other music challenges, and extra-musical challenges as being most difficult (see Table 4.3).

Table 4.2

Post-test Survey Results

\begin{tabular}{lcc}
\hline Question & $n$ & $\begin{array}{c}\text { Percentage of } \\
\text { Responses }\end{array}$ \\
\hline $\begin{array}{c}\text { Hardest element of sight-reading } \\
\text { Playing right rhythms }\end{array}$ & 182 & 52.7 \\
Playing right notes & 96 & 30.2 \\
Other & 55 & 17 \\
& 31 & \\
Sight-reading focus & 182 & 45.6 \\
Playing right rhythms & 83 & 42.3 \\
Playing right notes & 77 & 12.1 \\
Other & 22 & \\
consuming element in rehearsed music & 182 & 65.4 \\
Right rhythms & 119 & 33.5 \\
Right notes & 61 & 1.1 \\
Both & 2 & \\
Most time & 182 & 87.9 \\
Yes & 160 & 12.1 \\
No & 22 & \\
$\quad$ & 160 & 40.0 \\
Priming exercis were helpful & 64 & 33.8 \\
Specific & 54 & 26.3 \\
General & 42 & \\
Neither &
\end{tabular}

In reporting sight-reading focus, participant responses were split evenly between focusing on playing the right notes $(42.3 \%)$ and playing the right rhythms (45.6\%). Of the $12.1 \%$ of participants who chose to describe an "other" element on which they focused, $50 \%$ described playing "both" the right rhythms and notes as their primary focus during sight-reading. Similar to 
Table 4.3

"Other" Sight-reading Hardest Element Responses

\begin{tabular}{lcc}
\hline Descriptor & $\begin{array}{c}n \\
(N=31)\end{array}$ & $\begin{array}{c}\text { Percentage of } \\
\text { Responses }\end{array}$ \\
\hline Both rhythm \& notes & 20 & 64.5 \\
Pulse \& tempo & 5 & 16.1 \\
Key Signature & 3 & 9.7 \\
Partials \& hearing pitches & 2 & 6.5 \\
Articulation & 1 & 3.2 \\
Adding Dynamics & 1 & 3.2 \\
Skips \& leaps & 1 & 3.2 \\
Extra musical issues & 3 & 9.7 \\
\hline
\end{tabular}

Note. Participants could list more than one item; therefore total percentage of responses exceeds $100 \%$.

comments made regarding sight-reading challenges, participants described focusing on "other" issues related to both pitch and rhythm, such as key signature and tempo, in addition to overall musicality (see Table 4.4).

Table 4.4

"Other" Sight-reading Focus Responses

\begin{tabular}{lcc}
\hline Descriptor & $\begin{array}{c}n \\
(N=22)\end{array}$ & $\begin{array}{c}\text { Percentage of } \\
\text { Responses }\end{array}$ \\
\hline Both rhythm \& notes & 11 & 50 \\
Musicality (Phrasing, Style, Dynamics) & 5 & 22.7 \\
Pulse \& tempo & 4 & 18.2 \\
Key Signature \& Accidentals & 3 & 13.6 \\
Pitch \& other elements & 3 & 13.6 \\
Rhythm \& other elements & 2 & 9 \\
\hline
\end{tabular}

Note. Participants could list more than one item; therefore total percentage of responses exceeds $100 \%$.

Much like their responses to the element most challenging to play during sight-reading, most participants $(65.4 \%)$ indicated that playing the right rhythms took the most time to accomplish in their preparation of rehearsed music, while all but two of the remaining (33.5\%) indicated that playing the correct notes took more time. Although participants were asked to choose between pitch and rhythm, two circled both indicating they found both elements time 
consuming. Most participants (87.9\%) perceived the priming exercises to be helpful overall. Of those who indicated that the exercises were helpful, $40 \%$ indicated that the specific priming exercise was most helpful, $33.8 \%$ indicated that the general priming exercise was most helpful, and $26.3 \%$ indicated that while the exercises were helpful, one was not more helpful than the other. Although participants overwhelmingly believed the tasks to be helpful, this was not readily apparent in sight-reading accuracy scores. Participants did not play more accurately after priming tasks than after the control condition. This contrast is concerning given the importance of self-correction capabilities expected of independent musicians. Sight-reading accuracy did improve over time, however, so it is possible that participants' perceptions of helpfulness was based on a general sense rather than a specific connection to one task. It is also possible that many participants reported tasks as being helpful because they thought it was the expected answer. Even though priming tasks were presented only as exercises related to the sight-reading, it is highly likely that most participants presumed the purpose of the exercises was to have a positive impact on their sight-reading accuracy.

A series of bivariate comparisons were made to determine what, if any, relationships existed between participants' responses to each question as well as with their demographic data and performance on study tasks. A Pearson product-moment correlation yielded small but significant relationships between participants' perceived level of difficulty with the tasks and total scores on the tasks. In each case there was a negative correlation between difficulty level and score (see Table 4.5). Participants who rated the tasks as being more difficult, a higher numeric value, had lower accuracy scores, and participants who rated the tasks as being easier, a lower numeric value, had higher accuracy scores. Although not a large correlation coefficient, it 
seems that participants' perception of difficulty was related to their ability to accurately complete the tasks.

Table 4.5

Pearson Product Moment Correlation of Task Difficulty and Score

\begin{tabular}{lccc}
\hline & Total Score & Total Score & Total Score \\
& Task 1 & Task 2 & Task 3 \\
Task Difficulty & $r=-.255$ & $r=-.263$ & $r=-.227$ \\
Rating & & & \\
& $p=.001$ & $p<.001$ & $p=.002$ \\
& $N=182$ & $N=182$ & $N=182$ \\
\hline
\end{tabular}

Associations between survey data and grouping variables were computed using Chisquare techniques and Cramer's V measure of association for nominal level data. Comparisons were made based on experimental group, school, ensemble level, and instrument family. Three significant $(p<.05)$ associations emerged from these comparisons.

First, in four out of the five schools, responses indicated that playing the right rhythms was the most challenging aspect to these sight-reading tasks. Participants in the other school indicated that playing the right notes was the most challenging aspect. Next, participants in the top and second ensembles indicated that playing the right rhythms was the most challenging aspect. Participants in a third ensemble identified "other" elements as most challenging. Finally, participants in top ensembles indicated they most focused on playing the right rhythms. Participants in second ensemble indicated they most focused on playing the right notes. Participants in third ensembles indicated playing the right rhythms and playing the right notes equally often as the aspect on which they most focused. It is interesting to consider that while participants in top and third ensembles reported the same areas as being most challenging and their focus during sight reading, participants in second ensembles found rhythm most challenging but reported focusing on playing the right notes. There were no other significant 
associations between school or ensemble level and survey responses. There were also no significant associations between experimental group or instrument family and survey responses. 


\section{CHAPTER 5: DISCUSSION}

The complex patterns of sounds which are called music may, subject to certain limitations, be indicated with a relatively high degree of accuracy through the use of an equally complex system of musical notation....Music reading is a highly complex process because it involves not only the recognition and interpretation of these various symbols but frequently requires a simultaneous response in terms of vocal or instrumental performance. (Petzold, 1960, p. 271)

As Petzold so clearly states, music reading is a complex task. Empirical study of this task has focused on gaining a better understanding of the direct relationships within the task. In other words, if participants do this, then that happens. These relationships are important to our understandings of isolated variables in music reading; however, they may not account for the dynamic nature of the multiple variables inherent in real-world music reading and teaching. The present study was purposefully multifaceted to study music reading and performance in a context that more closely mirrored variables found in music classrooms.

Participants in this study were high school students who played either a woodwind or brass instrument. They were randomly assigned to either a pre-test/post-test or post-test only condition, as well as either a pitch or rhythm treatment condition. All participants completed three sight-reading tasks, under two different priming conditions and a control condition. Priming tasks were created to be either a literal reproduction of the pitch or rhythm of a stimulus exercise or a general pitch or rhythm task related to the stimulus exercise. These tasks were developed based on ideas taken from priming literature outside the field of music. However, they also represent common practice in many music classrooms. Teachers will often decontextualize elements of music through isolation in order to promote greater musical accuracy when put back into context. In addition to isolation, teachers will also use related exercises to reinforce previously learned material. The hope is that students will transfer what they practiced in 
isolation or related exercises to the music they are learning. A third condition, consisting of a brief conversation about the participants' enjoyment of playing their instrument, was used as a control in which no priming took place. It was hypothesized that by priming musicians with either pitch or rhythm tasks, the cognitive load of the complex task of reading and performing music might be reduced allowing for a more accurate performance of unrehearsed music.

This study was intended to be a step toward a better understanding of the function of pitch and rhythm in the initial performance of a piece of music through the effects of perceptual (specific) and conceptual (general) cognitive priming tasks on pitch, rhythm, and fluency accuracy. It sought to answer three main research questions:

1. What is the effect of perceptual (specific) and conceptual (general) cognitive priming tasks on pitch, rhythm, and fluency accuracy during sight-reading?

2. Is there a significant difference in pitch, rhythm, or fluency accuracy between students who are primed through pitch exercises and those who are primed through rhythm exercises prior to playing the musical selection as originally composed?

3. Does playing through a musical selection a second time significantly change the accuracy of pitch, rhythm, or fluency?

Data collected in this study provided answers for these questions. Perceptual and conceptual priming tasks did not produce a significant difference in pitch or fluency accuracy as compared to a control condition. However, rhythm accuracy scores were significantly lower after priming treatments than after the control condition. There was no significant difference in accuracy scores between participants who completed pitch treatments and those who completed rhythm treatments. Finally, playing through a musical selection a second time significantly increases pitch and fluency accuracy, but post-test scores of participants who played the musical selections 
twice were not significantly different from post-test scores of participants who played through each selection once. These simple answers, however, do not convey the underlying complexity for why the results may be what they are.

\section{Rhythm and Pitch}

Tasks in this study were designed to isolate the roles of rhythm and pitch in music reading. Previous studies (Cassidy, Betts, \& Hanberry, 2001; Henry, 2011; Pike \& Cater, 2010) have observed an interaction between pitch accuracy and timing accuracy. Building on those ideas, this study asked what the effects would be on the accuracy of performing music from notation if participants were primed with rhythm or pitch. It was hypothesized that accuracy would increase because prior experience with one or the other element in isolation would reduce the cognitive load during music reading. Results showed there was no significant difference in pitch accuracy or fluency scores based on priming condition, treatment condition, or exposure condition. These scores appear to have been neither helped nor hindered due to experimental manipulation. On the other hand rhythm scores were significantly lower under both specific and general priming conditions than they were under the control condition. This was true for participants regardless of treatment or exposure condition.

Rhythm accuracy results were unexpected in many ways. Rhythm scores in the current study were higher than both pitch and fluency scores. This is seemingly contrary to previous research and theories about sight-reading. In one of few published studies to consider component scores, rather than one overall performance score, Elliot's (1982a) analysis of sight-reading errors classified $61 \%$ of errors as rhythm errors. However comparisons to this number must be made with caution. All timing errors in Elliot's study were included under the umbrella of rhythm. In fact, the largest portion of those errors (46.22\%) were what Elliot termed as "meter 
signature" errors, in which participants played a piece marked as cut time in common time, for example. He also included pauses and tempo fluctuations and missed metronome markings in this category of errors. I am not suggesting that these errors should not be included as timing errors. I am suggesting they are very different from actual durational errors, or missed rhythms, however. This seems to be an important distinction to make when considering how to best teach music reading skills. Missed rhythms accounted for only $23 \%$ of rhythm errors committed in Elliot's study. The current study deliberately considered durational errors separate from other timing errors, which then were included under the umbrella of fluency. Comparing results based only on missed rhythms, results then more closely align with the specifics of Elliot's study.

Perhaps more unexpected were the significantly lower rhythm scores under priming conditions than the control condition. By its very definition, priming is said to have occurred when speed or accuracy of a task increases (Tulving \& Schacter, 1990). Given that accuracy scores did not significantly increase, it would be plausible to argue that no priming actually took place, at least not as intended. Alternatively, rhythm scores were very high overall. It is possible that participants were performing at or near their full potential for rhythm accuracy and would not have scored any higher no matter what the treatment had been.

However, the significantly lower rhythm accuracy scores during priming indicate the probability that something occurred during treatment. It is important to note that the difference of only two points between priming and control conditions, although significant, may not be practically meaningful. In the classroom, a student who demonstrates $90 \%$ accuracy is not very different from a student who demonstrates $92 \%$ accuracy. Therefore, the importance in this difference should be considered in terms of the connections to past research and implications for further research. 
Priming tasks for this study were developed as a first attempt to apply principles of priming to the performance of musical notation. Prior research with priming in music has focused on priming through listening (Jungers, 2007; Marmel \& Tillmann, 2009; PoulinCharronnat, Bigand, \& Madurell, 2005). In other words the aural perception of recorded music was used as a prime for other tasks. However, in this study the focus was on the visual perception of musical notation as translated into an aural performance, so exemplars of priming tasks were gathered from more traditional psychology literature. In that literature, priming tasks often focus on text based information; yet, nonverbal, visual stimuli have also been developed and used effectively (Tulving \& Schacter, 1990). It seemed then that using music notation, a nonverbal stimulus that maintains a semantic context, might be an effective manner in which to prime a performance based response. By experiencing either the pitch or rhythms of an unknown piece to be performed, the brain might be prepared to more efficiently deal with information from the notation.

In order for that to happen it was important that the information being primed was the focus of attention for the participants (Wiggs \& Martin, 1998). Instructions prior to each priming task clearly indicated that participants were about to play either a literal translation of the pitches or rhythms from the musical example with which it was associated, or they would be playing a pitch or rhythm exercise related to the musical example. Primes also needed to be structured in specific ways to achieve their desired results. General tasks in this study were intended to serve as conceptual primes. Conceptual priming is driven by the connection of categorical information and specific exemplars of those categories and is generally thought to be connected to semantic memory rather than implicit memory (Schacter \& Buckner, 1998; Tulving \& Schacter, 1990). Specific tasks in this study were intended to act as perceptual primes. Perceptual priming has 
been shown to be most effective when the prime and the test item are identical in format (Schacter \& Buckner, 1998) and meaning (Bainbridge, Lewandowsky, \& Kirsner, 1993).

The absence of a positive priming effect in this study might be related to an attentional matter. Post-test survey data indicated that while there was a fairly even split between participants who reported focusing on pitch and those who reported focusing on rhythm, there was no relationship between those responses and the experimental group to which participants were assigned. In other words, those in rhythm treatment groups did not report focusing on rhythm more often than pitch and vice versa. It might also be possible that the priming exercises, as developed in this study, were simply not appropriate for the intended tasks. Transferring concepts from one discipline to another can be an imperfect process. Last but not least, it is possible that although both pitch and rhythm exercises in this study were either literal transcriptions of the original music or general representations of that music, the isolated state of those elements changed their meanings from prime to test and therefore diminished the priming effects. This may be particularly true when considering rhythm accuracy.

Priming tasks in the pitch condition removed the original rhythmic values. Likewise in tasks under the rhythm condition, pitch values were removed while rhythmic values were preserved. The intention in this design was to isolate each factor; however, it may be that this isolation unintentionally changed the semantic context of the musical elements. Rhythm accuracy scores decreased while pitch accuracy and fluency were neither helped nor hindered. Based on results of this study, it seems possible that rhythmic meaning may be subject to a greater degree of perceived differentness than pitch. Boyle (1969) alludes to this idea when he observed that students could play a line of rhythms accurately on one pitch but had difficulty repeating those rhythms in context of a melody. Likewise, Pierce (1992) also found that playing 
only the rhythm did not produce significantly better results on melodies. By adding the simultaneous element of pitch, which is represented in a vertical direction, the horizontal reading of duration is compromised. This conclusion is supported by the physiological responses noted in Van Nuys and Weaver (1943). They observed that eye fixations (or pauses) are longer for rhythms than melodies, suggesting that rhythm required a greater time span to perceive and process. They also found that the accuracy of reading melodies is improved if the visual field is not limited; however, this was not the case for rhythm reading. It appeared rhythm was perceived and processed in time and not prepared for through involuntary eye movements looking ahead to what was coming next.

While this certainly applies to those in rhythm treatment groups, it does not necessarily explain why rhythm scores were lower in the pitch treatment condition. It may be that priming participants with pitch focused their attention on the element of pitch in a manner that changed the perception and performance of rhythm in different ways than what happened under the control condition. In other words, it may be possible that the normal patterns of processing were disrupted by the dominance of a different focus of attention. This supports the idea that although pitch processing may not be negatively affected by isolating musical elements, the perception of rhythm may be changed. It seems likely then that rhythm is processed in different manners than pitch.

In a review of brain research, Hodges and Nolker (2011) highlight the separation of pitch reading and rhythm reading shown in studies of musicians with brain damage. Although there are not believed to be specific regions of the brain where pitch and rhythm uniquely reside, these studies do indicate they can be processed separately. Schön and Besson (2002) also found that pitch and duration seem to be processed separately. Conversely, Neuhaus and Knösche (2008) 
concluded that pitch and rhythm were interdependent and processed simultaneously. Lee and Wang (2011) studied the visual processing of music notation by non-musicians. They found that although non-musicians seemed to process notation in ways similar to musicians, it was not clear whether pitch and rhythm were independent or interdependent. It should be noted that as with research in priming, brain research in this area is most often based on recognition tasks rather than performance tasks. Results of the current study support findings that recognize the distinct nature of pitch and rhythm. However, given the added complexity of performing from notation, rather than simply completing recognition tasks, it is not possible to draw conclusions as to whether these results support the independent or interdependent theory of processing.

\section{Practice Effects}

Results of this study indicated that participants performed more accurately over time. Pitch and fluency were significantly more accurate in post-testing than pre-testing. These results were not unexpected based on numerous prior sight-reading studies showing significant increases in scores from pre-test to post-test regardless of treatment effectiveness (Mishra, 2014). For purposes of the current study, it was not necessarily the gain from pre-test to post-test that was of primary interest. It was the issue of familiarity between pre-test and post-test. Many prior sight-reading studies chose to use equivalent test forms between pre-test and post-test. The same test form was used in pre-tests and post-tests here with the goal of gaining a better understanding

of the limits of what could be considered reading at sight. With no significant difference in posttest accuracy scores between participants who completed a pre-test and those who did not, this study adds to the evidence that using the same piece of music in pre-test and post-test performances might still be considered reading at sight. This is important as research in music 
reading moves forward because ensuring equivalent testing materials can be a source of limitation in developing and interpreting studies of this nature.

In addition to significant gains in scores between pre-tests and post-tests, accuracy scores in pitch and fluency also increased significantly from task to task. Each participant played three musical examples that were deemed equivalent in difficulty but were musically distinct. The tasks in this study were such that participants were only given enough time to briefly scan each musical example prior to playing through it. Therefore, the significant increases in scores were most likely not a result of practicing as such. It is plausible, however, to consider that the exercises themselves constituted an unintended priming experience. Each of the three musical exercises used the same key signature, harmonic structure, and rhythmic units. These underlying musical structures then may have served as conceptual primes as each participant worked through the three examples. Schacter and Buckner (1998) explain that conceptual priming is "most clearly observed on the category instance production task" (p. 187). In other words conceptual priming has occurred when given a category, participants respond with previously studied exemplars of that category. In music performance, it is possible to argue that a key signature, for example, is a category and playing pitches included in that key signature is a form of studying exemplars of that category. The process then of "studying" those pitches while playing the first example may have had a priming effect on the second example and the second on the third. It must be noted that only pitch and fluency significantly changed. Rhythm accuracy did not change over time.

\section{Further Influences}

Although not a central focus of the research questions in this study, the factors considered in developing the participant pool provide further aspects to be considered as theories of music 
reading and teaching are developed. School, ensemble level, and instrument family (woodwind and brass) were balanced across experimental groups in order to account for their influences on overall effects. Not surprisingly, there were significant differences in scores based on both school and ensemble level. The differences between schools, while mathematically significant, may not be as practically meaningful as differences based on other factors. Participants from School 1 played more fluently than students from Schools 3 and 5. Perhaps the most interesting part of this finding is not the difference in fluency. Instead the fact that School 1 had such a high mean score in pitch accuracy and only a 4 point difference between rhythm and pitch scores seems intriguing given the fact that other schools had anywhere from a 9 to 13 point difference between those scores. Across five different schools and ten different directors, differences could easily be attributed to differences in teaching methods or priorities, but the connection between high pitch accuracy and significantly higher fluency scores may be a connection worth pursuing further.

Participants enrolled in top ensembles at their schools scored significantly higher than members of second and third ensembles on both rhythm and fluency and higher than members of second ensembles on pitch. They also scored higher than members of third ensembles on pitch, but not significantly so. The significantly higher scores of participants in top ensembles were certainly expected. These ensembles were all auditioned groups based on musical performance skills. The fact that members of third ensembles had higher mean scores in pitch and fluency than those in second ensembles is also not beyond expectation. Third ensemble members in this study were freshmen students placed in the ensemble based on year in school (grade) rather than musical ability due to scheduling factors at the schools. It is therefore reasonable to believe that students in those ensembles could be more musically skilled than members of second ensembles. 
Of the three demographic factors considered in this study, instrument family may provide the most important information for future research. There were no significant differences in rhythm accuracy or fluency scores based on the instrument participants played, but pitch accuracy was significantly different. Mean pitch scores for woodwind players was 16.5 points higher than for brass players. This was both mathematically significant and musically meaningful. It was hypothesized that the issue of "right partials" might influence the scores of brass players. Elliot (1982a), in his analysis of sight-reading errors, found that over 30\% of pitch errors for all participants were incorrect harmonics. Through observations made during the current study, it seems that brass players were challenged by the partial issue in one of two main ways. First, there were a few students who played through large sections of the examples on the wrong partial. In other words the fingering for each note was correct but the sounding note was at the wrong harmonic on the instrument. The second way brass students made errors was to miss more isolated notes, usually in large leaps which crossed partials. For example, in one musical exercise, trumpet players were asked to play a second line G followed by a fourth line D. A common partial error was to miss the D but to play a third line B flat instead. Again, the correct fingering was used, but the wrong pitch was sounded. Although for some participants this type of error was isolated, most who made these mistakes seemed unaware that they were playing the wrong notes given the lack of correction, or attempt at correction, in their playing. Both of these types of errors point to a critical lack of awareness of what each note on the page should sound like. Without a clear, pre-conceived aural representation of the sound and of the intervals represented in melodies, brass participants, who must negotiate the challenges of controlling pitch based on the harmonic series, are significantly less accurate than their woodwind counterparts. This supports findings that skilled music readers seem to be able to 
transform visual notation into an auditory representation (Waters, Townsend, \& Underwood, 1998). Additionally, Mishra (2014) found in her meta-analysis that aural training was one of few treatments that significantly affected sight-reading scores. This suggests that the development of an aural representation of the sound is important for sight-reading activities and seems to be essential for brass players given the results found here.

It may be that this issue has not been more closely considered in prior studies due to the common use of overall performance scores rather than a breakdown of scores into separate components. It could also be that such a distinct difference in scores has not been observed because musical examples did not contain melodic features that required as broad a range of pitches, or because the participant sample was drawn from university level students who had more developed playing abilities overall. Regardless of the reasoning, the results presented here clearly indicate that instrument family must be considered in future research including high school age instrumentalists. More importantly these results suggest that high school brass students are lagging behind their woodwind counterparts in their abilities to accurately play the pitches of melodies at sight. With the large ensemble nature of most music classes at the secondary level, it is possible that this is an issue that has been masked by pitch references provided by other students in the class. However, in order to develop truly independent musicians this seems to be an important skill that needs further attention in the classroom.

\section{Toward Refined Understandings}

At first glance, the results of this study may seem to lack clarity in what might be concluded from them. The expected outcome of treatments where some degree of "learning" takes place is generally one of either no significant difference or some sort of increase in scores. The fact that rhythm scores decreased in this study under treatment conditions is at best difficult 
to interpret. However, taking into account a broader view of the many aspects the design of the study provided, it is possible to suggest potential explanations that may provide implications for both the classroom and further research.

When the results of both main and secondary analyses are taken together, a picture develops in which our cognition of rhythm seems to behave differently than pitch and fluency. Rhythm accuracy was significantly higher during control conditions and was unchanged over time. Both pitch accuracy and fluency increased over time and seem to behave in a parallel manner but were noticeably lower than rhythm scores. It is possible that participants simply focused on playing the right rhythms to the detriment of pitch accuracy. However, less than half of participants reported "playing the right rhythms" as their sight-reading focus on the post-test survey. This suggests that if the difference between pitch and rhythm scores is due to a focus issue, then it may not be entirely one of intentional focus. Neuroscience may provide further insights into these cognitive processes. Brain research involving recognition priming in music has found that response times are longer for pitch recognition than duration recognition (Schön \& Besson, 2002). Given the constraints of playing pitches in time presented in the current study, the significantly lower pitch accuracy results might be expected based on these findings from the neuroscience community. Although this may explain the relative relationship between pitch and rhythm scores, it does not seem to be helpful in explaining changes, or lack thereof, in scores over time. The goal of teaching and learning is to promote positive change over time and to do so in such a way as to retain those positive changes. Until we have a better understanding of what causes change in the visual processing of rhythm and pitch, we may continue to lack a coherent theory of how to best teach students to read music at sight. 
Tasks in the neuroscience literature are highly controlled recognition tasks that present one symbol at a time and measure response times and brain wave activity as participants decide whether or not that symbol is the same or different than given parameters. These results provide important clues toward a better understanding of the brain. On the other hand, they can only provide clues toward understanding how the brain works in isolated instances devoid of much of the context surrounding actual music making. Participants in the present study were not asked to determine if single notes were related to the key signature, they were asked to transform a visual symbol on a page into a sounded pitch on their instrument. They were asked to do this not by creating pitches in isolation, but by using successive pitches to create a melody. Likewise rhythms were not simply matched to time signatures but were used in various combinations to create interest and meaning in each exercise. These elements behave differently yet must be considered in tandem to gain a more ecologically valid understanding of the process of music reading.

Priming exercises in this study were intended to lessen the cognitive load in order to increase the speed and accuracy with which pitch and rhythm elements were recognized and performed. Rhythm accuracy was significantly worse after playing priming exercises than after having a short conversation with the researcher and accuracy did not get better over time. At the same time pitch and fluency seemed unchanged by these exercises. They were changed, however, through the repetition of different tasks over time. If we allow for the possibility that this repetition of tasks also served as an unplanned priming experience, then we can say pitch and fluency did get better as a result of priming tasks. So then why do priming tasks seem to help pitch and fluency and not rhythm? 
Going back to the priming literature, we see that most tasks are recognition tasks and that recognition based on priming was contingent upon semantic context. As was suggested earlier, it may be possible that this context assumption held for pitch but was violated for rhythm in this study. Consider that in the performance of a pitch on a wind instrument, one sees the note and presses a key or value to create that pitch. Putting aside for the moment the issue of appropriate sound production techniques to play in the right harmonic or octave, in a general sense the pitch notated on the staff always correlates to the same fingering pattern. No matter what other musical information is presented before or after the note, the note is still the same. This stability in meaning would suggest that pitch is susceptible to priming effects and accuracy should improve. It may be far more difficult to prime for rhythm, on the other hand, because durational value seems to have a relationship to what comes before it and the visual processing of it seems to be impacted by the pitch information being handled simultaneously. Some might argue that just as the pitch $\mathrm{D}$ is always the pitch $\mathrm{D}$, the value of a quarter note, or any value for that matter, is mathematically always the same. The difference in duration issues is one of perception. For example, a quarter note followed by two eighth notes is very different than a quarter note between two eighth notes. Add to that changes in note placement based on pitch and rhythm becomes a more time consuming element to process. This argument seems contrary to the observations made in the neuroscience literature. It is not that one is right and the other wrong. It is far more likely that these contrasting thoughts are brought about by the very different contexts on which they are based. One is based on recognition in isolation and the other on practical application in context. This argument also does not fully take into account the role of pattern recognition in rhythm reading and performance (Bebeau, 1982; Colley, 1987). The perception of durational values may change based on reading notes one at a time verses as rhythmic units. 
How then do these results and observations better inform our teaching practices? They begin to give us clues as to the relationship between elements and how they are processed. These clues might suggest ways to refine our classroom practices to better fit with how music reading is most successfully accomplished. Henry (2011) observed that "singers don't care when to sing until they know what to sing" (p. 81). Based on post-test survey data, participant perceptions seem to support this observation. Those in top ensembles, presumably students more skilled and experienced, reported "playing the right rhythms" as their sight-reading focus. Those in second ensembles, presumably lesser skilled musicians, reported "playing the right notes" as their sightreading focus. If, as Henry suggests, pitch is attended to before rhythm, it would be expected that lesser skilled musicians would be more focused on playing the right notes and more skilled musicians would be able to move beyond focusing on the notes to focusing on the rhythms.

Then again for wind players perhaps it is not a lack of caring about rhythmic value, as Henry states, but instead an issue of processing information in a complex task such as reading and simultaneously performing. Evidence in this study supports this hypothesis. Compare Elliot's (1982a) categorization of a variety of timing errors as rhythm errors and the separation of fluency into a distinct category for this study. As is common among most published research, Elliot includes all timing errors in the category of rhythm. The challenge with this definition of rhythm is that it does not seem to reflect the distinct roles of durational value knowledge and performance of music in time. While one certainly cannot perform music in time from notation without the knowledge of specific durations, evidence suggests that factors other than knowing how the rhythm goes may be more important to a fluent performance. Results in this study revealed that fluency, when considered independently, mirrored pitch accuracy, not rhythm accuracy. As pitch accuracy increased, so did fluency. This may be the strongest indicator that 
pitch plays a far more important role in instrumental sight-reading than has previously been acknowledged. The high rhythm accuracy scores combined with the behavior of fluency scores suggests that it is not the basic knowledge of rhythm values that causes fluency errors.

Researchers and practitioners alike have focused on the best ways to teach students to "count" or perform rhythms, yet it is not the counting that appears to be the issue. More likely it is the need to first identify and prepare to play pitches while simultaneously processing when and for how long to play those notes. Music educators may then be best served by engaging their students in experiences that support these simultaneous processes - experiences that build automaticity in pitch recognition in order to make that part of the process as efficient as possible, and experiences in rhythm reading that, instead of isolating rhythm, use pitch to enhance students' abilities to most benefit from those experiences when faced with novel pieces of music. Although scale pattern exercises seem to be common in large ensembles, rhythm exercises are more often constructed without specific reference to pitch or on a single pitch. It might be beneficial for teachers to pursue materials that provide many repetitions of specific rhythms, first with limited numbers of pitches and gradually expanding to include more pitches and intervals as fluency is gained (Fussell, 1967; Maxwell, 1974; Yaus, 1953). Duke and Byo (2010) created a beginning band method that seems to do just that within the context of making music rather than as contrived technical exercises, and perhaps it could serve as a model for materials beyond the beginning level.

\section{Implications and Directions for Future Research}

Music reading, defined as a process of creating sound from the perception of a visual symbol, is a complex task. As of yet, no definitive theory of music reading learning has been developed and most research exists in isolated studies rather than sustained lines of inquiry. In an 
effort to better understand the process of music reading, this study investigated the roles of pitch and rhythm during sight-reading. It asked what the effect of cognitive priming was on sightreading accuracy. Priming tasks, as presented in this study, were neither helpful nor harmful to pitch accuracy and fluency but seemed to have a negative impact on rhythm accuracy. This result must be interpreted with caution, however, given the small difference in scores and the high scores of rhythm accuracy overall. In spite of a lack of change due to experimental priming, pitch accuracy and fluency did improve over time suggesting that priming may have occurred through other means than treatment tasks. This study also investigated the use of pitch and rhythm in priming tasks. There was no difference in sight-reading accuracy between participants who completed pitch exercises and those who completed rhythm exercises. Finally, this study sought evidence regarding the effect of playing a sight-reading exercise a second time. As has been demonstrated in previous research, scores improved from pre-test to post-test. However, there was no difference in post-test scores between participants who played a pre-test and those who did not. It seems then that the second reading of a musical example might still be considered sight-reading.

Results from this study suggest that there is much work still to do. The relationships between the multiple factors involved in music reading is still unclear and deserves our attention as we continue to refine best practices for developing independent musicians. Future studies should continue to explore the use of priming in understanding the cognitive processes of sightreading. Researchers should consider using smaller units of music over multiple repetitions as priming tasks. A limitation of this study was the single play through of a long musical exercise during treatment. It is possible that both the length and lack of repetition of elements failed to produce a priming effect. By using smaller units, researchers may be able to gather more 
meaningful data about priming effects while simultaneously expanding understandings about the decontextualization process often used in ensemble rehearsals that it mirrors. Further, researchers might consider the relationship between the accuracy of priming task completion and musical performance. It was beyond the scope of this study to fully analyze each treatment for accuracy, but that information may prove useful to better understanding the process of music reading.

As the processes of successful music reading continue to be investigated, researchers should consider fluency as a factor independent from rhythm, or durational value. Previous studies observed potential relationships between fluency and accurate sight-reading (Cassidy, Betts, \& Hanberry, 2001; Drake \& Palmer, 2000; Pike \& Carter, 2010). With those observations in mind, this study intentionally looked at fluency separate from other musical elements. Results indicate that playing in a fluent manner is not predicated on rhythm accuracy but instead more closely follows pitch accuracy.

Given the importance of pitch, it will also be essential to continue to pursue the relationship of aural representations and reading music at sight. Results of this study demonstrated a significant difference between the pitch accuracy of brass and woodwind players. It is hypothesized that these differences were due to the lack of an accurate, pre-conceived sense of pitch and intervals by brass players, who must control pitch across various partials of the harmonic series. Not only does this result point to the need to consider brass and woodwind players independently in future research of this nature, it also suggests the need to continue developing understandings of the relationship between aural representations, or thinking in sound, and music reading. What does it mean to "think in sound" (McPherson, 1995, p. 157) and how can we teach for this in our music classrooms? How do students who "think in sound" read 
and perform from notation differently than those who do not? These seem to be important questions to answer given the acoustic nature of music performance.

Creating sound from notation is an important part of musical literacy and the continued and sustained development of understandings about that process is essential for providing bestpractices for music educators at all levels. 


\section{REFERENCES}

Alexander, M. L., \& Henry, M. (2012). The development of a string sight-reading pitch skill hierarchy. Journal of Research in Music Education, 60, 201-216. doi:10.1177/0022429412446375

Bachman, H. B. (1955). Improvement of sight reading. The Instrumentalist 10(4), 20.

Bainbridge, J.V., Lewandowsky, S., \& Kirsner, K. (1993). Context effects in repetition priming are sense effects. Memory and Cognition, 21, 619-626.

Bebeau, M. J. (1982). Effects of traditional and simplified methods of rhythm-reading instruction. Journal of Research in Music Education, 30, 107-119. doi:10.2307/3345042

Bennett, P. (1984). Tricks, mask, and camouflage: Is imitation passing for music reading? Music Educators Journal, 71(3), 62-69. doi:10.2307/3396409

Boyle, D. (1969). Rhythm sight reading: The key to music sight reading. The Instrumentalist, 24(2), 42-43.

Boyle, J. D. (1970). The effect of prescribed rhythmical movements on the ability to read music at sight. Journal of Research in Music Education, 18, 307-318. doi:10.2307/3344498

Boyle, J. D. \& Lucas, K.V. (1990). The effect of context on sightsinging. Bulletin of the Council for Research in Music Education, 106, 1-9.

Byo, J. L. (1988). The effect of barlines in music notation on rhythm reading performance. Contributions to Music Education, 15, 7-14.

Byo, J. L. (1992). Effects of barlines, pitch, and meter on musicians' rhythm reading performance. Journal of Band Research, 27(2), 34-44.

Byo, J. L. (1993). The influence of textural and timbral factors on the ability of music majors to detect performance errors. Journal of Research in Music Education, 41, 156-167. doi:10.2307/3345405

Campbell, P. S., \& Scott-Kassner, C. (2014). Music in childhood: From preschool through the elementary grades. Boston: Schirmer.

Cantwell, D. C. (1951). The use of mnemonics in music reading. Music Educators Journal, 38(2), 52. doi: $10.2307 / 3387588$

Cassidy, J. W. (1993). Effects of various sightsinging strategies on nonmusic majors' pitch accuracy. Journal of Research in Music Education, 41, 293-302. doi:10.2307/3345505 
Cassidy, J. W., Betts, S., \& Hanberry, M. A. (2001). The effect of structured left hand practice on piano performance accuracy among undergraduate music majors. Bulletin of the Council for Research in Music Education, 148, 31-36.

Cantwell, D. C. (1951). The use of mnemonics in music reading. Music Educators Journal, 38(2), 52. doi:10.2307/3387588.

Chaffin, C. (2011). An examination of the cognitive workload associated with conducting in an instrumental music context: A review of literature. Bulletin of the Council for Research in Music Education, 189, 73-87. Retrieved from http://www.jstor.org/stable/10.5406/bulcouresmused.189.0073

Clayton, K., Habibi, A., \& Bendele, M. S. (1995). Recognition priming effects following seriel learning: Implications for episodic priming effects. The American Journal of Psychology, 108, 547-561. Retrieved from http://www.jstor.org/stable/1423072

Colley, B. (1987). A comparison of syllabic methods for improving rhythm literacy. Journal of Research in Music Education, 35, 221-235. doi:10.2307/3345075

Conlee, J. S. (1966). Solfeggio for band. The Instrumentalist, 20(8), 49 \& 94-97.

Consortium of National Arts Education Associations. (1994). National standards for arts education. Reston, VA: MENC.

Crider, P. A. (1989). Sight-reading: Is it a lost art? The Instrumentalist 43(10), 29-35.

Davidson, L., \& Scripp, L. (1988). A developmental view of sightsinging. Journal of Music Theory Pedagogy, 2, 10-23.

Dell, G. S., Ratcliff, R., \& McKoon, G. (1981). Study and test repetition effects in item recognition priming. The American Journal of Psychology, 94, 497-511. Retrieved from http://www.jstor.org/stable/1422259

Demorest, S. M. (2001). Building choral excellence: Teaching sight-singing in the choral rehearsal. New York: Oxford University Press.

Drake, C., \& Palmer, C. (2000). Skill acquisition in music performance: Relations between planning and temporal control. Cognition, 74, 1-32.

Duke, R. A., \& Byo, J. L. (2010). The habits of musicianship: A radical approach to beginning band. Austin, TX: Center for Music Learning.

Duke, R. A., \& Pierce, M. (1991). Effects of tempo and performance context on transfer of performance skills. Journal of Research in Music Education, 39, 93-100. doi: $10.2307 / 3344689$ 
Duke, R. A., Simmons, A. L., \& Cash, C. D. (2009). It's not how much; it's how: Characteristics of practice behavior and retention of performance skills. Journal of Research in Music Education, 56, 310-321. doi:10.1177/0022429408328851

Earlenbaugh, D., \& Klein, N.K. (2011). Systematic sightreading. The Instrumentalist, 65(12), 33-34.

Elliot, C. A. (1982a). The identification and classification of instrumental performance sightreading errors. Journal of Band Research, 18(1), 36-42.

Elliot, C. A. (1982b). The relationships among instrumental sight-reading ability and seven selected predictor variables. Journal of Research in Music Education, 30, 5-14. doi: $10.2307 / 3344862$

Elliot, C. (1983). Sight-reading skill: It can be taught. The Instrumentalist, 38(2), 34-36.

Engel de Abreau, P. M. J., Conway, A. R. A., \& Gathercole, S. E. (2010). Working memory and fluid intelligence in young children. Intelligence, 38, 552-561. doi:10.1016/j.intell2010.07.003

Ester, D. P., Scheib, J. W., \& Inks, K. J. (2006). Takadimi: A rhythm system for all ages. Music Educators Journal, 93(2), 60-65.

Feldman, M. (1963). The art of sight reading. The Instrumentalist, 17(7), 60-61.

Fine, P., Berry, A., Rosner, B. (2006). The effect of pattern recognition and tonal predictability on sight-singing ability. Psychology of Music, 34, 431-447. doi: $10.1177 / 0305735606067152$

Fiske, R. (1969). Principles for improving sight-reading. The Instrumentalist, 24(2), 44.

Forssmark, K. A. (1941). A method for teaching the reading of rhythms. Music Educators Journal, 27(7), 60-62. doi:10.2307/3386120

Fuchs, L. S., Fuchs, D., Hosp, M. K., \& Jenkins, J. R. (2001). Oral reading reluency as an indicator of reading competence: A theoretical, empirical, and historical analysis. Scientific Studies of Reading, 5, 239-250. doi:10.1207/s1532799xssr0503_3

Fussell, R. C. (1967). Exercises for ensemble drill. Van Nuys, CA: Alfred.

George, S. (2013). Sightreading practice. The Instrumentalist, 67(7), 42-45.

Giles, M. M. (1991). Choral reading built on the basics. Music Educators Journal, 77(6), 26-29. doi:10.2307/3398209 
Goolsby, T. W. (1989). Computer applications to eye movement research in music reading. Psychomusicology, 8, 111-126.

Goolsby, T. W. (1994). Profiles of processing: Eye movements during sightreading. Music Perception: An Interdisciplinary Journal, 12, 97-123. doi:10.2307/40285756

Gordon, E. (1971). The psychology of music teaching. Englewood Cliffs, NJ: Prentice Hall.

Gregory, T. B. (1972). The effect of rhythmic notation variables on sight-reading errors. Journal of Research in Music Education, 20, 462-468. doi:10.2307/3343804

Grutzmacher, P. A. (1987). The effect of tonal pattern training on the aural perception, reading recognition, and melodic sight-reading achievement of first-year instrumental students. Journal of Research in Music Education, 35, 171-181. doi:10.2307/3344959

Gudmundsdottir, H. R. (2010). Pitch error analysis of young piano students' music reading performances. International Journal of Music Education, 28, 61-70. doi:10.1177/0255761409351342

Hahn, L. (1987). Music reading and language reading: Correlations in processes and instruction. Bulletin of the Council for Research in Music Education, 93, 41-48.

Hanberry, M. (2004). Effects of Practice Strategies, Metronome Use, Meter, Hand, and Musical Function on Dual-Staved Piano Performance Accuracy and Practice Time Usage of Undergraduate Non-Keyboard Music Majors (Doctoral Dissertation). Retrieved from http://etd.1su.edu/docs/available/etd-04082004-223228/

Henry, M. (2001). The development of a vocal sight-reading inventory. Bulletin of the Council for Research in Music Education, 150, 21-35.

Henry, M. (2003). A comparison of testing formats for vocal sight-reading. Texas Music Education Research [online journal, available at http://www.tmea.org/assets/pdf/research/Hen2003.pdf], 2-9.

Henry, M. (2004). The use of targeted pitch skills for sight-singing instruction in the choral rehearsal. Journal of Research in Music Education, 52, 206-217. doi:10.2307/3345855

Henry, M. (2011). The effect of pitch and rhythm difficulty on vocal sight-reading performance. Journal of Research in Music Education, 59, 72-84. doi:10.1177/0022429410397199

Henry, M. (2013). The effect of key on vocal sight-reading achievement. Texas Music Education Research [online journal, available at http://www.tmea.org/assets/pdf/research/Hen2013.pdf], 2-7.

Henry, M., \& Demorest, S. (1994). Individual sight-singing achievement in successful choral ensembles. Update: Applications of Research in Music Education, 13, 4-8. 
Heydenberg, F. (1960). Developing skills in sight-reading. Music Educators Journal 47(1), 106. doi: $10.2307 / 3389160$.

Hickman, D. R. (1980). Music speed reading. The Instrumentalist, 34(8), 32-33.

Hicks, C. E. (1980). Sound before sight: Strategies for teaching music reading. Music Educators Journal, 66(8), 53-67. doi:10.2307/3395858

Hodges, D. A. (1992). The acquisition of music reading skills. In Colwell, R. (Ed.), Handbook of research on music teaching and learning, a project of the Music Educators National Conference. New York: Schirmer Books.

Hodges, D. A., \& Nolker, D. B. (2011). The acquisition of music reading skills. In Colwell, R. \& Webster, P. R. (Eds.), MENC handbook of research on music learning: Volume 2 applications. Oxford: Oxford University Press.

Hoover, W. (1968). An approach to rhythm. The Instrumentalist, 23(2), 59-62.

Issac. M. J. (1966). Teaching rhythm. The Instrumentalist, 21(1), 47.

Jacobson, O. I. (1931). The reading of instrumental music as shown by photographing eyemovements during the reading process. School Music, 31(154), 10-11.

Jagow, S. (2007). Teaching instrumental music: Developing the complete band program. Galesville, MD: Meredith Music

Johnson, S. (2001). A system for sightreading. The Instrumentalist, 55(11), 12-14.

Jungers, M. (2007). Performance Priming in Music. Music Perception: An Interdisciplinary Journal, 24, 395-399. doi:10.1525/mp.2007.24.4.395

Keller, P. E. (2001). Attentional resource allocation in musical ensemble performance. Psychology of Music, 29, 20-38. doi:10.1177/0305735601291003

Killian, J. N., \& Henry, M. L. (2005). A comparison of successful and unsuccessful strategies in individual sight-singing preparation and performance. Journal of Research in Music Education, 53, 51-65. doi:10.1177/002242940505300105

Kinsler, V., \& Carpenter, R. H. S. (1995). Saccasic eye movements while reading music. Vision Research, 35, 1447-1458.

Kopiez, R. \& Lee, J. I. (2006). Towards a dynamic model of skills involved in sight reading music. Music Education Research, 8, 97-120. doi:10.1080/14613800600570785 
Kostka, M. J. (2000). The effects of error-detection practice on keyboard sight-reading achievement of undergraduate music majors. Journal of Research in Music Education, 48, 114-122. doi:10.2307/3345570

Lambrecht, B. (2008). Sightreading, a year-long approach. The Instrumentalist, 62(6), 32-37.

Lee, H. Y., \& Wang, Y. S. (2011). Visual processing of music notation: A study of event-related potentials. Perceptual and Motor Skills, 112, 525-535.

doi:10.2466/11.22.24.27.PMS.112.2.525-535

Lehmann, A. C. \& Ericsson, K.A. (1993). Sight-reading ability of expert pianists in the context of piano accompanying. Psychomusicology, 12, 182-195.

Lillya, C. P. (1953). Place of sight reading. The Instrumentalist, 8(3), 34-35.

Lowder, J. E. (1973). Evaluation of a sight-reading test administered to freshman piano classes. Journal of Research in Music Education, 21, 68-73. doi:10.2307/3343981

MacKnight, C. B. (1975). Music reading ability of beginning wind instrumentalists after melodic instruction. Journal of Research in Music Education, 23, 23-34. doi:10.2307/3345200

Madsen, C. K., \& Madsen, C. H. (1970). Experimental research in music. Englewood Cliffs, NJ: Prentice-Hall.

Marmel, F., \& Tillmann, B. (2009). Tonal Priming Beyond Tonics. Music Perception: An Interdisciplinary Journal, 26(3), 211-221. doi:10.1525/mp.2009.26.3.211

Maxwell, R. (1974). Fourteen weeks to a better band. Oskaloosa, IA: C. L. Barnhouse.

McHose, A. I., \& Tibbs, R. N. (1945). Sight Singing Manual. New York: F. S. Crofts \& Co.

McPherson, G. E. (1995). The assessment of musical performance: Development and validation of five new measures. Psychology of Music, 23, 142-161.

doi:10.1177/0305735695232003

Meinz, E. J., \& Hambrick, D. Z. (2010). Deliberate practice is necessary but not sufficient to explain individual differences in piano sight-reading skill: The role of working memory capacity. Psychological Science, 21, 914-919. doi:10.1177/0956797610373933

Miksza, P. (2007). Effective practice: An investigation of observed practice behaviors, selfreported practice habits, and the performance achievement of high school wind players. Journal of Research in Music Education, 55, 359-375. doi:10.1177/0022429408317513

Miller, C. H. (1930). Teaching sight reading without syllables. Music Supervisors Journal, 17(1), 18-19. doi:10.2307/3383961 
Mishra, J. (2014). Improving sightreading accuracy: A meta-analysis. Psychology of Music, 42, 131-156. doi:10.1177/0305735612463770

Mixon, K. (2002). Start with rhythms and tapping when beginners learn to read. The Instrumentalist, 57(1), 50.

Mixon, K. (2008). Rhythm reading. The Instrumentalist, 62(12), 36-38.

National Association for Music Education (2014). Core music standards. Reston, VA: NAfME. Retrieved from http://www.nafme.org/wp-content/uploads/2014/06/Core-MusicStandards-Ensemble-Strand1.pdf

National Association of Schools of Music. (2015). Standards and competencies. Retrieved from http://nasm.arts-accredit.org/index.jsp?page=Standards-Handbook

Neuhaus, C., \& Knösche, T. R. (2008). Processing of pitch and time sequences in music. Neuroscience Letters, 441, 11-15. doi:10.1016/j.neulet.2008.05.101

Nye, R. E. (1948). Syllables, numbers, and sight reading. Music Educators Journal, 35(2), 52 53. doi: $10.2307 / 3387030$

Palmer, M. (1976). Relative effectiveness of two approaches to rhythm reading for fourth-grade students. Journal of Research in Music Education, 24, 110-118. doi:10.2307/3345154

Paas, F. G. W. C., \& van Merriënboer, J. J. G. (1994). Instructional control of cognitive load in the training of complex cognitive tasks. Educational Psychology Review, 6, 351-371. Retrieved from http://www.jstor.org/stable/23359294

Pearson, B. (1996). Hearing the sounds before reading the notes. The Instrumentalist, 51(3), 4246.

Penttinen, M., \& Huovinen, E. (2011). The early development of sight-reading skills in adulthood: A study of eye movements. Journal of Research in Music Education, 59, 196220. doi:10.1177/0022429411405339

Petzold, R. G. (1960). The perception of music symbols in music reading by normal children and by children gifted musically. Journal of Experimental Education, 28, 271-319. Retrieved from http://www.jstor.org/stable/20156514

Pierce, M. A. (1992). The effects of learning procedure, tempo, and performance condition on transfer of rhythm skills in instrumental music. Journal of Research in Music Education, 40, 295-305.

Pike, P. D., \& Carter, R. (2010). Employing cognitive chunking techniques to enhance sightreading performance of undergraduate group-piano students. International Journal of Music Education, 28, 231-246. doi:10.1177/0255761410373886 
Ployhar, J. D. (1972). I recommend. Van Nuys, CA: Alfred Publishing.

Poulin-Charronnat, B., Bigand, E., \& Madurell, F. (2005). The Influence of Voice Leading on Harmonic Priming. Music Perception: An Interdisciplinary Journal, 22, 613-627. doi:10.1525/mp.2005.22.4.613

Price, H. E., Blanton, F., \& Parrish, R. T. (1998). Effects of two instructional methods on high school band students' sight-reading proficiency, music performance, and attitude. Update: Applications of Research in Music Education, 17(1), 14-20. doi:10.1177/875512339801700104

Pursell, A. (2007). The effectiveness of iconic-based rhythmic instruction. Journal of Band Research, 43(1), 38-53.

Random.org. (2015). "Sequences". Random.org. Retrieved from https://www.random.org/sequences/

Reely, R. (1994). Sight-reading with skill. The Instrumentalist, 48(6), 42-46.

Reid, C. S. (1995). Sight-reading. Music Educators Journal, 81(5), 50-52. doi:10.2307/3398856

Reifinger, J. L. (2012). The acquisition of sight-singing skills in second-grade general music: Effects of using solfège and of relating tonal patterns to songs. Journal of Research in Music Education, 60, 26-42. doi:10.1177/0022429411435683

Richards, M. H. (1964). Threshold to music. Palo Alto, CA: Fearon.

Russell, C. R. (2015). Effects of pitch and rhythm study on accuracy and fluency during sightreading. Unpublished manuscript.

Salzberg, R. S., \& Wang, C. C. (1989). A comparison of prompts to aid rhythmic sight-reading of string students. Psychology of Music, 17, 123-131. doi:10.1177/0305735689172003

Savler, R. (1945). Teaching the reading of piano music. Music Educators Journal, 32, 22-23 \& 72-75. doi: $10.2307 / 3386787$

Schacter, D. L., \& Buckner, R. L. (1998). Priming and the brain. Neuron, 20, 185-195. doi:10.1016/S0896-6273(00)80448-1

Schleuter, S. L. (1997). A sound approach to teaching instrumentalists. New York: Simon \& Schuster Macmillan.

Schön, D., \& Besson, M. (2002). Processing pitch and duration in music reading: A RT-ERP study. Neuropsychologia, 40, 868-878. doi:10.1016/S0028-3932(01)00170-1

Shaw, J. (2006). Sightreading with a purpose. The Instrumentalist, 60(6), 30-34. 
Sheldon, D. A. (1996). Visual representation of music: Effects of beamed and beamless notation on music performance. Journal of Band Research, 31(2), 86-101.

Sight-reading. (n.d.). In The Oxford Dictionary of Music. Retrieved from http://www.oxfordmusiconline.com:80/subscriber/article/opr/t237/e9422

Sight Reading Factory. (2015). "Sight Read". Gracenotes, LLC. Retrieved from https://www.sightreadingfactory.com/app

Silvey, C. T. (1937). Solmization in music reading. Music Educators Journal, 24(2), 21-22. doi: $10.2307 / 3385167$

Snyder, A. M. (1963). Guidelines for a music reading program. Music Educators Journal, 49(4), 65-68. doi:10.2307/3393635.

Solomon, E. (1984). Sight-reading or sight-guessing? The Instrumentalist, 38(6), 14-15.

Sorlien, L. C. (1951). 'Rithmetic and rhythm. The Instrumentalist, 6(2), 10-11.

Stauffer, D.W. (2005). Learning to read music fluently. Music Educators Journal, 92(1), 21-22. doi:10.2307/3400211

Tulving, E., \& Schacter, D. L. (1990). Priming and human memory systems. Science, 247, 301306. Retrieved from http://www.jstor.org/stable/2873625.

Van Nuys, K., \& Weaver, H. E. (1943). Memory span and visual pauses in reading rhythms and melodies. Psychological Monographs, 55(1), 33-50.

Ward, S. (1966). Patterned music reading. The Instrumentalist, 21(3), 52-53.

Waters, A. J., Townsend, E., \& Underwood, G. (1998). Expertise in music sight reading: A study of pianists. British Journal of Psychology, 89, 123-149.

Waters, A. J., \& Underwood, G. (1998). Eye movements in a simple music reading task: A study of expert and novice musicians. Psychology of Music, 26, 46-60. doi:10.1177/0305735698261005

Watkins, J. G. (1942). Objective measurement of instrumental performance. (Doctoral dissertation). Teachers College, Columbia University, New York.

Watkins, J. G. \& Farnum, S. E. (1954) The Watkins-Farnum performance scale. Winona, MN: Hal Leonard.

Watkins, J. G. \& Farnum, S. E. (1962) The Watkins-Farnum performance scale. Winona, MN: Hal Leonard. 
Whaley, G. (2004). Solving rhythm problems. The Instrumentalist, 58(12), 16-20.

Wickens, C. D., Larish, I., \& Contorer, A. (1989). Predictive performance models and multiple task performance. Proceedings of the Humand Factors and Ergonomics Society Annual Meeting, 33, 96-100. doi:10.1177/154193128903300221

Wiggs, C. L., \& Martin, A. (1998). Properties and mechanisms of perceptual priming. Current Opinion in Neurobiology, 8, 227-233. Retrieved from http://biomednet.com/elecref/0959438800800227

Wilkins, A. J., \& Kiff, I. E. (2015). On the clarity of the musical stave. Psychology of Music, 43, 870-880. doi: 10.1177/0305735614546124

Williams, R., \& King, J. (1998). Foundations for superior performance: Warm-ups \& technique for band. San Diego, CA: Neil A. Kjos.

Wolf, T. (1976). A cognitive model of musical sight-reading. Journal of Psycholinguistic Research, 5, 143-171. doi: 10.1007/BF01067255

Wood, R. E. (1986). Task complexity: Definition of the construct. Organizational Behavior and Human Decision Processes, 37, 60-82. doi:10.1016/0749-5978(86)90044-0

Wright, M. E. (1976). Do it! Music Educators Journal, 62(7), 62-63. doi:10.1177/002743217606200702

Wurtz, P., Mueri, R. M., \& Wiesendanger, M. (2009). Sight-reading of violinists: Eye movements anticipate the musical flow. Experimental Brain Research, 194, 445-450. doi:10.1007/s00221-009-1719-3

Yaus, G. C. (1953). 101 Rhythmic rest patterns. Van Nuys, CA: Belwin-Mills. 


\section{APPENDIX A: IRB EXEMPTION FORM}

\section{ACTION ON EXEMPTION APPROVAL REQUEST}

TO:

\author{
Christine Russel \\ Music
}

FROM:

Dennis Landin

Chair, Insttutional Review Board

DATE: November 10, 2015

RE:

IRB\# E9848
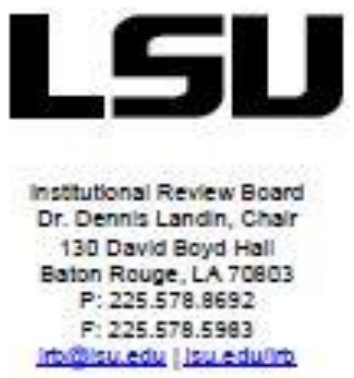

TITLE: Effects of Pitch and Rhythm Priming on Accuracy and Fluency during Sight-reading

New Protocol/Modification/Continuation: New Protocol

Review Date: $11 / 18 / 2015$

Approved_ $X$ Disapproved

Approval Date: 11/9/2015 Approval Expiration Date: 11/8/2018

Exemption CategoryiParagraph: 1

Signed Consent Waived?: №

Re-review frequency: (three years unless otherwise stated)

LSU Proposal Number (f applicable):

Protocol Matches Scope of Work in Grant proposal: (f applicable)

By: Dennis Landin, Chairman

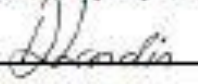

PRINCIPAL INVESTIGATOR: PLEASE READ THE FOLLOWING -

Continuing approval is CONDITIONAL on:

1. Adherence to the approved protocol, famillarity with, and adherence to the ethical standards of the Belmont Report, and LSU's Assurance of Complance with DHHS regulations for the protectlon of human subjects"

2. Prior approval of a change in protocol, Including revision of the consent documents or an increase in the number of subjects over that approved.

3. Obtaining renewed approval (or submittal of a temination report), prior to the approval expiration date, upon request by the IRB office (Irrespective of when the project actually begins); notincation of project termination.

4. Retention of documentation of informed consent and study records for at least 3 years after the study ends.

5. Continuing attention to the physical and psychoiogical well-being and informed consent of the Indlvidual participants, including notfication of new information that might affect consent.

6. A prompt report to the IRB of any adverse event affecting a participant potentlally arising from the study.

7. Notincation of the IRB of a sericus complance fallure.

8. SPECIAL NOTE:

'A.I investigators and support start have access to coples of the Beimont Report, LSU's Assturance wth DHHS, DHHS (45 CFR 46) and FDA regulations goveming use of human sublects, and other relevant documents in print in this ofice or on our World Woe Weo slte at http:Www. Isu edulvo 
APPENDIX B: EXERCISE 10 FORM C

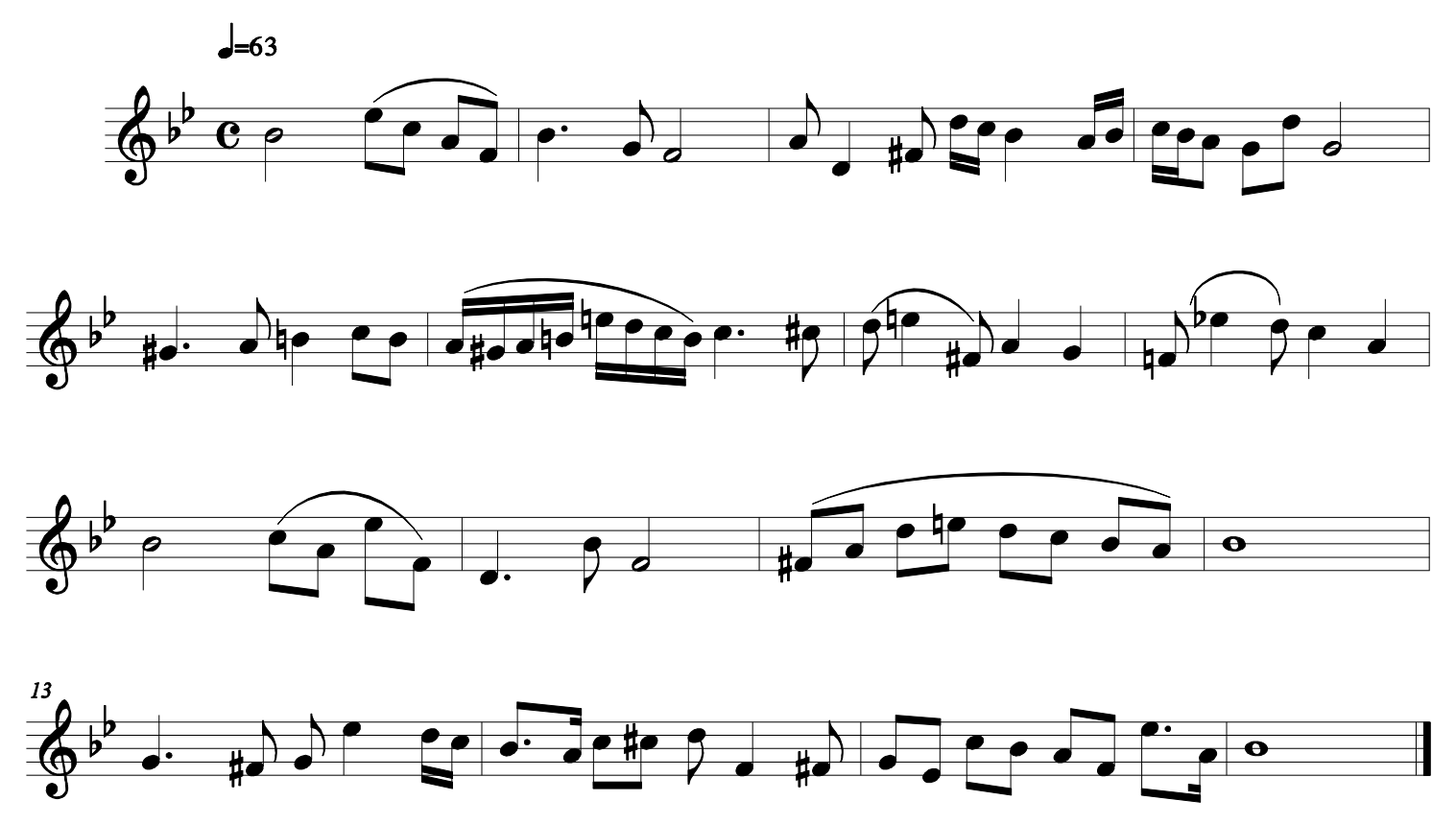




\section{APPENDIX C: STUDY TREATMENTS}

Rhythm Treatment A

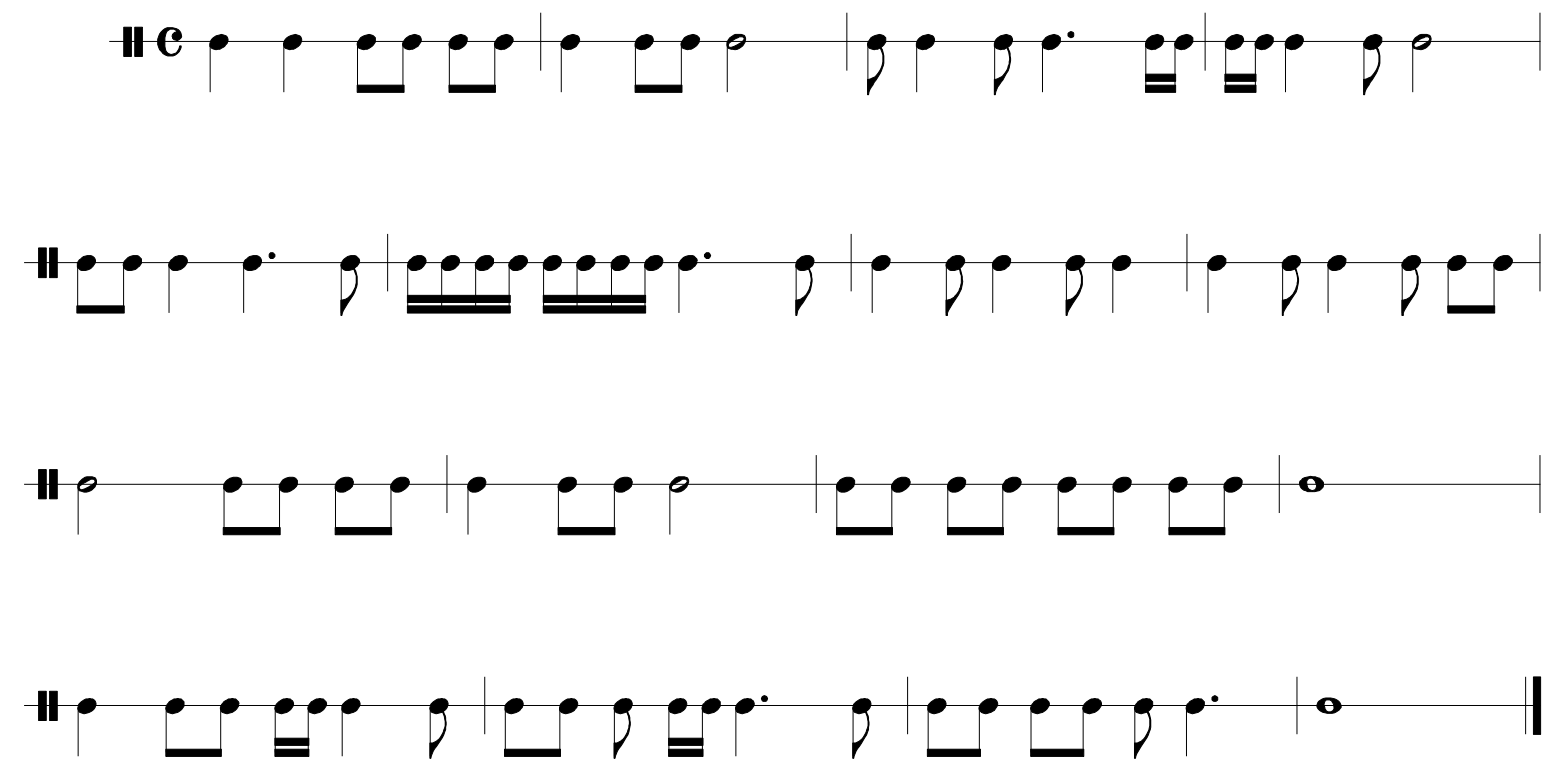

Rhythm Treatment B

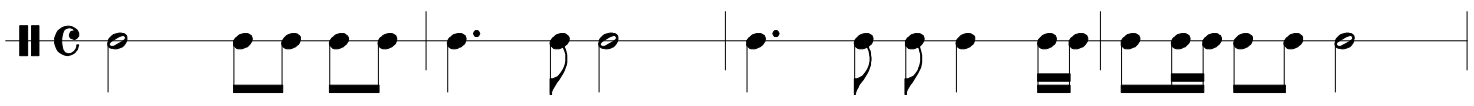

H०.

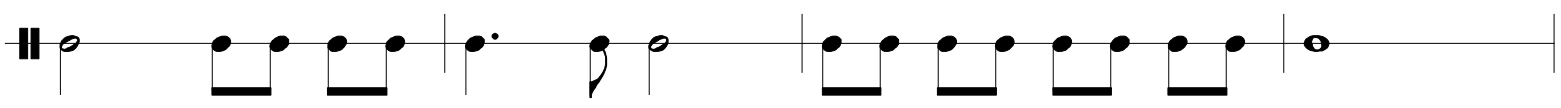

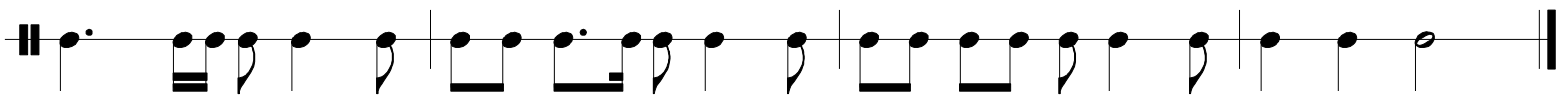


Rhythm Treatment C

He
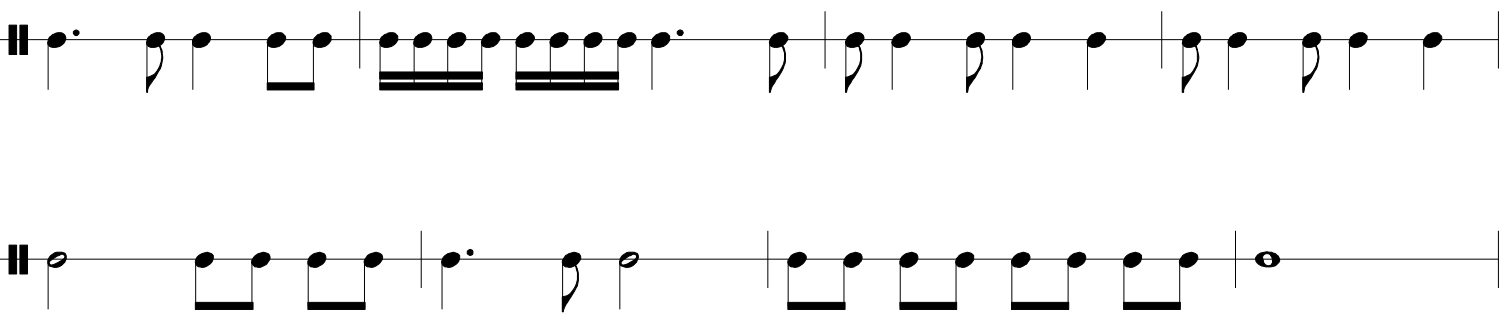

Hค.

General Rhythm Treatment

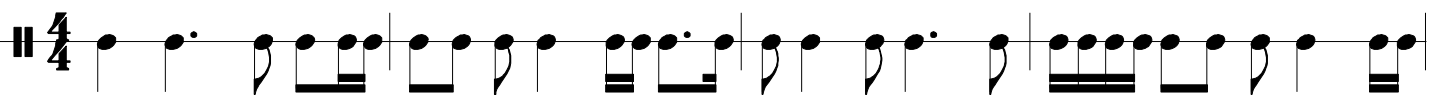

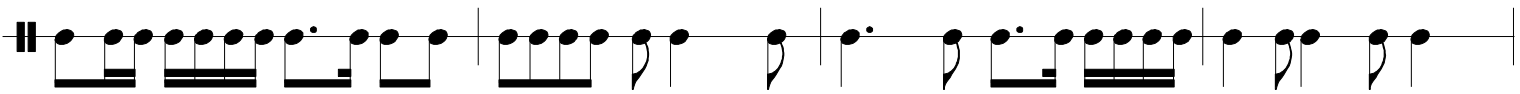

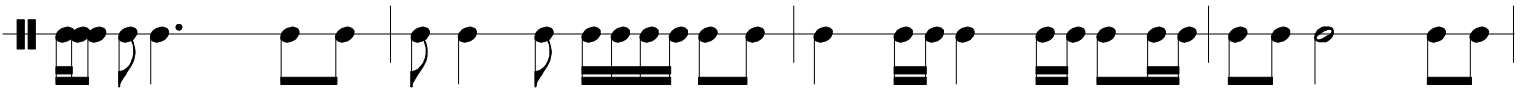

H०00. 
Pitch Treatment A

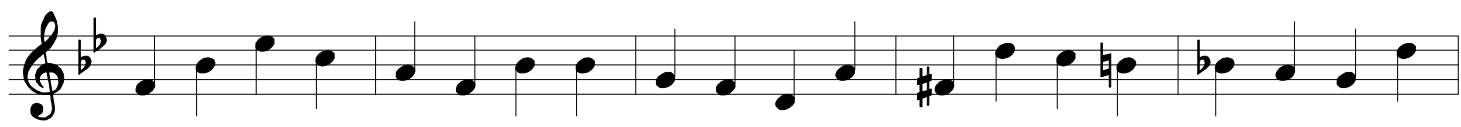

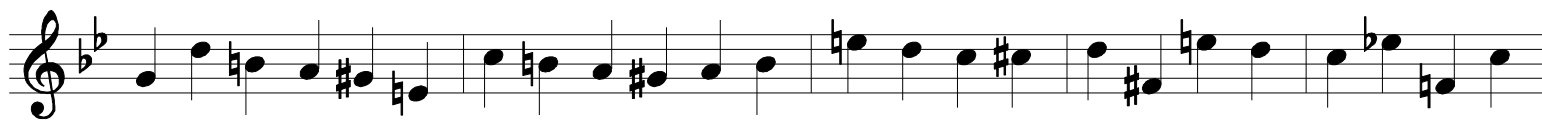
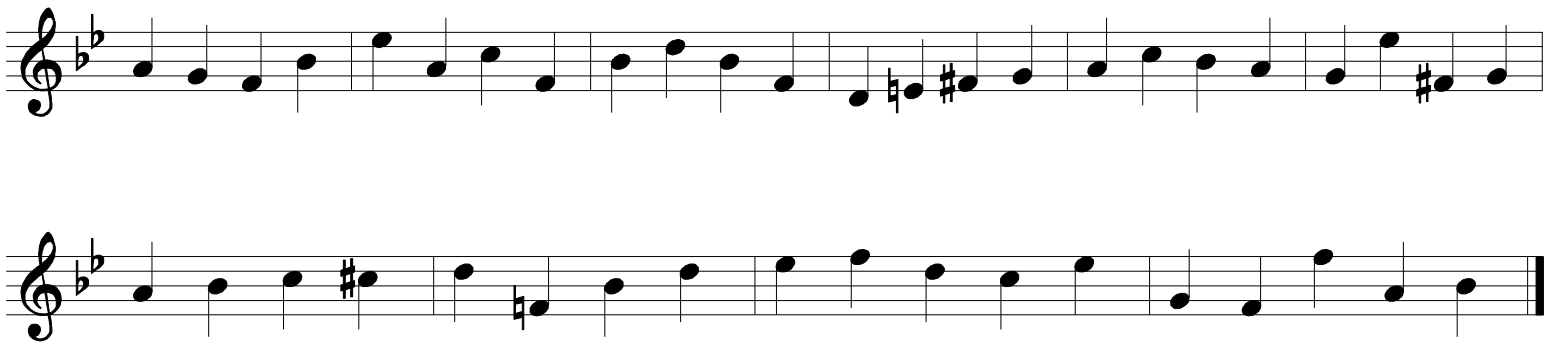

Pitch Treatment B
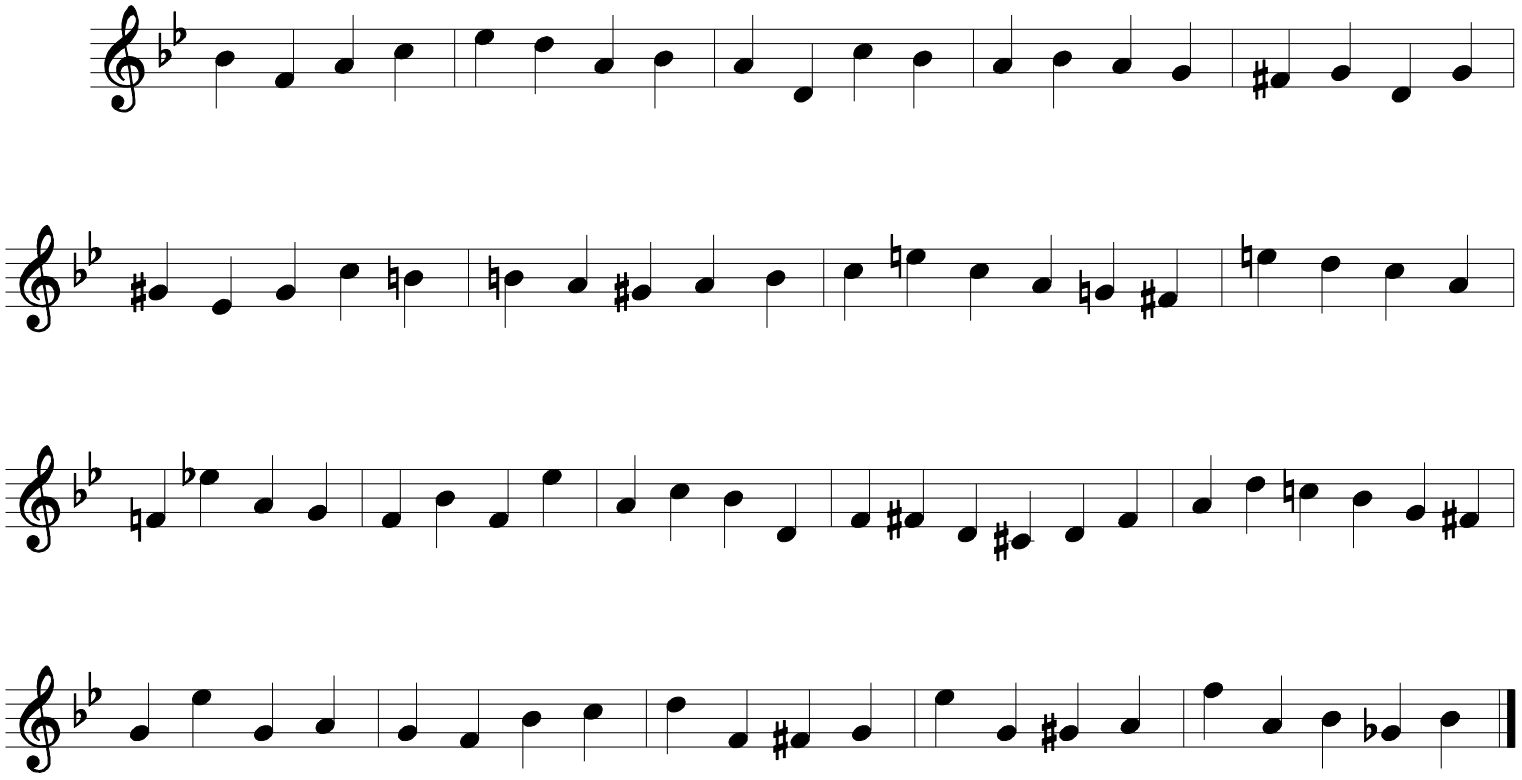
Pitch Treatment C
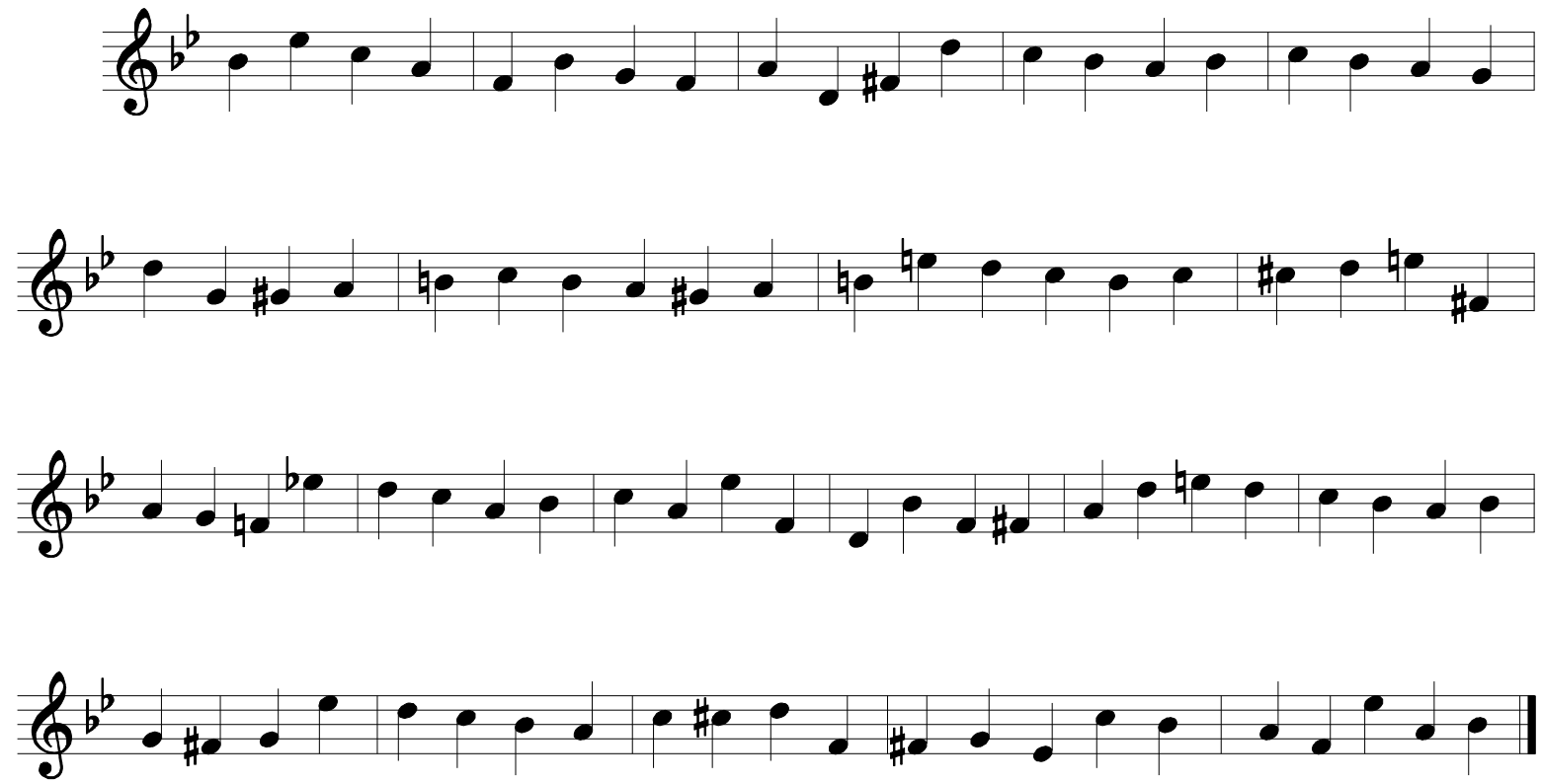

General Pitch Treatment
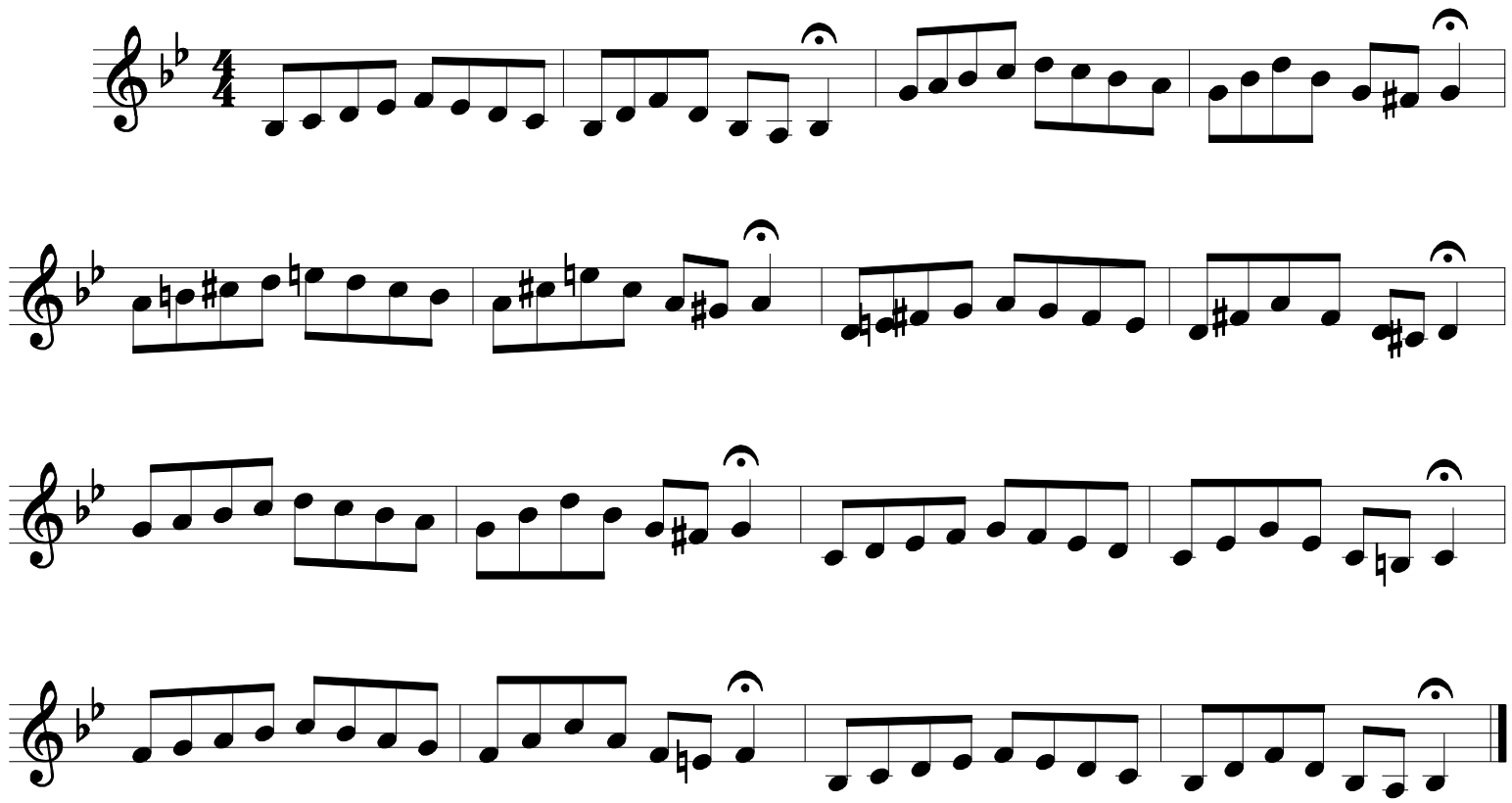


\section{APPENDIX D: LETTER OF EXPLANATION}

January 10, 2016

Dear Student and Parents,

My name is Christine Russell and I am currently a doctoral student in the Music Education department at LSU. Before coming to Louisiana I was a high school band director for 9 years in northern Indiana. I am currently completing requirements for my degree by investigating the way high school students read music for the first time (sight-reading).

As a student sight-reads, he or she must pay attention to both the notes to play (pitch) and to when and for how long to play those notes (rhythm). Because sight-reading is such an important skill for musicians, it is helpful to know as much about the areas of pitch and rhythm as we can. I am conducting a research project that will help us to learn more about the sight-reading process and I would like to invite you/your student to participate in this project.

The study will be conducted at your school during your band class or after school rehearsal and will take no more than 15 minutes of your time. Students will be recorded sight-reading short musical examples during that time but will remain anonymous through all data analysis and future reporting. There are no risks to participating in the study. Participation is voluntary and you can withdraw from the study at any time.

If you are willing to be a part of this project, please sign the consent forms attached to this letter. The first form is a parental permission form and the second is a student assent form. The student should sign the assent form and have their parent/guardian serve as a witness. Please return the forms to your school band director.

Thank you for your consideration and I hope that you will be able to be a part of this project.

Sincerely,

Christine Russell

Doctoral Student, School of Music

Lousiana State University 


\section{APPENDIX E: PARENTAL PERMISSION FORM}

Project Title: $\quad$ Effects of Pitch and Rhythm Study on Accuracy and Fluency during Sight-reading

Performance Site: $\quad$ Ascension, East Baton Rouge, and Livingston Parish Schools, LA

Investigator:

Principal Investigator

Christine Russell

(260) 417-5895

cruss15@1su.edu
Faculty Supervisor

James L. Byo

(225) 578-2593

jbyo@lsu.edu

Purpose: $\quad$ The purpose of this research project is to investigate the effects of pitch and rhythm study on sight-reading accuracy and fluency.

Inclusion Criteria: $\quad$ Student participants $(N \leq 250)$ must be currently enrolled in a high school band class and have played a woodwind or brass instrument for a minimum of 3 years.

Description of the Study: In order to determine the effects of pitch and rhythm on sightreading accuracy, students will be asked to play through a short musical example they have never seen before either once or twice. In addition to playing the sight-reading example, one third of the students will also be asked to play through a short rhythm exercise based on the sight-reading music. One third of the students will be asked to play through a short pitch sequence based on the sightreading music. One third of the students will simply sight-read the musical example and not complete any additional exercises.

Students will complete these tasks individually. The entire process will take no more than 10 minutes and will be completed during the students' band classes or after school band rehearsals.

Benefits: $\quad$ The study may identify strategies that increase the understanding of the musical sight-reading process.

Risks: $\quad$ There are no known risks.

Right to Refuse: Participation is voluntary, and a student will become a part of the study only if both the student and parent agree to the student's participation. At any time, either the participant may withdraw from the study or the participant's parent may withdraw the participant from the study without penalty or loss of any benefit to which they might otherwise be entitled. 
Privacy: $\quad$ Results of the study may be published, but no names or identifying information will be included for publication. Student identity will remain confidential unless disclosure is required by law.

Financial Information: There is no cost for participation in the study, nor is there any compensation to the students for participation.

Signatures:

The study has been discussed with me and all my questions have been answered. I may direct additional questions regarding study specifics to Christine Russell at cruss15@1su.edu or 260417-5895. If I have questions about participants' rights or other concerns, I can contact Dennis Landin, Chairman, Institutional Review Board, (225) 578-8692, irb@1su.edu, www.lsu.edu/irb. I will allow my child to participate in the study described above and acknowledge the investigators' obligtion to provide me with a signed copy of this consent form upon request.

Yes, I give my permission for my child to participate.

Parent's Signature Date:

Child's Name (print) 


\section{APPENDIX F: STUDENT ASSENT FORM}

$\mathrm{I}$, , agree to be in a study that investigates the effects of rhythm and pitch study on sight-reading accuracy. I agree to sight-read a musical example on my band instrument. I also agree to play through either a rhythm exercise or a pitch sequence in addition to the sight-reading if asked to do so. I understand that I may choose to not complete the sight-reading or additional exercises at any time.

Student Signature:

Age:

Student name (print): Date:

Witness: Date:

(Witness was present for the assent process.) 


\section{APPENDIX G: STUDENT DEMOGRAPHIC FORM}

Name

Gender (circle one) $\mathrm{M} \quad \mathrm{F}$

School

Grade (circle one)

$10 \quad 11$

12

Primary Band Instrument

How many years have you played this instrument?

School Ensemble(s)

What other instruments do you play (including piano and voice) and how long have you played them?

Do you play in any ensembles outside of school? YES NO

If yes, which ones?

Do you take private lessons?

YES

NO

If yes, on what instruments and for how many years (or months) on each?

Participant \#

Group \#

Audio \# 


\section{APPENDIX H: COMPLETE TESTING SCRIPTS \\ Pre-Test/Post-Test Rhythm Group}

Thank you for agreeing to participate in this study. Today you are going to sight-read several musical examples, play through rhythm exercises based on those examples, and finally play the original examples again. You will have a short time to look at each example before you play them and I will give you the starting tempo with a metronome before you begin playing. For each step I will give you specific instructions to help you through the process. Are you ready to begin?

[Student should respond in the positive]

\section{First Stimulus Exercise}

I will place the musical example on the music stand. After I do so, you will have 30 seconds to silently study the music. You may use that time as you wish but please do not bring your instrument up to your mouth until the end of the time. After 30 seconds I will turn on the metronome and ask you to play through the example. I will turn the metronome off after the first measure. Do you have any questions?

[Answer any questions. Audio recorder is started.]

Let's begin.

[Musical example is placed on the music stand and 30 second study time begins.]

[At the end of 30 seconds, the metronome is turned on.]

That's the end of the study time; please play through the example now as best as you can.

[Student plays musical example]

[After student finishes playing, researcher removes the music from sight.] 


\section{Specific Rhythm Treatment}

Thank you. Now I would like you to play through only the rhythms from the music you just read. You may choose to play the exercise on any note you would like, but please play the same note for the entire exercise. I will give you the starting tempo with a metronome. Keeping a steady tempo for the entire exercise, I'd like you to now play through the exercise from the beginning to the end as best as you can.

[Researcher places rhythmic treatment on the stand and allows for a brief scan of the exerciseno more than 15 seconds - before student plays the exercise.]

[Researcher removes the rhythmic treatment from the stand when student finishes playing.]

Thank you. I'd like for you to play through the original music for me one more time. After I put it on the stand you will again have 30 seconds to silently study the music. You may use that time as you wish but remember please do not bring your instrument up to your mouth until the end of the time. After 30 seconds I will turn on the metronome and ask you to play through the example. I will turn the metronome off after the first measure. Here we go.

[Researcher places the original music on the stand and 30 second study time begins.]

[At the end of 30 seconds, the metronome is turned on.]

That's the end of the study time; please play through the example now as best as you can.

[Student plays musical example]

[After student finishes playing, researcher removes the music from sight.]

\section{Second Stimulus Exercise}

I will now place a second musical example on the music stand. After I do so, you will have 30 seconds to silently study the music. You may use that time as you wish but please do not bring your instrument up to your mouth until the end of the time. After 30 seconds I will turn on the 
metronome and ask you to play through the example. I will turn the metronome off after the first measure. Do you have any questions?

[Answer any questions.]

Let's begin.

[Musical example is placed on the music stand and 30 second study time begins.]

[At the end of 30 seconds, the metronome is turned on.]

That's the end of the study time; please play through the example now as best as you can.

[Student plays musical example]

[After student finishes playing, researcher removes the music from sight.]

\section{General Rhythm Treatment}

Thank you. Now I have a rhythm exercise for you to play. It uses many of the same rhythms of the music you just played but in a different order. You may choose to play the exercise on any note you would like, but please play the same note for the entire exercise. I will give you the starting tempo with a metronome. Keeping a steady tempo for the entire exercise, I'd like you to now play through the exercise from the beginning to the end as best as you can.

[Researcher places rhythmic treatment on the stand and allows for a brief scan of the exerciseno more than 15 seconds - before student plays the exercise.]

[Researcher removes the rhythmic treatment from the stand when student finishes playing.] Thank you. I'd like for you to play through the original music for me one more time. After I put it on the stand you will again have 30 seconds to silently study the music. You may use that time as you wish but remember please do not bring your instrument up to your mouth until the end of the time. After 30 seconds I will turn on the metronome and ask you to play through the example. I will turn the metronome off after the first measure. Here we go. 
[Researcher places the original music on the stand and 30 second study time begins.]

[At the end of 30 seconds, the metronome is turned on.]

That's the end of the study time; please play through the example now as best as you can.

[Student plays musical example]

[After student finishes playing, researcher removes the music from sight.]

\section{Third Stimulus Exercise}

I will now place the final musical example on the music stand. After I do so, you will have 30 seconds to silently study the music. You may use that time as you wish but please do not bring your instrument up to your mouth until the end of the time. After 30 seconds I will turn on the metronome and ask you to play through the example. I will turn the metronome off after the first measure. Do you have any questions?

[Answer any questions.]

Let's begin.

[Musical example is placed on the music stand and 30 second study time begins.]

[At the end of 30 seconds, the metronome is turned on.]

That's the end of the study time; please play through the example now as best as you can.

[Student plays musical example]

[After student finishes playing, researcher removes the music from sight.]

\section{Contact Control Treatment}

Thank you. I'm interested to know, what do you like about playing your instrument? Do you have a favorite piece of music that you've played in band?

[Student verbally responds to questions. Conversation continues for approximately 1 minute and 15 seconds.] 
That's really interesting. Thank you for sharing that with me. I'd like for you to play through the original music for me one more time. After I put it on the stand you will again have 30 seconds to silently study the music. You may use that time as you wish but remember please do not bring your instrument up to your mouth until the end of the time. After 30 seconds I will turn on the metronome and ask you to play through the example. I will turn the metronome off after the first measure. Here we go.

[Researcher places the original music on the stand and 30 second study time begins.]

[At the end of 30 seconds, the metronome is turned on.]

That's the end of the study time; please play through the example now as best as you can. [Student plays musical example]

[After student finishes playing, researcher stops recording and removes the music from sight.] That finishes all of the tasks. Thank you so much for coming in and playing for me today. I really appreciate how helpful you have been! 


\section{Pre-Test/Post-Test Pitch Group}

Thank you for agreeing to participate in this study. Today you are going to sight-read several musical examples, play through pitch exercises based on those examples, and finally play the original examples again. You will have a short time to look at each example before you play them and I will give you the starting tempo with a metronome before you begin playing the musical example. For each step I will give you specific instructions to help you through the process. Are you ready to begin?

[Student should respond in the positive]

\section{First Stimulus Exercise}

I will place a musical example on the music stand. After I do so, you will have 30 seconds to silently study the music. You may use that time as you wish but please do not bring your instrument up to your mouth until the end of the time. After 30 seconds I will turn on the metronome and ask you to play through the example. I will turn the metronome off after the first measure. Do you have any questions?

[Answer any questions. Audio recorder is started.]

Let's begin.

[Musical example is placed on the music stand and 30 second study time begins.]

[At the end of 30 seconds, the metronome is turned on.]

That's the end of the study time; please play through the example now as best as you can.

[Student plays musical example]

[After student finishes playing, researcher removes the music from sight.] 


\section{Specific Pitch Treatment}

Thank you. Now I would like you to play only the pitches from the music you just read. I will give you the starting tempo with a metronome. Keeping a steady tempo for the entire exercise, I'd like you to now play through the exercise from the beginning to the end as best as you can. [Researcher places pitch sequence on the stand and allows for a brief scan of the exercise - no more than 15 seconds - before student plays the exercise.] [Researcher removes the pitch sequence from the stand when student finishes playing.] Thank you. I'd like for you to play through the original music for me one more time. After I put it on the stand you will again have 30 seconds to silently study the music. You may use that time as you wish but remember please do not bring your instrument up to your mouth until the end of the time. After 30 seconds I will turn on the metronome and ask you to play through the example. I will turn the metronome off after the first measure. Here we go.

[Researcher places the original music on the stand and 30 second study time begins.]

[At the end of 30 seconds, the metronome is turned on.]

That's the end of the study time; please play through the example now as best as you can.

[Student plays musical example]

[After student finishes playing, researcher removes the music from sight.]

\section{Second Stimulus Exercise}

I will now place a second musical example on the music stand. After I do so, you will have 30 seconds to silently study the music. You may use that time as you wish but please do not bring your instrument up to your mouth until the end of the time. After 30 seconds I will turn on the metronome and ask you to play through the example. I will turn the metronome off after the first measure. Do you have any questions? 
[Answer any questions.]

Let's begin.

[Musical example is placed on the music stand and 30 second study time begins.]

[At the end of 30 seconds, the metronome is turned on.]

That's the end of the study time; please play through the example now as best as you can.

[Student plays musical example]

[After student finishes playing, researcher removes the music from sight.]

\section{General Pitch Treatment}

Thank you. Now I have a series of scales for you to play based the music you just played. Each scale pattern uses the same notes as the music you played but arranged in scales rather than a melody. I will give you the starting tempo with a metronome. Keeping a steady tempo, I'd like you to now play through the exercise from the beginning to the end as best as you can. [Researcher places scale sequence on the stand and allows for a brief scan of the exercise - no more than 15 seconds - before student plays the exercise.]

[Researcher removes the scale sequence from the stand when student finishes playing.] Thank you. I'd like for you to play through the original music for me one more time. After I put it on the stand you will again have 30 seconds to silently study the music. You may use that time as you wish but remember please do not bring your instrument up to your mouth until the end of the time. After 30 seconds I will turn on the metronome and ask you to play through the example. I will turn the metronome off after the first measure. Here we go.

[Researcher places the original music on the stand and 30 second study time begins.]

[At the end of 30 seconds, the metronome is turned on.]

That's the end of the study time; please play through the example now as best as you can. 
[Student plays musical example]

[After student finishes playing, researcher removes the music from sight.]

\section{Third Stimulus Exercise}

I will now place the final musical example on the music stand. After I do so, you will have 30 seconds to silently study the music. You may use that time as you wish but please do not bring your instrument up to your mouth until the end of the time. After 30 seconds I will turn on the metronome and ask you to play through the example. I will turn the metronome off after the first measure. Do you have any questions?

[Answer any questions.]

Let's begin.

[Musical example is placed on the music stand and 30 second study time begins.]

[At the end of 30 seconds, the metronome is turned on.]

That's the end of the study time; please play through the example now as best as you can.

[Student plays musical example]

[After student finishes playing, researcher removes the music from sight.]

\section{Contact Control Treatment}

Thank you. I'm interested to know, what do you like about playing your instrument? Do you have a favorite piece of music that you've played in band?

[Student verbally responds to questions. Conversation continues for approximately 1 minute and 15 seconds.]

That's really interesting. Thank you for sharing that with me. I'd like for you to play through the original music for me one more time. After I put it on the stand you will again have 30 seconds to silently study the music. You may use that time as you wish but remember please do not bring 
your instrument up to your mouth until the end of the time. After 30 seconds I will turn on the metronome and ask you to play through the example. I will turn the metronome off after the first measure. Here we go.

[Researcher places the original music on the stand and 30 second study time begins.]

[At the end of 30 seconds, the metronome is turned on.]

That's the end of the study time; please play through the example now as best as you can.

[Student plays musical example]

[After student finishes playing, researcher stops recording and removes the music from sight.]

That finishes all of the tasks. Thank you so much for coming in and playing for me today. I

really appreciate how helpful you have been! 


\section{Post-Test Only Rhythm Group}

Thank you for agreeing to participate in this study. Today you are going play through rhythm exercises based on musical examples and then you will sight-read those examples. You will have a short time to look at each example before you play them and I will give you the starting tempo with a metronome before you begin playing. For each step I will give you specific instructions to help you through the process. Are you ready to begin?

[Student should respond in the positive. Audio recorder is started.]

\section{Specific Treatment}

First I have a rhythm exercise for you to play. You will be playing through only the rhythms from the music you are about to play. You may choose to play the exercise on any note you would like, but please play the same note for the entire exercise. I will give you the starting tempo with a metronome. Keeping a steady tempo for the entire exercise, I'd like you to now play through the exercise from the beginning to the end as best as you can. Do you have any questions?

[Answer any student questions.]

Let's begin.

[Researcher places rhythmic treatment on the stand and allows for a brief scan of the exerciseno more than 15 seconds - before student plays the exercise.]

[Researcher removes the rhythmic treatment from the stand when student finishes playing.]

First Stimulus Exercise

Thank you. Now I'd like for you to play through a music excerpt for me. After I put it on the stand you will have 30 seconds to silently study the music. You may use that time as you wish but please do not bring your instrument up to your mouth until the end of the time. After 30 
seconds I will turn on the metronome and ask you to play through the example. I will turn the metronome off after the first measure. Here we go.

[Researcher places the musical example on the stand and 30 second study time begins.]

[At the end of 30 seconds, the metronome is turned on.]

That's the end of the study time; please play through the example now as best as you can.

[Student plays musical example]

[After student finishes playing, researcher removes the music from sight.]

\section{General Rhythmic Treatment}

Now I have a rhythm exercise for you to play. It uses many of the same rhythms of the music you are about to play but in a different order. You may choose to play the exercise on any note you would like, but please play the same note for the entire exercise. I will give you the starting tempo with a metronome. Keeping a steady tempo for the entire exercise, I'd like you to now play through the exercise from the beginning to the end as best as you can.

[Researcher places rhythmic treatment on the stand and allows for a brief scan of the exerciseno more than 15 seconds - before student plays the exercise.]

[Researcher removes the rhythmic treatment from the stand when student finishes playing.]

\section{Second Stimulus Exercise}

Thank you. Now I'd like for you to play through a music excerpt for me. After I put it on the stand you will have 30 seconds to silently study the music. You may use that time as you wish but please do not bring your instrument up to your mouth until the end of the time. After 30 seconds I will turn on the metronome and ask you to play through the example. I will turn the metronome off after the first measure. Here we go.

[Researcher places the musical example on the stand and 30 second study time begins.] 
[At the end of 30 seconds, the metronome is turned on.]

That's the end of the study time; please play through the example now as best as you can.

[Student plays musical example]

[After student finishes playing, researcher removes the music from sight.]

\section{Contact Control Treatment}

Thank you. I'm interested to know, what do you like about playing your instrument? Do you have a favorite piece of music that you've played in band?

[Student verbally responds to questions. Conversation continues for approximately 1 minute and 15 seconds.]

\section{Third Stimulus Exercise}

That's really interesting. Thank you for sharing that with me. I'd like for you to play through a final musical example for me. After I put it on the stand you will again have 30 seconds to silently study the music. You may use that time as you wish but remember please do not bring your instrument up to your mouth until the end of the time. After 30 seconds I will turn on the metronome and ask you to play through the example. I will turn the metronome off after the first measure. Here we go.

[Researcher places the original music on the stand and 30 second study time begins.]

[At the end of 30 seconds, the metronome is turned on.]

That's the end of the study time; please play through the example now as best as you can.

[Student plays musical example]

[After student finishes playing, researcher stops recording and removes the music from sight.]

That finishes all of the tasks. Thank you so much for coming in and playing for me today. I really appreciate how helpful you have been! 


\section{Post-Test Only Pitch Group}

Thank you for agreeing to participate in this study. Today you are going play through pitch exercises based on musical examples and then you will sight-read those examples. You will have a short time to look at each example before you play them and I will give you the starting tempo with a metronome before you begin playing the musical example. For each step I will give you specific instructions to help you through the process. Are you ready to begin?

[Student should respond in the positive. Audio recorder is started.]

\section{Specific Treatment}

First I have a series of notes for you to play. I would like you to play only the pitches from music you are about to play. I will give you the starting tempo with a metronome. Keeping a steady tempo for the entire exercise, I'd like you to now play through the exercise from the beginning to the end as best as you can. Do you have any questions?

[Answer any questions]

Let's begin.

[Researcher places pitch sequence on the stand and allows for a brief scan of the exercise - no more than 15 seconds - before student plays the exercise.]

[Researcher removes the pitch sequence from the stand when student finishes playing.]

\section{First Stimulus Exercise}

Thank you. Now I'd like for you to play through a music excerpt for me. After I put it on the stand you will have 30 seconds to silently study the music. You may use that time as you wish but please do not bring your instrument up to your mouth until the end of the time. After 30 seconds I will turn on the metronome and ask you to play through the example. I will turn the metronome off after the first measure. Here we go. 
[Researcher places the original music on the stand and 30 second study time begins.]

[At the end of 30 seconds, the metronome is turned on.]

That's the end of the study time; please play through the example now as best as you can.

[Student plays musical example]

[After student finishes playing, researcher removes the music from sight.]

\section{General Pitch Treatment}

Thank you. Now I have a series of scales for you to play based on the music you are about to play. Each scale pattern uses the same notes as the music you will play but arranged in scales rather than a melody. I will give you the starting tempo with a metronome. Keeping a steady tempo, I'd like you to now play through the exercise from the beginning to the end as best as you can.

[Researcher places scale sequence on the stand and allows for a brief scan of the exercise - no more than 15 seconds - before student plays the exercise.]

[Researcher removes the scale sequence from the stand when student finishes playing.]

\section{Second Stimulus Exercise}

Thank you. Now I'd like for you to play through a music excerpt for me. After I put it on the stand you will have 30 seconds to silently study the music. You may use that time as you wish but please do not bring your instrument up to your mouth until the end of the time. After 30 seconds I will turn on the metronome and ask you to play through the example. I will turn the metronome off after the first measure. Here we go.

[Researcher places the original music on the stand and 30 second study time begins.]

[At the end of 30 seconds, the metronome is turned on.]

That's the end of the study time; please play through the example now as best as you can. 
[Student plays musical example]

[After student finishes playing, researcher removes the music from sight.]

\section{Contact Control Treatment}

Thank you. I'm interested to know, what do you like about playing your instrument? Do you have a favorite piece of music that you've played in band?

[Student verbally responds to questions. Conversation continues for approximately 1 minute and 15 seconds.]

\section{Third Stimulus Exercise}

That's really interesting. Thank you for sharing that with me. I'd like for you to play through a final musical example for me. After I put it on the stand you will again have 30 seconds to silently study the music. You may use that time as you wish but remember please do not bring your instrument up to your mouth until the end of the time. After 30 seconds I will turn on the metronome and ask you to play through the example. I will turn the metronome off after the first measure. Here we go.

[Researcher places the original music on the stand and 30 second study time begins.]

[At the end of 30 seconds, the metronome is turned on.]

That's the end of the study time; please play through the example now as best as you can.

[Student plays musical example]

[After student finishes playing, researcher stops recording and removes the music from the stand.]

That finishes all of the tasks. Thank you so much for coming in and playing for me today. I really appreciate how helpful you have been! 


\section{APPENDIX I: SCORING INSTRUCTIONS}

Thank you so much for agreeing to help out in this interesting project that looks at sight-reading among high school students. You will be listening to audio files and scoring them for rhythm, pitch, and fluency accuracy. The scoring unit will be the beat. For this study, each element (rhythm, pitch, fluency) will be assessed independently and judged as either right or wrong. Therefore a participant could earn credit for playing one of the elements correctly even if there were mistakes in another element.

Please use the following guidelines in your scoring:

1. Pitch errors -

a. Tones added or omitted will count as an error. Repeated tones will not count as an error (see Fluency errors)

b. Tones played on the wrong pitch will count as an error

i. Fuzzy attacks, minor irregularities, and poor intonation will not count as errors as long as most of the note is recognizable as the correct pitch

ii. If the wrong pitch is sounded on the attack, but it is fingered correctly and immediately corrected without retonguing, it should not be counted as an error.

2. Rhythm errors (i.e., wrong partial, wrong octave)

a. Any note not given its correct value in relation to the notes around it will count as an error. (see Fluency errors)

b. Sustained notes must be held within one count of the correct beat.

3. Fluency errors -

a. An error in fluency will be assigned to beats in which there is a disruption to the pulse in one of the following ways

i. Pauses or hesitations between notes within or between beats - assign an error to the beat in which the error was made (within) or to the beat that did not occur in time (between)

ii. Pauses or hesitations between measures - assign an error to the second of the two measures

iii. Repetition of notes in a measure (going back and replaying a note, not adding notes) - assign an error to the beat immediately following where the break to repeat occurred

iv. Radical/abrupt change in tempo (more than $12 \mathrm{bpm}$ ) - count an error for the beat in which it happens

4. Other musical elements

a. Do not mark errors for any other musical element. Disregard all expression markings and articulation markings.

How to use the score sheet:

1. Mark the audio file \# on the appropriate line.

2. For each beat there are boxes for rhythm $(\mathrm{R})$, pitch $(\mathrm{P})$, and fluency $(\mathrm{F})$. Please place a mark under the appropriate letter if you hear an error in that beat.

3. Leaving a box blank indicates that the element was played correctly in that beat.

4. You may listen to each recording as many times as necessary to score each file.

5. Score all music as it is played the first time. If a student repeats any part of the music, disregard the repeated material and begin scoring again when they reach new material.

6. Leave the spaces at the bottom for rhythm, pitch, and fluency blank. I will fill them in later. 
APPENDIX J: SAMPLE SCORING FORM

$f^{b} e_{0} \because \therefore \quad \therefore \quad \therefore \quad \therefore \cdots$

\begin{tabular}{|l|l|l|l|l|l|l|l|l|l|l|l|l|l|l|l|l|}
\hline & 1 & 2 & 3 & 4 & 1 & 2 & 3 & 4 & 1 & 2 & 3 & 4 & 1 & 2 & 3 & 4 \\
\hline $\mathrm{R}$ & & & & & & & & & & & & & & & & \\
\hline $\mathrm{P}$ & & & & & & & & & & & & & & & & \\
\hline $\mathrm{F}$ & & & & & & & & & & & & & & & & \\
\hline
\end{tabular}

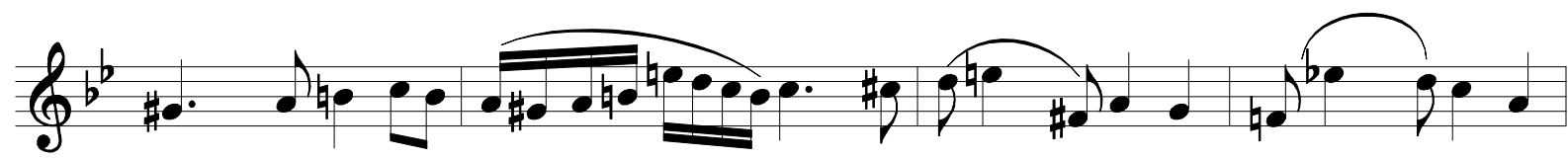

\begin{tabular}{|l|l|l|l|l|l|l|l|l|l|l|l|l|l|l|l|l|l|}
\hline & 1 & 2 & 3 & 4 & 1 & 2 & 3 & 4 & 1 & 2 & 3 & 4 & 1 & 2 & 3 & 4 \\
\hline $\mathrm{R}$ & & & & & & & & & & & & & & & & \\
\hline $\mathrm{P}$ & & & & & & & & & & & & & & & & \\
\hline $\mathrm{F}$ & & & & & & & & & & & & & & & & \\
\hline
\end{tabular}

$g^{b} \rho+090000$

\begin{tabular}{|l|l|l|l|l|l|l|l|l|l|l|l|l|l|l|l|l|}
\hline & 1 & 2 & 3 & 4 & 1 & 2 & 3 & 4 & 1 & 2 & 3 & 4 & 1 & 2 & 3 & 4 \\
\hline $\mathrm{R}$ & & & & & & & & & & & & & & & & \\
\hline $\mathrm{P}$ & & & & & & & & & & & & & & & & \\
\hline $\mathrm{F}$ & & & & & & & & & & & & & & & & \\
\hline
\end{tabular}

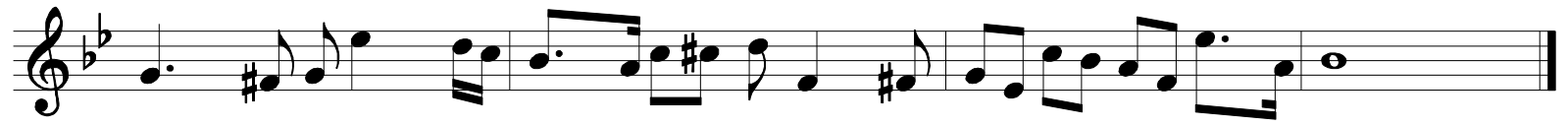

\begin{tabular}{|l|l|l|l|l|l|l|l|l|l|l|l|l|l|l|l|l|}
\hline & 1 & 2 & 3 & 4 & 1 & 2 & 3 & 4 & 1 & 2 & 3 & 4 & 1 & 2 & 3 & 4 \\
\hline $\mathrm{R}$ & & & & & & & & & & & & & & & & \\
\hline $\mathrm{P}$ & & & & & & & & & & & & & & & & \\
\hline $\mathrm{F}$ & & & & & & & & & & & & & & & & \\
\hline
\end{tabular}




\section{APPENDIX K: POST-TEST SURVEY}

1. Did you find these sight reading tasks difficult? (Circle one number)

Not At All

1

$2 \quad 3$

4

5

6

One of the hardest things I've done

$7 \quad 8$

2. What was the hardest part for you? (Circle one or fill in a word or two)

$\begin{array}{ll}\begin{array}{c}\text { Playing the } \\ \text { right rhythms }\end{array} & \begin{array}{l}\text { Playing the } \\ \text { right notes }\end{array}\end{array}$

3. When you are sight-reading on what do you most focus? (Circle one or fill in a word or two)

Playing the Playing the Other:

right rhythms right notes

4. When you are practicing your music, which usually takes more time to get right? (Circle one)

Playing the Playing the

right rhythms right notes

5. Do you think the exercises you did today helped you sight-read the music better? (Circle one)

$$
\text { Yes } \quad \text { No }
$$

If yes, did one help you more than the other? (Circle one)

Yes, the first one. Yes, the second one. No

Participant
Group




\section{VITA}

Christine Russell holds a Bachelor of Music degree in Music Education from DePauw University (1993) and Master of Music from Bowling Green State University (2002). She taught instrumental music to students in grades 4 through 12 in northeast Indiana for nine years prior to beginning doctoral studies in Louisiana. While at Louisiana State University, she has been an instructor of music appreciation classes in the general education curriculum, methods classes in the music education department, and overseen student teachers in the classroom. She has also been active as an adjudicator and clinician for local schools and most recently served as orchestra conductor for Kids Orchestra, an El Sistema inspired music program serving over 800 elementary aged students in Baton Rouge. Ms. Russell has presented research at regional and national conferences and has accepted a position as Assistant Professor of Music Education at the University of Akron beginning in the fall of 2016. 